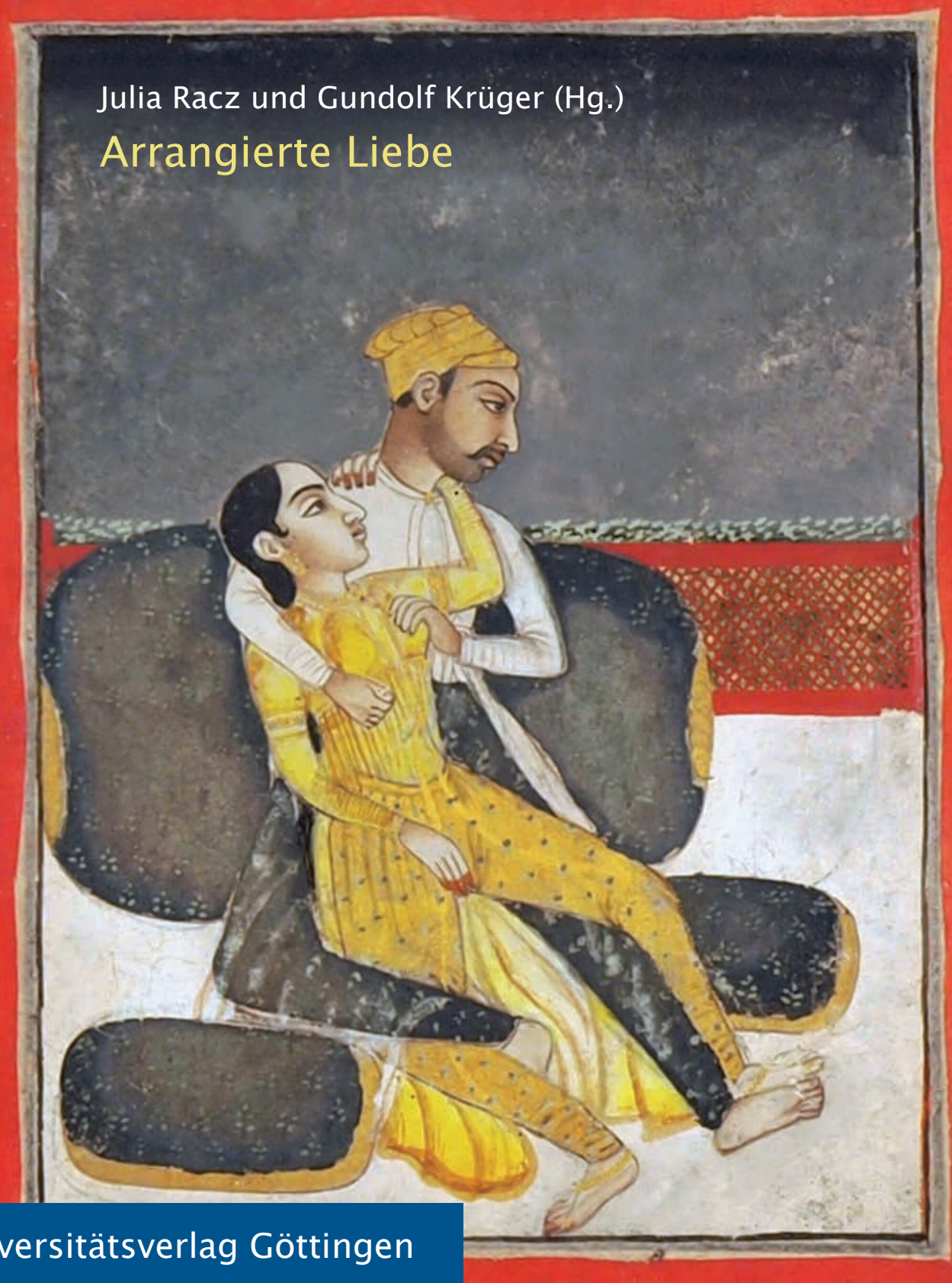

Universitätsverlag Göttingen 

Julia Racz und Gundolf Krüger (Hg.)

Arrangierte Liebe

This work is licensed under the Creative Commons License 3.0 "by-nd", allowing you to download, distribute and print the document in a few copies for private or educational use, given that the document stays unchanged and the creator is mentioned.

You are not allowed to sell copies of the free version.

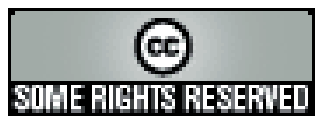


erschienen im Universitätsverlag Göttingen 2013 


\section{Arrangierte Liebe}

Leitfaden zur Sonderausstellung in der Ethnologischen Sammlung der Universität Göttingen

herausgegeben von Studierenden des Instituts für Ethnologie der Universität unter der Leitung von Julia Racz und Gundolf Krüger

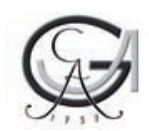

Universitätsverlag Göttingen 2013 
Bibliographische Information der Deutschen Nationalbibliothek

Die Deutsche Nationalbibliothek verzeichnet diese Publikation in der Deutschen Nationalbibliographie; detaillierte bibliographische Daten sind im Internet über <http://dnb.ddb.de> abrufbar.

Dieses Buch ist auch als freie Onlineversion über die Homepage des Verlags sowie über den OPAC der Niedersächsischen Staats- und Universitätsbibliothek (http://www.sub.uni-goettingen.de) erreichbar und darf gelesen, heruntergeladen sowie als Privatkopie ausgedruckt werden. Es gelten die Lizenzbestimmungen der Onlineversion. Es ist nicht gestattet, Kopien oder gedruckte Fassungen der freien Onlineversion zu veräußern.

Satz und Layout: Franziska Lorenz Covergestaltung: Franziska Lorenz Titelabbildung: BiKat73 (Erläuterungen s. Abbildungsverzeichnis)

(C) 2013 Universitätsverlag Göttingen

http:/ / univerlag.uni-goettingen.de

ISBN: 978-3-86395-077-4 
Impressum

Begleitband:

Herausgeber: Julia Racz und Dr. Gundolf Krüger.

Texte und Mitarbeit: Carl Edward Archibald Albrecht, Jessica Allermann, Antje Bartschat, Janis Bäcker, Jeannette Bukel, Franziska Brinkmann, Kathrin Laura Cisakowski, Taina Engineer, Arja Frömel, Sarah Gleisberg, Theresa Goy, Luise Görlitz, Lara Groth, Lisa Gutt, Wiebke Grimmig, Viet Hoang, Madeline Kaupert, Ronja Kästner, Gundolf Krüger, Tina Krüger, Lilian Leifert, Frederike Nelius, Aurelia Ohloff, Julia Racz, Marie-Theres Rohner, Sharon Rösner, Ronja Rutschmann, Wiebke Schaper, Robert Scheck, Flavia Ticona Schlösser, Johanna Schreiber, Daniel Schüler, Stefan Thiele, Luise Weinhold, Eva Wenzel, Nicole Zornhagen.

Idee: Julia Racz

Fotos: Harry Haase, Institut für Ethnologie der Universität Göttingen.

Druck: Universitätsverlag Göttingen.

Ausstellung:

Die Ausstellung ist eine Kooperation der Ethnologischen Sammlung der Universität Göttingen (Julia Racz und Dr. Gundolf Krüger), der Galerie Alte Feuerwache (Gisela Hyllus, Jörg Dreykluft), des Städtischen Museums Göttingen (Dr. Ernst Böhme und Andrea Rechenberg M.A.) und des Museumsverbunds Südniedersachsen e.V.

Technische Mitarbeit: Arnold Dittmann, Harry Haase, Horst Leibeling, Scheiter Großbildtechnik GbR und Nicole Zornhagen.

Leihgeber: Geowissenschaftliches Museum der Universität Göttingen (Dr. Mike Reich), Kulturhistorische Sammlung Heinz Kirchhoff der Universität Göttingen (Dr. Anita Schmidt-Jochheim), Kunstsammlung der Universität Göttingen (Dr. Anne-Katrin Sors), Musikinstrumentensammlung des Musikwissenschaftlichen Seminars der Universität Göttingen (Dr. Klaus-Peter Brenner), Privatsammlung Dagny und Ronja Krüger Braunschweig/Köln und Zoologisches Museum der Universität Göttingen (Dr. Gerd Tröster).

Dank:

Für die freundliche Unterstützung von Ausstellung, Begleitband und Begleitprogramm dankt die Ethnologische Sammlung der Dr. Walther Liebehenz-Stiftung, der Galerie Alte Feuerwache, der Göttinger Gesellschaft für Völkerkunde e.V., dem Institut für Ethnologie der Universität Göttingen, der Parfümerie Liebe, der Sparkasse Göttingen und dem Städtischen Museum Göttingen.

Göttingen, Sonderausstellung vom 7. April bis 5. Mai 2013. 



\section{Inhalt}

\section{Einführung}

Julia Rac飞:

Arrangierte Liebe -

Einleitende Gedanken

Viet Hoang und Tina Krüger:

Wie funktioniert Verliebtheit? -

Biochemische Aspekte

Marie-Theres Robner:

„Ihr kennt euch aus dem Internet?“

Sarah Gleisberg:

Mit dem Handy Grenzen überschreiten

Kathrin Cisakowski:

Liebesbotschaften per SMS

Lara Groth:

Symbole der Liebe.

Lilian Leifert:

Herz, Ring und Mondperle -

Liebessymbole im interkulturellen Vergleich

Asien

Ronja Rutschmann:

Kamasutra - Das Lehrbuch der Liebe

Jessica Allermann:

Lotosschuhe - Schritte wie eine Seiltänzerin

Wiebke Grimmig:

Die Geisha - Ein lebendes Kunstwerk

Franziska Brinkmann:

Shunga - Erotische Fantasien und große Kunst

Stefan Thiele:

Das geschriebene Bild

Taina Engineer:

Cakrasamvara - Nur eine von Buddhas

unendlichen Erscheinungsformen

\section{Ronja Kästner:}

Herzgeist oder göttlicher Funke - Die Wirkung

von Akupunktur

Afrika

9 Frederike Nelius:

Der Dildo - Lustwerkzeug der Liebe

Viet Hoang:

14 Der Buschmannrevolver als Instrument für

den Liebeszauber.

18 Tina Krüger:

Gesichtsmasken der Makonde -

20 Abbilder eines Schönheitsideals

Wiebke Schaper:

23 Vom Zauber afrikanischer Fruchtbarkeitspuppen 75

Eva Wenzel:

25 Bitetelelo-Lieder und Bongo-Flava -

Von Liebe in der Musik

30 Ozeanien

Lisa Gutt:

Die Brauthaube ambusap der Iatmul

aus Papua-Neuguinea

.37 Ronja Rutschmann:

Brautpreis - Die Frau als Ware?

40 Gundolf Krüger:

Love-making und die gesellschaftliche Rolle der

45 Zeremonialjungfrau taupou in der

traditionellen Kultur Samoas

Luise Weinhold:

Zeichen der Schönheit - Die Kunst des

Tatauierens in Polynesien.

Abbildungsnachweis 



\section{Einführung}

\section{Arrangierte Liebe - Einleitende Gedanken}

\section{Julia Racz.}

Liebe ist...

Herzrasen, Schlaf- und Appetitlosigkeit, Schweißausbrüche und Stimmungsschwankungen sind Symptome von Verliebtheit (Scheiner 2006:41f.). Ursache dafür ist ein Cocktail aus verschiedenen Hormonen, die in unserem Gehirn, dem Zentrum der Liebe, produziert werden (Walter 2006:89f.). Verliebte benehmen sich häufig sehr auffällig. Sie sind „krank vor Liebe“, so dass ihr Verhalten daher oft mit dem von Zwangsneurotikern verglichen wird, denn sie sind besessen und diese Besessenheit richtet sich auf die geliebte Person (Röttger-Rössler 2002:155). Ob Rama und Sita, Romeo und Julia oder Edward und Bella, alle diese literarischen Vorbilder haben eines gemeinsam: Für die Liebe überwinden sie Hindernisse und sind sogar bereit zu sterben. In Liebesdichtungen werden gefühlsbetonte Aspekte wie Sehnsucht, Treue, Bewährung, Opfer und Verzicht thematisiert, wobei die Grenzen zur erotischen Literatur fließend sind (Schweikle 1990:267). Lieben heißt deshalb auch Leiden. Um ihr physisches und psychisches Gleichgewicht wiederherzustellen, versuchen Verliebte über Musik, Tanz, Kunst und Literatur ihren Empfindungen Ausdruck zu verleihen. Der romantischen Fantasie und Kreativität sind keine Grenzen gesetzt. Anleihen übernehmen die Künstler dabei aus bestehenden kulturellen Ausdrucksformen, die sie durch eigene Schöpfungen verändern und bereichern (RöttgerRössler 2002:157). Diese Kunstwerke sind ein wichtiger Bestandteil der sozialen und kulturellen Kommunikation, lassen sie doch ein dynamisches Erscheinungsbild der Liebe zu. Dies betrifft auch Zeichen und Symbole, die einen zentralen Teil der kulturellen Verständigung bilden (s. Beiträge Groth und Leifert in diesem Band).

\section{Arrangierte Liebe?}

Es hat viele wissenschaftliche Versuche gegeben, die Geheimnisse von Lust und Liebe zu entschlüsseln. (vgl. dazu Buss 1994, Fisher 2005, Röttger-Rössler und Engelen 2006).

Was meint nun aber der Ausstellungstitel „Arrangierte Liebe"? Ein Blick in Kluges Etymologisches Wörterbuch der deutschen Sprache verrät uns, dass das Verb „,arrangieren“ mit der Bedeutung „in Ordnung bringen, einrichten“ aus dem Französischen entlehnt wurde (Seebold 2002:61). Und unter dem Eintrag ,lieb“ finden wir die Erläuterung „begehren, verlangen“ (Seebold 2002:574). Der Titel drückt aus, worum es in der Ausstellung geht: Gibt es romantische Liebe in arrangierten Ehen und wie stellt sich diese dar? Mit dem Verb ,arrangieren" wird aber auch eine Aktivität beschrieben: Was tun Menschen alles für die Liebe?

In der Ethnologie blieb die romantische Liebe als Forschungsgegenstand lange Zeit unberücksichtigt. Dombrowski führt dies auf zwei Ursachen zurück: 1. „Die Annahme der romantischen Liebe als 
»typisch« westlich geht mit der Idee einher, dass »traditionelle« bzw. nicht-westliche Gesellschaften durch den Kontakt mit europäischer bzw. amerikanischer Kultur die romantische Liebe kennengelernt und übernommen haben.

2. Polygame und/oder arrangierte Ehen werden als grundsätzlicher Widerspruch zur romantischen Liebe aufgefasst.“ (2011:49f.).

Dass sich Menschen zwischen dem Ideal romantischer Verliebtheit und gesellschaftlich anerkannten Formen der Partnersuche bewegen, scheint ein globales Phänomen zu sein. In vielen außereuropäischen Gesellschaften hat die Tradition der arrangierten Ehe an ihrer Gültigkeit nichts verloren. Aber auch in der westlichen Welt kann man eine Form der arrangierten Partnerwahl beobachten: Laut singlebörsenvergleich.de waren allein im Jahr 2009 deutschlandweit 6,5 Millionen Personen online auf Partnersuche (Dombrowski 2011:7). Auf der Suche nach Liebe nehmen Menschen überall auf der Welt enorme Anstrengungen auf sich. Sie werden also aktiv, wobei sich ihr Verhalten dabei lediglich durch kulturspezifische Liebes- und Beziehungsvorstellungen unterscheidet (Dombrowski 2011:9).

Im Kontext der Ausstellung soll die romantische Liebe als eine Idealvorstellung verstanden werden, die immer wieder auf ihre Alltagstauglichkeit hin geprüft wird.

\section{Ausdrucksformen der Liebe}

Die ethnologische Emotionsforschung konzentrierte sich in der Vergangenheit darauf, dem Phänomen der romantischen Liebe über die Erhebung von lokalen Emotionsvokabularien auf die Spur zu kommen, wobei non-verbale Repräsentationsformen weitestgehend unbeachtet blieben (RöttgerRössler 2002:149). Dies betraf auch den Bereich der materiellen Kultur, aus dem jedoch beachtliche Erkenntnisse im Hinblick auf ein tiefergehendes Verständnis des Alltagsgeschehens von Gesellschaften gezogen werden können (Johansen 1992:1; Hahn 2005:7). Liebe ist insofern als Bestandteil eines komplexen Bedeutungsnetzwerkes zu begreifen, zu dem auch die materielle Kultur gehört, „Dinge werden (wieder) als Produzenten von Bedeutungen, von sozialen Beziehungen und Praktiken, von Identitäten, Wertvorstellungen und Erinnerungen betrachtet." (Tietmeyer et. al. 2010:7).

Museen sind Orte, an denen Wissen hervorgebracht wird. In einer Ausstellung werden Objekte deshalb nicht nur wegen ihres ästhetischen Reizes präsentiert, sondern in einen bestimmten Bedeutungszusammenhang gestellt, der Fragen beantworten und zu einem Dialog anregen kann. Dem Kulturanthropologen Ganter zufolge treten „,in der Lebenssituation um Liebe und Hochzeit wie kaum in anderen Situationen Kräfte des Gestalterischen in Erscheinung, die alle am Geschehen Beteiligten erfasst. "[sic] (1973:2). Nicht nur die Pluralität der Stile ist bemerkenswert, sondern auch, dass sie allein für diese Lebenssituation geschaffen werden. Die Liebe offenbart ein ästhetisches Bedürfnis, 
das durch die ,gängige künstlerische Produktion nicht hinreichend gedeckt werden kann." (Ganter 1973:2).

\section{Stationen der Ausstellung}

Die Ausstellung untersucht die Ambivalenz zwischen romantischen Idealen und alltäglich praktizierten kulturspezifischen Verhaltensweisen in der Partnersuche. Anhand von Exponaten aus verschiedenen kulturellen Kontexten wird dieses Spannungsverhältnis von subjektiven Bedürfnissen und gesellschaftlichen Praktiken dargestellt.

Die Liebe kann als eine Synthese von biologischen und kulturellen Faktoren betrachtet werden (Röttger-Rössler 2002:148). Aus diesem Grund nähert sich die Ausstellung einleitend dem Zustand der Verliebtheit aus dem Blickwinkel biologischer Faktoren an und zeigt, wie verschiedene chemische Botenstoffe in unserem Körper, die sogenannten Neurotransmitter, das Gefühlskarussell in Bewegung setzen (Kast 2004:14ff.).

Charles Darwin ist einer der ersten Attraktivitätsforscher. Das schillernde Gefieder von Pfauen oder Paradiesvögeln, Hirschgeweihen oder Hahnenkämmen bereiteten ihm Kopfschmerzen, denn sie ließen sich nicht zufriedenstellend in seine Überlegungen des „survival of the fittest" eingliedern. Darwin erkannte, dass die Stärksten ihre Fitness über ihre Attraktivität ausdrückten, um sich im Schönheitswettbewerb gegen ihre Konkurrenten durchsetzen zu können (Neffe 2008:66). Auch für uns ist es mit einem ansprechenden Erscheinungs- bild und dem richtigen Auftreten möglich, den einen angebeteten Partner für uns zu gewinnen.

Jede Kultur hat ihre eigenen Logiken des Begehrens. Status und Selbstdarstellung wirken sich dabei entscheidend auf die Attraktivität aus. Der Biologe Neffe fasst unser Verhalten folgendermaßen zusammen: „Schönheitsideale sind biologisch und kulturell bedingt, mehr noch, beide beeinflussen einander unablässig und untrennbar. Der eine Teil wird über Gene vererbt, der andere über Tradition und Erziehung. Seit Menschengedenken manipulieren Angehörige aller Völker ihr körperliches Äußeres, ob durch Piercing, Körperbemalung oder Tattoo, Schmuck, Schminke, Kleidung, Bodybuilding oder Skalpell.“ (2008:68). Als attraktiv galten früher in China Lotosfüße, bei den Maori waren es blau tätowierte Lippen und in Mosambik Schmucknarben, die die Chancen bei der Partnerwahl erhöhten (s. Beiträge Allermann, T. Krüger in diesem Band). Der Wunsch, die eigene sexuelle Attraktivität zu optimieren, drückt sich in dem Gebrauch von Kosmetik, Parfüms oder der Auswahl von Frisuren und Kleidung aus. Sollte sich die Verliebtheit jedoch einmal nicht unmittelbar einstellen, so lässt sich das vielversprechende Aphrodisiakum finden.

Neue Kommunikationsmöglichkeiten, auf deren Basis sich Liebesbeziehungen entwickeln können, eröffnen das Internet und Mobiltelefon, dabei wird das Internet als Teil der materiellen Kultur aufgefasst, da ,sich kulturelle Vorstellungen, gesellschaftliche Normen und lokale Gewohnheiten in dem Gebrauch des Internets" widerspiegeln (Dombrowski 2011:11). Online-Dating ist auch 
bei uns lange Zeit als normabweichend und moralisch fragwürdig angesehen worden. Diese Form der Partnersuche wurde abgewertet, weil sie nicht den herrschenden romantischen Liebesidealen entsprach. Heute werden diese Online-Portale jedoch zunehmend dazu benutzt, einen möglichst passenden Partner zu finden.

Mobiltelefone gelten als „Extensionen unseres Selbst und unserer Persönlichkeit, unserer sozialen Beziehungen und des weiteren kulturellen Kontextes, in dem wir leben“ (Bell 2006:96). Sie sind ein wichtiger emotionaler Speicher: Fotos, Klingeltöne und Accessoires personalisieren dieses Artefakt. Gefühle, Erinnerungen und öffentliche Images werden mit ihm verbunden und lassen es zu einem „Fetisch“ werden (Fortunati 2006:173ff.). Mobilfunkbetreiber bieten sogar Serviceangebote zur Partnersuche an (Hjorth 2006:68). Mit dem Handy werden Zweierbeziehungen gepflegt und durch heimliches Absetzen von SMS-Botschaften, kulturelle Grenzen gesprengt (s. Beiträge Rohner, Gleisberg und Cisakowski in diesem Band).

Die Ausstellung führt den Besucher in ein Reich von Liebeszauber, stellt Lehrwerke der Liebe wie das Kamasutra oder die japanischen Frühlingsbilder vor und zeigt, wie Menschen aus verschiedenen Regionen der Welt mit den Themen Partnervermittlung, Liebe und Ehe umgehen (s. Beiträge Rutschmann und Brinkmann in diesem Band).

Das Ausstellungsvorhaben nahm in der von Herrn Dr. Gundolf Krüger abgehaltenen Vorlesung mit Übung „Objekt-Kultur-Identität“ im Sommersemester 2011 seinen Anfang. In dieser
Veranstaltung beschäftigten wir uns vor allem mit der Anfertigung von Wandtexten. Die Studierenden des Seminars „Ausstellungspraxis“ (Krüger/ Racz) des Wintersemesters 2011/12 bauten auf diesen Vorarbeiten auf, erstellten in der Folge aber eigene Katalogtexte. Diese entstanden auf der $\mathrm{Ba}-$ sis von Biografien jener Objekte, die auch für die Ausstellung ausgewählt worden sind. In dem vorliegenden Band sind beide Textsorten vertreten, was die z.T. unterschiedliche Qualität der Aufsätze ausmacht.

Insgesamt sind die Studierenden aus beiden Veranstaltungen zu bemerkenswerten Ergebnissen auf dem Gebiet der „Arrangierten Liebe“ gekommen. Das Ausstellungs- und Buchprojekt gelang zum einen durch ihr Engagement, aber zum anderen auch durch die Großzügigkeit von Sponsoren, Leihgebern und Kooperationspartnern sowie die unermüdliche Unterstützung der Mitarbeiter des Instituts. Ihnen allen sei an dieser Stelle ganz herzlich gedankt.

\section{Literatur}

Buss, David

1994 Die Evolution des Begehrens. Geheimnisse der Partnerwahl. Hamburg: Kabel.

\section{Dombrowski, Julia}

2011 Die Suche nach der Liebe im Netz. Eine Ethnographie des Online-Datings. Bielefeld: transcript. 
Fisher, Helen

2005 Warum wir lieben. Die Chemie der Leidenschaft. Düsseldorf und Zürich: Walter.

\section{Fortunati, Leopoldina}

2006 Das Mobiltelefon als technologisches Artefakt. In: Glotz, Peter; Bertschi, Stefan und Chris Locke: Daumenkultur: Das Mobiltelefon in der Gesellschaft. Bielefeld: transcript. S. 171-184.

\section{Ganter, Theo}

1973 Liebe und Hochzeit. Ausstellung im Schweizerischen Museum für Volkskunde Basel. Februar 1972 bis Mai 1973. In: Führer durch das Museum für Völkerkunde und Schweizerische Volkskunde, Korrespondenzblatt der Schweizerischen Gesellschaft für Volkskunde, 63. Jg., Heft 3, Basel. S. 33-48.

\section{Hahn, Hans Peter}

2005 Materielle Kultur: eine Einführung. Berlin: Reimer.

\section{Hjorth, Larissa}

2006 Postalische Präsenz: Eine geschlechtsspezifische Fallstudie zur Personalisierung von Mobiltelefonen in Melbourne. In: Glotz, Peter; Bertschi, Stefan und Chris Locke: Daumenkultur: Das Mobiltelefon in der Gesellschaft. Bielefeld: transcript. S. 61-77.

\section{Johansen, Ulla}

1992 Materielle oder materialisierte Kultur? In: Zeitschrift für Ethnologie, Band 117, S. 1-15.

Kast, Bas

2004 Die Liebe und wie sich Leidenschaft erklärt. Frankfurt am Main: Fischer.

Neffe, Jürgen

2008 Darwin. Das Abenteuer eines Lebens.

München: Bertelsmann.

Röttger-Rössler, Birgitt

2002 Emotion und Kultur: Einige Grundfragen. In: Zeitschrift für Ethnologie, Band 127, Heft 2. S. 147-162.

Röttger-Rössler, Birgitt und Eva-Maria Engelen (Hrsg.) 2006 »Tell me about love«. Kultur und Natur der Liebe. Paderborn: mentis.

\section{Scheiner, Elisabeth}

2006 Über die „Lieblosigkeit der Biologie“. In: Röttger-Rössler, Birgitt und Eva-Maria Engelen (Hrsg.): »Tell me about love«. Kultur und Natur der Liebe. Paderborn: mentis. S. 35-58.

\section{Schweikle, Günther}

1990 Liebesdichtung. In: Schweikle, Günther und Irmgard (Hrsg.): Metzler Literaturlexikon. Begriffe und Definitionen. 2., überarbeitete Auflage. Stuttgart: Metzler. S. 267. 


\section{Seebold, Elmar}

2002 arrangieren und lieb. In: Kluge, Friedrich: Etymologisches Wörterbuch der deutschen Sprache. 24., durchgesehene und erweiterte Auflage. Berlin und New York: Walter de Gruyter. S. 61 und S. 574.

Tietmeyer, Elisabeth und Claudia Hirschberger, Karoline Noack, Jane Redlin (Hrsg.)

2010 Die Sprache der Dinge - kulturwissenschaftliche Perspektiven auf die materielle Kultur. Münster, New York, München und Berlin: Waxmann.

\section{Walter, Henrik}

2006 Liebe im Scanner. In: Röttger-Rössler, Birgitt und Eva-Maria Engelen (Hrsg.): »Tell me about love«. Kultur und Natur der Liebe. Paderborn: mentis.

S. 81-97.

Wie funktioniert Verliebtheit? -

Biochemische Aspekte

\section{Viet Hoang und Tina Krüger}

Warum verlieben wir uns? Eine revolutionäre Antwort darauf lieferte uns der Biologe und Evolutionstheoretiker Charles Darwin: Er führt dieses Phänomen auf die Notwendigkeit des Wettbewerbs bei der Partnerwahl zurück, die unabdingbar für den Erhalt der Art, also die Fortpflanzung und Brutpflege ist und nennt es sexuelle Selektion (Buss 1994:8f.). Ist diese Erklärung aber ausreichend? Der Versuch sei nun, ein paar ausgewählte Hormone in Bezug auf ihre Wirkung beim Menschen im Zustand der Verliebtheit einzuordnen. Dazu dienen Ansätze, die Röttger-Rössler und Engelen in »Tell me about love« zusammengetragen haben. Auffällig ist, dass immer wieder auf drei verschiedene Motivationssysteme Bezug genommen wird: Romantische Anziehung, Bindung und Lust (Fisher 2004:97f.).

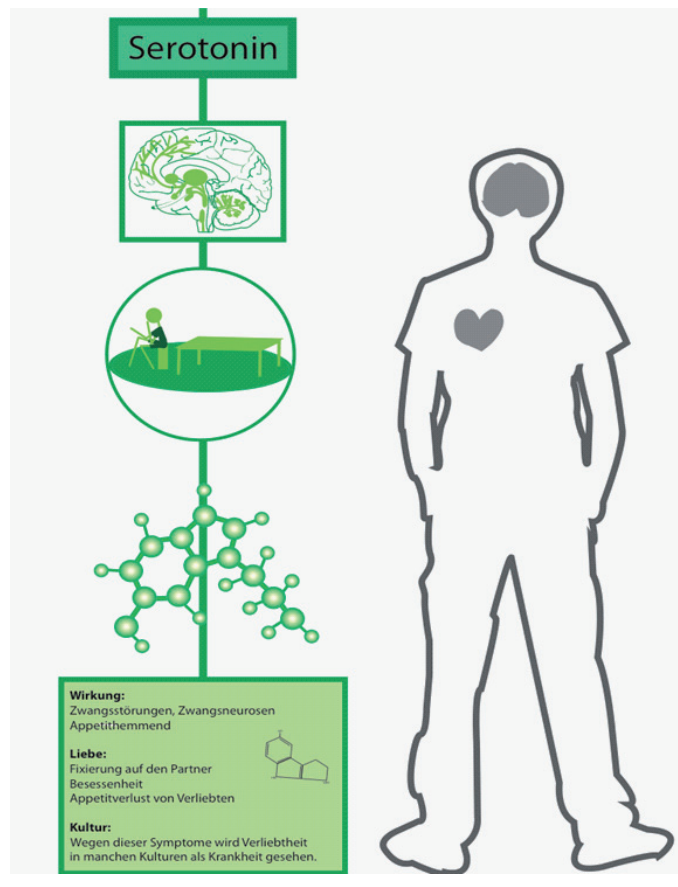

Abbildung 1: Hormonmodell 


\section{Das Zusammenspiel der Hormone}

Serotonin wird besonders über die Nahrung aufgenommen. Es ist in hohem Maße in Walnüssen, Bananen, Pflaumen und Kakao enthalten, um nur ein paar Beispiele zu nennen. 14 verschiedene Rezeptoren im menschlichen Körper sind empfänglich für Serotonin. Deshalb löst es vielfältige Wirkungen aus. Von Interesse hier sind Zwangsneurosen/Zwangsstörungen und seine appetithemmende Wirkung, bei einem niedrigen Serotoninspiegel. Dies sind Eigenschaften, die besonders frisch Verliebten zugeschrieben werden. Serotonin gehört also zum Motivationssystem der romantischen Anziehung, da es die Fokussierung der Aufmerksamkeit auf den neuen Partner unterstützt, dies sogar bis zu einem gewissen Grad der Besessenheit (Fisher 2004:71). Außerdem könnte man damit eventuell erklären, warum viele Menschen bei Liebeskummer so viel Schokolade essen, da sie den Serotoninspiegel erhöht und die Besessenheit vom Partner eventuell verringert.

Noradrenalin sei hier der Vollständigkeit halber nur kurz erwähnt. Es entsteht aus Dopamin, wirkt im Gehirn im Zentralnervensystem/sympathischen Nervensystem und hat ähnliche Auswirkungen wie Serotonin. Es löst Hochgefühle, Schlaflosigkeit, Appetitverlust, und Energieschübe aus. Außerdem steigert es die gerichtete Aufmerksamkeit. All dies sind typische Verhaltensmuster von Verliebten.

Dopamin ist im Gegensatz zu Serotonin abhängig von der subjektiven Wahrnehmung. Es wird bei positiv empfundenen Reizen im „Belohnungssystem“ oder nucleus accumbens im Gehirn ausgeschüttet (Scheiner 2006:44). Durch einen hohen Dopamingehalt im Gehirn werden Hochgefühle, Schlaflosigkeit, Appetitver- lust, Energieschübe, Belohnungsgefühle, Hyperaktivität, gesteigerte Energie, Zittern, beschleunigte Atmung, Anspannung, Manie und sogar Angst ausgelöst (Fisher 2004:70). In Bezug auf das Phänomen Liebe kann dieses Hormon viele der Charakteristika von Verliebten erklären: Der typische Appetitverlust bei Verliebtheit, die ständige Anspannung im Kontakt mit der begehrten Person, ein Übermaß an Energie und Hochgefühlen. Serotonin und Dopamin könnten demnach für das Gefühl der Verliebtheit oder wie Röttger-Rössler es nennt, für die romantische Anziehung verantwortlich sein (2006:73).

Nicht überraschend ist es, dass Verliebtheit in manchen Kulturen als Krankheit erachtet wird, wenn man bedenkt, dass in diesem Zustand eine fast zwanghafte Fokussierung aller Energie und Aufmerksamkeit auf eine einzige Person stattfindet (vgl. dazu Röttger-Rössler 2006:67f.).

\section{Warum gibt es Monogamie?}

Oxytocin wird im Hypothalamus des Gehirns gebildet und in der Hirnanhangdrüse gespeichert. Die Ausschüttung erfolgt beim Orgasmus oder wenn eine Person gestreichelt wird. Es wirkt beruhigend, verbessert die Wundheilung, verringert den Blutdruck, die Stressanfälligkeit und unterstützt Gewichtszunahme. Diese Auswirkungen des Oxytocins unterstützen ein Gefühl von Ruhe und Geborgenheit sowie Verbundenheit. Diese bilden die Basis für eine exklusive Bindung zwischen zwei Partnern. Durch den Geschlechtsakt oder Kose-Einheiten des Partners wird Oxytocin ausgeschüttet und es werden die oben beschrieben Gefühle 
ausgelöst. Der Mensch fühlt sich wohl und geborgen, sieht also keine Motivation, nach anderen Partnern zu suchen. Interessant ist außerdem, dass es in den Milchdrüsen der Frau Rezeptoren für Oxytocin gibt. Diese werden beim Stillen eines Säuglings stimuliert. Es besteht die Vermutung, dass dadurch die Mutter-Kind-Bindung in hohem Maße gestärkt wird (Scheiner 2006:46).

Vasopressin ist ein weiteres Hormon, welches die Paarbindung zweier Personen unterstützt. Jedoch funktioniert es in unterschiedlicher Weise bei Frauen und Männern. Ein hoher Vasopressinspiegel bei Frauen beeinflusst deren Fürsorge- und Sozialverhalten. Beide Gefühle werden durch das Vasopressin gesteigert. Beim Mann wird es hauptsächlich bei sexueller Erregtheit ausgeschüttet. In einer monogamen Partnerschaft ist die Vasopressinausschüttung also ausschließlich mit der Partnerin verbunden. Die Bindung des Paares wird demnach durch Sex im weiteren Sinne und das dabei ausgeschüttete Vasopressin im engeren Sinne gestärkt. Bei der Frau wächst außerdem das Fürsorgebedürfnis für den Partner.

Hier zeigt sich also, dass Vasopressin und Oxytocin aufgrund ihrer beruhigenden Wirkung die monogame Paarbindung unterstützen können. Dabei ist es erstaunlich wie eng diese Hormone mit dem Geschlechtsakt zwischen zwei Partnern verbunden sind. Wohlgefühl, Geborgenheit, Fürsorge und Ruhe machen die Partnerschaft attraktiv. Die Bindung ist wesentlich weniger energieraubend als das Stadium der Verliebtheit (Scheiner 2006:45).

\section{Woher kommt die Lust?}

Bei beiden bereits gezeigten Aspekten der Liebe scheint die sexuelle Lust eine entscheidende Rolle zu spielen. Doch woher kommt die Motivation für Sex und Fortpflanzung?

Testosteron ist dasjenige Hormon, welches seinen Einfluss auf die Libido des Menschen nimmt, und damit für die Lust verantwortlich ist. Es wird beim Mann in den Hoden und bei der Frau in den Eierstöcken gebildet. Ein hoher Testosteronspiegel steigert das sexuelle Verlangen, die Ausdauer und Lebenslust. Testosteron ist also die Motivation für den Geschlechtsakt zwischen zwei Personen (Hüther 2006:215). Neben Lustgefühlen kann Testosteron außerdem dominante und aggressive Verhaltensweisen auslösen. Diese seien eher mit der Fortpflanzung in Verbindung gebracht. Durch Imponiergehabe und einen erhöhten Begattungsdrang bei hohem Testosteronspiegel steigt die Wahrscheinlichkeit, einen geeigneten Sexualpartner auf sich aufmerksam machen zu können.

Die sexuelle Lust existiert also nicht unabhängig von dem Drang nach Fortpflanzung (Scheiner 2006:42).

\section{Warum Hormone erforschen?}

Der Nutzen um das Wissen der Funktion der Hormone wird deutlich, wenn man die zahllosen Bemühungen der Menschheit bedenkt, Liebe und Lust zu beeinflussen. Von Amor bis Zaubertrank erstreckt sich die Vielfalt der Liebesbemühungen und das schon seit Anfang der Menschheit. In je- 
der Tageszeitung finden wir Horoskope über die besten Liebeskonstellationen des Tages, Kontaktanzeigen mit Hinweisen auf Vorzüge der Suchenden, wissenschaftliche Studien über Liebe als soziales Phänomen oder die Chemie der Liebe und zwischendrin noch Werbung für Parfums, die das andere Geschlecht magisch anziehen sollen.

Die Liebe ist also im Alltag nicht nur gegenwärtig, sondern wahrscheinlich Thema Nummer eins! Einige Wissenschaftler gehen davon aus, dass Liebe, Beziehung und Treue rein biochemisch gesteuert seien. Mit einem fundierten Verständnis der Biochemie wäre es folglich möglich, Liebe zu steuern, Menschen zu ver- und entlieben oder über die Liebeskummerphase mit Ersatzhormonen zu helfen (Scheiner 2006:45).

\section{Literatur}

\section{Buss, David}

1994 Die Evolution des Begehrens. Geheimnisse der Partnerwahl. Hamburg: Kabel.

\section{Fisher, Helen}

2004 Warum wir lieben. Die Chemie der Leidenschaft. Düsseldorf [u.a.]: Walter.

\section{Hüther, Gerald}

2006 Auf der Suche nach den biologischen Grundlagen der Liebe. In: Röttger-Rössler, Birgitt und Eva-Maria Engelen (Hrsg.): »Tell me about love«. Kultur und Natur der Liebe. Paderborn: mentis. S. 207-220.

\section{Röttger-Rössler, Birgitt}

2006 Kulturen der Liebe. In: Röttger-Rössler, Birgitt und Eva-Maria Engelen (Hrsg.): »Tell me about love«. Kultur und Natur der Liebe. Paderborn: mentis. S. 59-80.

\section{Scheiner, Elisabeth}

2006 Über die „Lieblosigkeit der Biologie“. In: Röttger-Rössler, Birgitt und Eva-Maria Engelen (Hrsg.): »Tell me about love«. Kultur und Natur der Liebe. Paderborn: mentis. S. 35-58. 
„Ihr kennt euch aus dem Internet?“

\section{Marie-Theres Rohner}

Lange Zeit galt allgemeinhin: Wer sich im Internet kennengelernt hat, hat es im wahren Leben nicht geschafft. Internet-Dating ist etwas für Verzweifelte, für Nerds, für Leute, die mit 30 Jahren noch bei den Eltern wohnen. Heute hat sich dieses Bild weitgehend gewandelt:

Jeder vierte deutsche Internetbenutzer hat bereits Erfahrung mit Internet-Dating und jeder zweite glaubt, dass er online sein Liebesglück finden kann. Wenn man hinter die Kulissen schaut, handelt es sich tatsächlich selten um ,schräge Vögel“, die sich für diesen Schritt entscheiden, sondern um Menschen mit ganz normalen Problemen: Viele müssen hohen beruflichen Anforderungen standhalten und sind häufig unterwegs. Es bleibt ihnen oftmals wenig Zeit, sich an Orten aufzuhalten, wo sie potentielle Partner treffen könnten. Außerdem läuft das Internet-Dating sehr entspannt ab. $\mathrm{Zu}$ Hause vor dem Computer kann man es sich gemütlich machen, ohne sich Gedanken über sein Aussehen machen zu müssen. Der Druck ist wesentlich geringer als beim ersten Date in Echtzeit.

Denise (29) und Max (32) sind seit einem Jahr zusammen und haben sich im Internet kennengelernt. Sie sagen:

Denise: „Viele fragen, ob wir das wirklich nötig hatten, uns im Internet kennenzulernen.

Sicher nicht. Ich wollte nur lieber vom Sofa aus suchen, als in der Bar."

Max: „Ich habe nicht im Netz gesucht, weil sonst nix geklappt hat.

Aber es ist einfacher. Weil man gleich sieht: Sie ist auch solo und will jemanden kennenlernen."

Kathrin (27) und Michael (29), ebenfalls durch das Internet zusammen, sagen:

Kathrin: „Ich hatte gar nicht erwartet, online die große Liebe zu finden.

Ich war vor allem neugierig, wer da so unterwegs ist.

Und dass Michael einfach nur mailte ,Na $\mathrm{Du}^{6}$, fand ich verdammt lässig."

Michael: „Wie viele dachte ich, dass sich auf Online-Singlebörsen nur Verzweifelte rumtreiben. Aber ich wurde eines Besseren belehrt. Es gibt da sehr nette Leute, ich habe kaum Freaks getroffen.“ (Spilker 2010:26).

Die Soziologin Eva Illouz spricht allerdings eine Warnung aus: Durch das Überangebot an potentiellen Partnern seien die Suchenden schnell überfordert und man selbst gerate in Wettbewerb mit einer Unzahl an Namenlosen. Unsere körperliche Attraktion wird durch das Internet ausgelöscht, die einen wichtigen Aspekt in der Partnersuche darstellt (2006:123). Man muss sich riechen können. Internet-Dating wird auch in Verbindung mit Kriminalität gebracht. Es ist also sinnvoll, sich an einige Schutzmaßnahmen zu halten: Nicht gleich alle persönlichen Daten preisgeben und bei einem Treffen einen öffentlichen Platz wählen; zur Not das Treffen beenden, wenn man bemerkt, dass deroder diejenige sich im Internet als jemand ganz 
anderes ausgegeben hat. Allgemein gilt InternetDating aber nicht als gefährlich, solange man sich vorsichtig verhält.

Eine Konkurrenz zu herkömmlichen Partnerbörsen sind heute soziale Netzwerke wie Facebook. Während man bei vielen Partnerbörsen noch Geld dafür zahlen muss, den Namen und das Bild des Auserwählten zu sehen, ist dies bei Facebook kostenlos möglich.

Die Bekannten und Freunde eines jeden Benutzers sind abrufbar, ein Aspekt, der bei Partnerbörsen völlig außer Acht gelassen wird. Im richtigen Leben lernt man sich meistens auch über Freunde auf Partys oder das soziale Umfeld kennen. Partnerbörsen überprüfen lediglich die Übereinstimmung der Profile von wildfremden Menschen. Eine Kombination von beidem lässt vielleicht nicht mehr lange auf sich warten.

Das Internet gewinnt heute einen immer gröBeren Stellenwert. Die soziale Vernetzung ist einfacher als je zuvor. Somit werden wohl auch Paare, die sich übers Internet kennengelernt haben, in $\mathrm{Zu}$ kunft immer mehr zum Alltag gehören. Es bleibt nur eine Frage: Ist das noch romantisch?

\section{Literatur}

Illour, Eva

2006 Gefühle in Zeiten des Kapitalismus. Frankfurt am Main: Suhrkamp.

Spilker, Isabell

2010 Ihr habt euch aus dem Internet?! Maxi,
Ausgabe Juli 2010 S. 26-30

[Elektronisches Dokument] http://www.bild.de/ infos/partnersuche/partnerschaft/internetdating-10502656.bild.html [12.07.2011]

\section{Praetorius, Michael}

2010 [Elektronische Ressource] http://www. praetorius.com/blog/wer_braucht_noch_onlinedating_plattformen.html/ [12.07.2011]

\section{DIE ZEIT ONLINE}

2010 [Elektronische Ressource] http://www.zeit. de/lebensart/partnerschaft/2010-03/onlinepartnersuche-studie [12.07.2011] 


\section{Mit dem Handy Grenzen überschreiten}

\section{Sarab Gleisberg}

Vor der Entwicklung neuer Medien, die unsere Kommunikation erleichtert haben, sind unsere Beziehungen hauptsächlich aus dem näheren Umfeld entstanden. Mit den Möglichkeiten, die uns heutzutage zur Verfügung stehen, um miteinander in Kontakt zu bleiben, können wir diese Grenzen überschreiten. Mit Hilfe des Telefons und des Internets haben wir die Chance, Beziehungen zu pflegen, die nicht länger von geographischen Entfernungen abhängig sind. Das Handy erlaubt uns, diese Kontakte immer und überall wahrzunehmen und mit Freunden, Verwandten und Bekannten in Verbindung zu bleiben (Peil 2011:231).

Das Handy hat für uns drei wesentliche Anwendungsbereiche: Es dient unserer Sicherheit, weil wir in Notfällen schnell Verbindung zu Polizei, Ärzten oder Bekannten aufnehmen können. Es wird immer häufiger zur Planung und Koordinierung unseres privaten und beruflichen Alltagslebens oder zur Interaktion mit uns bekannten aber auch fremden Menschen genutzt. Durch die vielen Nutzungsmöglichkeiten kommt es zu einer emotionalen Bindung des Nutzers an sein Handy. In Krisensituationen stützt es uns, da wir schnell Hilfe anfordern oder geliebte Menschen erreichen können. Es fördert unsere Beziehungen, da wir leichter den Kontakt aufrechterhalten können, gerade wenn diese über eine längere Entfernung bestehen. Diese ständige Verbundenheit kann aber genauso gut negative Ge- fühle produzieren, zum Beispiel von Verpflichtungen, da wir auch für weniger geliebte Personen zu jedem Zeitpunkt erreichbar sind. Wir machen das Gerät zu unserem, binden es an uns, in dem wir es personalisieren. Dies geschieht zum einen durch das Speichern von Erinnerungen und Gefühlen, wie Fotos und Nachrichten, die wir immer bei uns tragen. Auch das Erstellen oder Auswählen unseres Klingeltons, Hintergrundbilder und anderer personalisierender Prozesse macht das Handy zu unserem Eigentum und zu einem Spiegel unserer Identität (Hjorth 2006:69).

Das Handy ermöglicht vor allem eine unauffälligere Art der Kommunikation. So ist es einfacher, unbemerkt Nachrichten zu versenden als zu telefonieren. Aus diesem Grund kann es auch dabei helfen, die Regeln der eigenen sozialen Gesellschaft zu umgehen, ohne sie öffentlich zu brechen und die Konsequenzen dafür tragen zu müssen (Reichenbach 2005:372f.). Dies ist zum Beispiel in Ländern wie Japan so, in denen das soziale Zusammenleben von vorgeschriebenen Regeln und Formen organisiert wird, aber auch in Ländern, die bestimmte Regelungen bezüglich des Kontaktes zwischen den Geschlechtern vorschreiben. In dem islamischen Inselstaat Bahrain, der im Persischen Golf östlich von Saudi-Arabien liegt, ist dies der Fall. Hier besteht ein erster Unterschied in der Nutzungsweise beim Schreiben von SMS. Während wir das Kurznachrichtensystem hauptsächlich zur Kommunikation von individuellen persönlichen Mitteilungen nutzen, werden in Bahrain normalerweise standardisierte Nachrichten in Form von Sprüchen, Reimen, Redewendungen und Witzen versendet. 
Besonders beliebt ist hierbei das Thema Sex, welches in der Öffentlichkeit ein Tabu ist. Neue oder besonders witzige SMS werden häufig untereinander ausgetauscht oder im geselligen Beisammensein vorgetragen. Wenn hierbei der Inhalt zu anstößig ist, werden unverheiratete Mädchen weggeschickt (Reichenbach 2005:364f.).

Da es dem Ruf der Familie schadet, wenn eine Frau öffentlich Kontakt zu fremden Männern pflegt, kommen Partnerschaften nur selten durch Verabredungen zustande, weshalb eine Dating-Kultur dort nicht existiert. Traditionell werden potentielle Ehepartner von Angehörigen ausgewählt und erst nach der offiziellen Verlobung darf das Paar öffentlich miteinander ausgehen (Reichenbach 2005:368). Durch die Weitergabe der eigenen Handynummer an mögliche Partner, kommt es inzwischen immer häufiger zu Ehen, bei denen die Wahl des Lebensgefährten/-in eigenständig getroffen wurde. Oftmals sind es Männer, die ihre Nummern an Frauen weitergeben, die ihnen gefallen. Dies geschieht meist schnell und unauffällig, in Einkaufszentren, Cafés, bei Stau und an Ampelkreuzungen, indem sie ihnen einen Zettel im Vorbeigehen zustecken, auf den Tisch legen oder sogar durch das Autofenster werfen. Erfolgreicher ist die Weitergabe der Nummer jedoch, wenn man sich bereits vorher gesehen oder im Alltag kennengelernt hat, etwa in der Universität, bei der Arbeit oder im Internet. Wenn das Mädchen Interesse hat, dann werden zunächst SMS geschrieben, später unauffällig Telefonate geführt oder sogar heimliche Treffen vereinbart (Reichenbach 2005:369). Hierbei werden oft auch kleine Tricks genutzt, um den Austausch vom eigenen Umfeld zu verbergen. Einer dieser Tricks wäre, dass schnell ins Englische gewechselt wird, wenn jemand das Gespräch mithören kann. Der Vorteil liegt darin, dass die englische Form von „Du“, im Gegensatz zu der arabischen, neutral und nicht geschlechterspezifisch ist. So kann jemand, der das Telefonat mit anhört nicht wissen, ob der Gesprächspartner am anderen Ende männlich oder weiblich ist. Wenn die Absichten auf beiden Seiten ernst sind, dann wird der Partner schließlich der Familie vorgestellt, wobei aber die Art des Kennenlernens meistens verschwiegen und stattdessen eine Vermittlung über Bekannte vorgetäuscht wird (Reichenbach 2005:369).

Dieses Phänomen, gesellschaftliche Strukturen zu umgehen, ohne mit ihnen zu brechen, kann man auch in Japan finden. Traditionell verankerte Muster kollektiver Orientierung im sozialen Leben setzen bei den Japanern ein Verhalten voraus, welches die Stabilität und Harmonie der Gruppe nicht gefährdet. Demzufolge gibt es bestimmte Benimmregeln für verschiedenste Situationen, die verhindern sollen, dass man aus dem Rahmen fällt (Peil 2011:237). Aus diesem Grund ist das Konzept von Anonymität und des intimen Fremden sehr beliebt. Es geht hierbei hauptsächlich darum, Kontakt zu fremden Menschen herzustellen, mit denen man über Tabu-Themen sprechen kann, ohne die gesellschaftlichen Konsequenzen fürchten zu müssen. Es ist eine moderne Form der Brief-Freundschaft, bei der man sich nicht anpassen oder nach Regeln richten muss. Dies kann dazu führen, dass sich die Beziehung zu einer langfristigen Freundschaft oder sogar Partnerschaft und Liebe entwickelt. Es hilft 
in jedem Fall dabei, neue Menschen kennenzulernen, was aufgrund der Geschlossenheit des Gruppensystems eher schwierig ist.

Das Konzept von anonymer Kontaktaufnahme wurde schon in den 1980er Jahren aufgegriffen, von Vermittlungsdiensten über das Festnetztelefon. Man hat hierbei bestimmte Servicenummern angerufen, die einen dann wahllos mit einer anderen Person verbunden haben oder auch mit mehreren gleichzeitig über Konferenzschaltung, einer so genannten ,party line"(Peil 2011:269). Diese Telefon-Dating-Clubs waren die Vorläufer der Internet-Partnerbörsen und Chaträume. Sie wurden zunächst durch den Pager abgelöst, wodurch sich das Konzept des beru-tomo, wörtlich Klingelfreund, entwickelte. Der Unterschied zu den bisherigen Telefon-Dating-Clubs besteht vor allem darin, dass kein Dating-Service in Anspruch genommen werden musste. Hierbei schickte man an eine beliebige Nummer eine kurze Nachricht, mit der Bitte um Kontaktaufnahme. Wenn der Empfänger Interesse hat, dann ist er oder sie dieser Aufforderung nachgekommen. Anfangs werden dann nur Belanglosigkeiten ausgetauscht, jedoch war das Ziel häufig eine intime Beziehung aufbauen zu können, einen Lebensgefährten oder Ehepartner zu finden. Diese Romantisierung des intimen Fremden beruht hauptsächlich auf der Darstellung in den Medien, wie Film und Fernsehen. Besonders ansprechend ist die Idee, soziale Grenzen überschreiten zu können und die Entfaltung der eigenen Identität, sein „real me“ („,wirkliches Ich $^{\text {") }) ~ f r e i ~ v o n ~ d e n ~ g e s e l l s c h a f t l i c h e n ~ R e g e l n ~ e n t w i-~}$ ckeln zu können (Peil 2011:269ff.). Hat man diese intime Beziehung hergestellt, kommt die Rolle der so genannten love hotels ins Spiel. In diesen Hotels kann man Zimmer für die ganze Nacht oder auch nur für ein paar Stunden mieten. Es gibt sie in verschiedensten Preisklassen, womit auch ihr Angebot und Komfort variiert. Sie werden nicht nur von Paaren genutzt, die ihre Beziehung geheim halten wollen, sondern auch von Verheirateten oder anderen offiziellen Partnerschaften. Der Grund hierfür ist, dass man in Japan oft in Mehrgenerationenhäusern oder -wohnungen lebt, welche besonders in den Großstädten sehr beengt sein können und den Paaren nur wenig Raum für ungestörte Zweisamkeit bieten (Peil 2011:223).

Das Handy hilft dabei, bestimmte soziale Grenzen in der Gesellschaft zu umgehen oder gar zu überschreiten, ohne ganz mit ihnen zu brechen oder gegen alle Werte zu verstoßen. Dies zeigt insbesondere, dass die Paare nach wie vor ihre Familien einschalten, wenn die Beziehung ernst wird. In dem wir es durch kreative Prozesse personalisieren, kann es ein Hilfsmittel für den Ausdruck unserer Identität sein oder wie im Beispiel Japan dazu beitragen, diese erst zu konstruieren. Es verbindet uns mit anderen Menschen mit allen positiven, wie auch negativen Aspekten der ständigen Erreichbarkeit. So können wir mit Hilfe des Handys unsere sozialen Räume erweitern, aber ermöglichen gleichzeitig ein Eindringen in unsere privaten Räume. 


\section{Literatur}

\section{Burkart, Günther}

2007 Handymania: Wie das Mobiltelefon unser Leben verändert hat. Frankfurt am Main [u.a.]: Campus.

Glotr, Peter; Bertschi, Stefan und Chris Locke

2006 Daumenkultur: Das Mobiltelefon in der

Gesellschaft. Bielefeld: transcript.

\section{Hjorth, Larissa}

2006 Postalische Präsenz: Eine geschlechtsspezifische Fallstudie zur Personalisierung von Mobiltelefonen in Melbourne. In: Glotz, Peter, Bertschi, Stefan und Chris Locke: Daumenkultur: Das Mobiltelefon in der Gesellschaft. Bielefeld: transcript. S. 61-77.

\section{Peil, Corinna}

2011 Mobilkommunikation in Japan: Zur kulturellen Infrastruktur der Handy-Aneignung. Bielefeld: transcript.

\section{Reichenbach, Anke}

2005160 Zeichen Liebe und Subversion: Mobile Kommunikation in Bahrain. In: Geisenhainer, Katja und Katharina Lange (Hrsg.): Bewegliche Horizonte: Festschrift zum 60. Geburtstag von Bernhard Streck. Leipzig: Leipziger Universitätsverlag. S. 351-373.

\section{Liebesbotschaften per SMS}

\section{Kathrin Cisakowski}

Seit den späten 1990er Jahren und dem frühen 21. Jahrhundert ist weltweit ein Boom des Mobiltelefons festzustellen. In den meisten asiatischen Ländern hat die Anzahl der Mobilfunkteilnehmer die Anzahl der Festnetz-Verbindungen längst übertroffen. In Singapur gibt es sogar mehr Handys als Einwohner, denn viele besitzen mehr als nur eins.

$\mathrm{Ob}$ im Job oder privat, das Handy ist in den meisten Teilen der Welt kaum noch weg zu denken. Ein Handy verändert den Umgang mit Raum und Zeit. Es bietet die Möglichkeit ständiger Erreichbarkeit und schneller Kommunikation und erleichtert somit soziale Beziehungen - auch über größere Entfernungen - aufrecht zu erhalten.

Das Handy gilt zudem oft als Statussymbol: Wer hat das modernere Handy, welches hat die besseren Funktionen? Die meisten Menschen fühlen sich ohne Handy sogar ,nackt“. Dies hängt damit zusammen, dass sie Fotos, Musik, persönliche Notizen, wichtige SMS und ihre ganzen Kontakte auf dem Handy gespeichert haben und sozusagen ihr "Leben in der Hosentasche tragen".

Das Handy bietet wirtschaftliche Vorteile, aber auch im Privatleben ist es vorteilhaft, ein Handy zu besitzen, denn man kann mit ihm seine Familie und Freunde immer erreichen. Ein Mann aus Ruanda erzählt, wie er seine Ehefrau mit dem Handy anruft, um sie zu informieren, wann er am Abend nach Hause kommt. Das Handy bietet dort eine 
Möglichkeit, den Alltag besser zu koordinieren, da die Ehefrau dann weiß, wann sie das Essen kochen kann. Ein anderer Mann aus der gleichen Region beschreibt, wie sein vierjähriger Sohn ihn mit dem Handy der Mutter anruft, um ihm zu sagen, wie sehr er ihn vermisse (Donner 2006:47). Außerdem kaufen viele Eltern ihren Kindern Handys, um nicht mehr beunruhigt sein zu müssen, wenn diese das Haus verlassen.

Aber nicht nur die Funktion des Telefonierens mit dem Handy spielt eine große Rolle. Viele Handynutzer, vor allem Jugendliche, nutzen die Funktion des „Anklingelns“ („,beeping“), eine Art Lockruf, um Handykosten zu minimieren. Oft meint dies „Bitte um Rückruf,“ kann aber auch andere Bedeutungen haben, wie vorher vereinbarte Botschaften, z.B. „ich bin gut angekommen“, „bitte hol mich jetzt ab“, aber manchmal auch ,ich denke gerade an dich“, was eine Beziehung festigen soll (Donner 2006:48).

Auch das Schreiben von SMS ist in vielen Teilen der Welt eine wichtige Tätigkeit im Alltag geworden. In China, wo sich der größte Handymarkt der Welt befindet, werden täglich geschätzte 100 Millionen SMS versendet. Es wird gescherzt, China befinde sich im „Zeitalter des Daumens“. In Singapur und Malaysia gibt es sogar Hochgeschwindigkeits-SMS-Schreib-Meisterschaften (Bell 2006:89). Meistens besteht eine SMS aus 160-240 Zeichen. Es ist daher notwendig, sich kurz zu fassen. Aus diesem Grund wenden viele Benutzer Abkürzungen, wie z.B. „cu“ (see you) oder „ssz“ (schreib schnell zurück) an. Außerdem werden - nicht nur von Jugendlichen - sogenannte Emoticons ver- wendet, wie z.B.:“:)“ (lachendes Gesicht) oder „<3“ (Herz). Diese Emoticons sind sprachunabhängige Zeichensysteme und können von jedem verstanden werden.

Im Chinesischen symbolisieren einzelne Schriftzeichen jedoch auch ganze Wörter, sodass eine SMS-Botschaft viel umfangreicher sein kann und somit das Handy zum literarischen Instrument wird. In vielen Ländern, auch in China, ist es ein Trend, „Schrottbotschaften“, Scherze und Sprichwörter per SMS auszutauschen. Das wichtigste Thema hierbei, wobei es sich oft um ein Tabuthema handelt, über das man nicht offen sprechen kann, ist Sex, gefolgt von Politik. In Artikeln indischer Zeitungen wird sogar geschrieben, Handys würden von Frauen genutzt werden, um ihre Sexualität zu erkunden, Heiratspläne der Familie zu durchkreuzen oder die Kontrolle der Ehemänner zu unterlaufen, indem sie sich mit anderen Männern SMS-Botschaften schreiben oder mit ihren Freundinnen Sex-Witze per SMS austauschen (Bell 2006:95).

Auch in der Partnerschaft spielen Handys eine große Rolle. Vor dem Zeitalter des Handys war es meistens nur möglich, seinen Partner im näheren Umfeld kennen zu lernen. Ansonsten war es schwierig eine Beziehung über eine längere Distanz aufrecht zu erhalten. Heute hingegen ist dies kein Problem mehr. Das Handy ist in Fernbeziehungen eines der wichtigsten Medien. Es ermöglicht den ständigen Kontakt zwischen Partnern. Es gibt zum Beispiel viele chinesische Männer, die über die Grenze nach Vietnam gehen, um sexuelle Dienstleistungen in Anspruch zu nehmen und sich dann dort in eine Frau verlieben. Um miteinander in 
Kontakt zu bleiben, nutzen beide das Handy, um sich gegenseitig Liebesbotschaften per SMS zu schreiben. (Chan 200:216).

\section{Literatur}

\section{Bell, Genevieve}

2006 Das Daumenzeitalter: Eine kulturelle Deutung der Handytechnologie aus Asien. In: Daumenkultur. Das Mobiltelefon in der Gesellschaft. Peter Glotz, Stefan Bertschi und Chris Locke (Hrsg.). Bielefeld: transcript. S. 79-104.

\section{Chan, Yuk Wah}

2009 Cultural and Gender Politics in ChinaVietnam Border Tourism. In: Tourism in southeast asia challenges and new directions. Edited by Michael Hitchcock, Victor T. King and Michael Parnwell. NIAS Press. S. 216.

\section{Donner, Jonathan}

2006 Die sozialen und wirtschaftlichen Implikationen der Mobiltelefonie in Ruanda: Eine Typologie unter dem Gesichtspunkt Telefonbesitz und Telefonzugang. In: Daumenkultur. Das Mobiltelefon in der Gesellschaft. Peter Glotz, Stefan Bertschi und Chris Locke (Hrsg.) Bielefeld: transcript. S. 41-59.

\section{Symbole der Liebe}

\section{Lara Groth}

\section{Zur Frage von Symbolhaftigkeit}

Als Symbol bezeichnet man ein Sinnbild, das den Inhalt einer Sache oder einer abstrakten Idee zum Ausdruck bringt. Es steht also stellvertretend für etwas anderes (Zerbst: 2003:9). Dabei können eine Vielzahl von Symbolen für einen bestimmten Gegenstand stehen, aber auch verschiedene Gegenstände mit einem gleichen Symbol in Verbindung gebracht werden. Unter Symbolik versteht man demzufolge die sinnbildliche Darstellung von diesen abstrakten Ideen und Sachen, wie zum Beispiel der Liebe (Brockhaus Bd. 18, 1982:45). So gibt es in verschiedenen Kulturen unterschiedliche Symbole und Zeichen, die mit Liebe in Zusammenhang stehen, auch wenn ihnen bei anderen Ethnien vielleicht eine ganz andere Bedeutung innewohnt. Im Folgenden sollen ein paar Liebessymbole aus dem asiatischen Raum vorgestellt werden.

\section{Sinnbild für die Liebe und die Entstehung des Lebens: Der Lotos}

Der Name „Lotos“ stammt aus dem Griechischen und bedeutet „geschätzte Pflanze“ (vgl. auch Objekt: As1924 Cakrasamvara, Engineer: Beitrag in diesem Band).

In vielen asiatischen Ländern wie Indien, Nepal und China ist der mit den Seerosen und Proteen 
verwandte Lotos eine äußerst wichtige Pflanze mit vielen positiven Bedeutungen, und ähnlich wie die Rose im europäischen Raum ist er unter anderem ein Symbol für die Liebe (Peter:2005). Allerdings spielte der Lotos bereits im Alten Ägypten eine relevante Rolle. Er stand für die Sonne und das Leben sowie für Unsterblichkeit und Auferstehung. Der Sonnengott Horus soll einer Lotosblume entstammen, dies symbolisiert somit die Entstehung der Sonne aus dem Element Wasser. Von Ägypten kam das Symbol nach Indien und Ostasien, wo der Lotos im Hinduismus und Buddhismus als Sinnbild für die Entstehung und Geburt des Lebens steht. Im Hinduismus soll der Schöpfergott Brahma aus einer Lotosblume geboren worden sein und daraufhin ein geordnetes Universum aus dem Chaos kreiert haben. Der Lotos ist somit der Ursprung des Lebens (Ward 1952:135ff.). Ähnlich sieht es im Buddhismus aus. Hier soll Buddha ebenfalls einer Lotosblume entstammen. Aus diesem Grund wird er häufig auf oder mit einem Lotos dargestellt (vgl. As1924 Cakrasamvara). Auch ist der Lotos eng mit dem Wissen um das Nirwana verbunden. So wie sich die menschliche Seele aus der materiellen Welt in das reine Nirwana erheben soll, so entfaltet sich die Lotosblume aus schmutzigen Gewässern (Peter:2005).

As the lotos, O King, is untarnished by the water, so in Nirvana untarnished by any evil dispositions. This is the one quality of the lotus inherent in Nirvana. (Ward 1952:138).

In China symbolisiert vor allem der weiße Lotos die Erhabenheit und Reinheit. Wie bereits erwähnt, wächst der Lotos aus schlammigem Gewässer, wird aber aufgrund einer Wachsschicht an den Blättern nicht von ihm beschmutzt und erhebt sich aus dem Wasser, anstatt auf ihm zu schwimmen. Die rote Lotosblüte steht für das weibliche Geschlechtsorgan, während der Stängel der Pflanze das männliche darstellt. „Lotospäckchen“ sind Portemonnaies aus Seide und ,kleines Portemonnaie“ ist ebenfalls ein Begriff für die Vagina. Die blaue Lotosblüte stellt Sauberkeit und Bescheidenheit dar. So ist das Wort „Lotos“ in einem weiblichen Namen ein Zeichen für den Wunsch, dass sich die Frau „,rein und ehrbar" verhält (Eberhard 1983:184). In Männernamen deutet das Wort „Lotos“ eher auf eine Verbundenheit mit dem Buddhismus hin.

Im Chinesischen hat die Pflanze zwei Bezeichnungen. Lien-bua und ho. Das Wort lien steht auch für (ehelich) verbinden, ununterbrochen und lieben, sowie für Bescheidenheit. Es lässt sich also durchaus ein $\mathrm{Zu}-$ sammenhang zwischen der sprachlichen und der symbolischen Bedeutung des Lotos erkennen. Ho hingegen meint „Einheit“. Aus diesem Grund stehen zwei Lotosblüten für „Gemeinsames Herz und Harmonie“" (Eberhard 1983:184).

Der Lotos ist aufgrund seiner vielen Samen auBerdem ein Symbol für Fruchtbarkeit, Überfluss und Erotik. Ein Beispiel hierfür sind die zusammengebundenen Füße der Chinesinnen in früherer Zeit (vgl. Allermann Beitrag in diesem Band). Dieser Brauch geht auf einen alten buddhistischen Text zurück. Darin wird die Geschichte der Tochter eines Heiligen erzählt. Überall, wo sie ihre Füße hinsetzte, sprossen Lotosblüten aus dem Boden. Bei Nachstellungen dieser Szene brauchten die 
Frauen kleine Füße, um gut auf den Blüten laufen und tanzen zu können. Lyrisch nennt man diese zusammengebundenen Füße auch ,gebogener Lotos“ (Eberhard 1983:184). Es gibt außerdem noch viele Sinnbilder und Sprüche, die sich mit dem Lotos befassen. Die Darstellung von Lotos (Symbol für ein Mädchen) und Fisch (Junge oder Mann) ist beispielsweise ein Sinnbild für die Liebe. Die Formulierung eines Mannes, er habe ,eine Lotosblüte mit doppeltem Stil“" getroffen, meint, dass er eine ehemalige Geliebte wiedergesehen hat. In China gibt es auch den „Tag des Lotos“. Dieser ist am 8. Tag des 1. chinesischen Monats. Es wird gesagt, dass eine Frau Menstruationsbeschwerden bekommt, wenn sie an diesem Tag näht. Wie man sieht ist der Lotos eine äußerst präsente Pflanze im asiatischen Raum, die eine große Rolle in zwei der größten Religionen spielt und mit der viele Sprüche und Bräuche verbunden sind. Er wird gemeinhin äußerst positiv gesehen und symbolisiert viele Tugenden.

\section{In Europa gefürchtet, in China verehrt:}

\section{Der Drache}

Das Jahr 2012 steht im Zeichen des Drachen, jedenfalls nach dem chinesischen Kalender. Der Drache ist hier das fünfte Tier des chinesischen Tierkreises. In China ist er ein besonders beliebtes Sternzeichen und das Jahr des Drachen wird als außerordentlich glückbringend angesehen.

In Europa gilt der Drache seit Auftreten des Christentums eher für „monsterhafte“ Kreaturen in Geschichten und für ,gottfeindliche Urmächte“ (Becker 1992:57), die bekämpft werden müs- sen und den Teufel darstellen. Der Heilige Georg wird der Legende nach als besonders erfolgreicher Drachenbezwinger gefeiert, der z.B. eine Stadt in Libyen von einem Drachen befreit hat, dem viele Jungfrauen zum Opfer fielen. Als die Königstochter in Gefahr geriet, kam der Heilige Georg in die Stadt und rettete sie nach einem schweren Kampf (Gebhardt 2005:58). Allerdings ist der Drache in der vorchristlichen Zeit auch durchaus positiv besetzt gewesen und ihm wurden viele magische und heilende Eigenschaften zugeschrieben (Joger 2007:89). Zudem ist er ein Sinnbild für die ,innere Welt der Emotionen“ (Fontana 2004:133).

In China ist er eines der komplexesten Symbole und kann für unterschiedliche Wesen stehen. Die meisten Darstellungen zeigen den chinesischen Drachen mit einem schlangenähnlichen Körper, mit schuppiger Haut und Hörnern. Es gibt vier Kategorien von Drachen. Den Himmelsdrachen, der für die Kraft des Himmels steht, den Geisterdrachen, der es regnen lässt, den Erddrachen, der über Quellen und Flüsse herrscht und Schatzhüterdrachen (Eberhard 1983:62). Schatzhüterdrachen sind auch in der europäischen Mythologie zu finden. In der Nibelungen-Sage besiegt der junge Siegfried beispielsweise einen Drachen, der einen Schatz bewacht. Typisch für den europäischen Raum wird hier der Drache negativ dargestellt und Siegfried als siegreicher Held gefeiert (Schuker 2006:46).

Der Drache steht in einem engen Zusammenhang mit der Schlange, obwohl diese, im Gegensatz zu ihm, eher das Weibliche symbolisiert. In Südchina repräsentieren Schlangen sogar das weibliche Geschlechtsorgan und der Traum von einer Schlange 
deutet auf die Geburt einer Tochter hin (Burkolter 1981:71). Zudem sagt man dem magischen Tier nach, dass es seine Größe verändern und sich sogar unsichtbar machen kann.

Drachen, im Chinesischen lung, symbolisieren den Osten, den Sonnenaufgang, die Zeugungskraft und den (Frühlings-)regen. In Nordchina meint man, dass er den Winter unter der Erde verbringt und am 2. Tag des 2. chinesischen Monats in den Himmel steigt und für den ersten Regen sorgt, nachdem die Felder wieder bestellt werden können. Während dieser Prozedur ist der Drache jedoch nicht sichtbar, da er von Regenwolken verdeckt wird. Der Drache ist also ein äußerst wichtiges Fruchtbarkeitssymbol. Sein Gegner ist der weiße Tiger, der für den Westen und den Tod steht (Eberhard 1983:61).

Der Drache ist das Sinnbild für die männliche Natur (yang) und die Zeugungskraft. Deshalb ist auch die Zahl neun dem Drachen zugeordnet, da sie ebenfalls für männliche Kraft steht. Frisch Vermählten wünscht man in China häufig den Kindersegen: „Der Drache hat neun Söhne, jeder von anderer Art" (Eberhard 1983:62). Jedem der neun Söhne sind verschiedene Eigenschaften zugeordnet, wie z.B. Tapferkeit, Stärke, gute Beobachtungsgabe oder aber auch, dass einer besonders gerne isst (Eberhard 1983:63). Drache und Phönix symbolisieren die männliche und weibliche Natur (ying und yang) und sind eine Metapher für ein Ehepaar.

In Mittelchina wird von Männern am chinesischen Neujahrsfest ein Drachentanz aufgeführt, der dem Tanz ähnelt, mit dem Frischvermählte von der Hochzeitsfeier verabschiedet werden. Eine der Tanzszenen deutet den Kuss eines Paares an. In Südchina werden am 5. Tag des 5. chinesischen Monats Wettrennen in Booten, die mit Drachenmustern verziert sind, durchgeführt. Fiel im Alten China ein Mann dabei ins Wasser und ertrank, galt dies als Opfer für den Flussdrachen, der daraufhin Fruchtbarkeit schenkte. Das Wort Drache ist in China auch im Alltag geläufig und in vielen Namen von Früchten, Parfüms etc. zu finden (Eberhard 1983:62ff.).

Drachen scheinen Menschen, sowohl positiv als auch negativ, zu allen Zeiten fasziniert zu haben und Wissenschaftler stellen Thesen über die möglichen Vorbilder für Drachen auf, die von Dinosaurier-Fossilien bis zu Alligatoren und Waranen reichen (Joger 2007:84). Auffallend ist jedoch, dass Drachen in vielen Schöpfungsmythen ganz unterschiedlicher Ethnien auftreten, eine zumindest ähnliche Gestalt haben und ein Bindeglied zwischen Erde und Himmel darstellen (Gebhardt 2005:45).

\section{„I was made for loving you":}

\section{Die Mandarinente (yúan-yang)}

Ein weiteres Liebessymbol in Asien, besonders in China, ist die Mandarinente. Diese Entenart stammt aus Ostasien, aber auch in Europa wird sie wegen ihres besonderen Äußeren oft in Parks gehalten. Die Mandarinente lebt mit einem Partner zusammen. Mit diesem schwimmt sie gemeinsam, fliegt Seite an Seite und kreuzt beim Schlafen die Hälse. Nach dem Tod eines Partners sucht sich die verbleibende Mandarinente, so sagt man, keinen neuen. Aufgrund dieser monogamen Lebensweise 
gilt sie als Sinnbild für eine gute Ehe und eheliche Treue.

Deshalb sind viele Vorhänge und Decken von Ehebetten mit Mandarinenten verziert und Kopfkissen mit diesem Motiv gelten als ein besonders gutes Geschenk für Ehepaare.

Ein weiteres Symbol, das sowohl die Mandarinente als auch die Lotosblume mit einbezieht, ist ein Mandarinentenpaar, bei dem die eine Ente eine Lotosblume, die andere eine Lotosfrucht im Schnabel trägt. Dies soll die Geburt eines Sohnes ankündigen (Eberhard 1983:189). Ein Bild, das ein Mandarinentenpaar in einem Teich in dem Lotosblumen wachsen zeigt, steht für den Ausdruck „Mandarinenten, die im Lotos spielen“. Mit diesem Satz bezeichnet man ein Paar, dass unwiderruflich und schwer verliebt ist (Living Chinese Symbols: 2005:online). Es gibt auch Sprüche, die von Mandarinenten handeln. Mit der Bezeichnung „Mandarinenten im Tau" meint man zum Beispiel ein unverheiratetes Liebespaar. Zudem ist die „Mandarinentenvereinigung" eine Beischlafposition (Eberhard 1983:189). Neben der Mandarinente stehen auch Gänse und Phönixe in China für das Eheglück.

\section{Literatur}

Becker, Udo

1992 Lexikon der Symbole. Köln: KOMET.

1982 Brockhaus Lexikon Band 18. München:

DTV.

\section{Burkolter-Trachsel, Max}

1981 Der Drache: Das Symbol und der Mensch (Dissertation). Bern: Paul Haupt.

\section{Eberhard, Wolfram}

1983 Lexikon chinesischer Symbole: geheime Sinnbilder in Kunst und Literatur, Leben und Denken der Chinesen. Köln: Diederichs.

Fontana, David

2004 Die Sprache der Symbole. Ein visueller Schlüssel zur Bedeutung der Symbole. Düsseldorf: Patmos.

Gebhard, Dr. H. und Dr. M. Ludwig

2005 Von Drachen, Yetis und Vampiren, Fabeltieren auf der Spur. München: BLV Buchverlag.

Joger, Ulrich und Jochen Luckhardt

2007 Schlangen und Drachen, Kunst, Natur.

Darmstadt: WBG.

[Elektronische Ressource] Living Chinese Symbols: Chinese Language and Lifestyle Guide 2005 The Lotus Flower - One of the most auspicious Chinese symbols. http://www.living-chinese-symbols.com/lotus-flower.html [11.4.2012] 


\section{Peter, Bernhard}

2005 [Elektronische Ressource] Lotus- vielfältiges Symbol in Asien. http://www.bernhardpeter. de/Indien/Sonstige/seite376.htm/ [10.4.2012]

\section{Schuker, Karl}

2006 Drachen, Mythologie - Symbolik - Geschichte. Köln: TASCHEN GmbH.

Ward, William E.

1952 The Lotus Symbol: It's Meaning in Buddhist Art and Philosophy. The Journal of Aesthetics and Art Criticism 11(2): S. 135-146.

Zerbst, Marion und Werner Waldmann (Hrsg.)

2003 DuMonts Handbuch: Zeichen und Symbole. Herkunft. Bedeutung. Verwendung. Köln: DuMont. S. 9.
Herz, Ring und Mondperle -

Liebessymbole im interkulturellen

Vergleich

\section{Lilian Leifert}

Das Herz der Liebe

Das Herz ist in Deutschland, Spanien, Schweden oder den USA, seit langer Zeit das bekannteste Symbol für die Liebe. Doch auch in vielen anderen Teilen der Welt wie zum Beispiel in China oder Südamerika kennt man es inzwischen. Die Vorstellung, dass das Herz in direkter Verbindung mit den Gefühlen steht, reicht weit in die Vergangenheit zurück. Lange Zeit ging man davon aus, dass das Herz der Sitz des Geistes sei. Man schrieb ihm also die Eigenschaften zu, die man heute mit dem Gehirn in Verbindung bringt. Dies rührt vermutlich daher, dass sich das Herz in Momenten großer Gefühle regt: Es schlägt schneller, setzt einen Herzschlag aus, scheint einem förmlich aus der Brust zu springen (Chrismon 2011:12). Die Bedeutung, die man dem Herzen auch heute noch zuschreibt, hat sich in unzähligen solchen Redewendungen und Sprichwörtern niedergeschlagen. Man spricht von Menschen, die „kein Herz haben“ oder „herzlos“ sind. Jemand hat ein ,großes Herz" oder „,nimmt sich ein Herz“. Da ist einem das „Herz in die Hose gerutscht", man leidet unter ,gebrochenem Herzen“, oder das „Herz hüpft vor Freude“, sind geläufige Ausdrücke.

Obwohl wir heute wissen, dass die Gefühle im 
Kopf entstehen und die anderen Organe des Körpers genauso wichtig für unsere Gesundheit sind, wird das Herz gemeinhin als Zentrum des Lebens und der Entstehung von Liebe wahrgenommen (Chrismon 2011:12). Diese Zusammenhänge lassen darauf schließen, wieso dem Symbol eine solche Bedeutung zukommt. Auch in der Dichtung, $\mathrm{Mu}-$ sik und vielen anderen Künsten wird das Herz als Symbol für die romantische Liebe, als Symbol für den Sitz des Gefühls verwendet.

Ein sehr schönes Beispiel hierfür ist das Gedicht „Strauch mit herzförmigen Blättern“ von Erich Fried (1990:9).

\section{Strauch mit heraförmigen Blättern \\ Sommerregen warm: \\ Fällt ein schwerer Tropfen \\ bebt das ganze Blatt \\ So bebt jedes Mal mein Herz. \\ wenn dein Name auf es fällt.}

Dieses Gedicht zeigt nicht nur, wie Gefühl und Herz in Verbindung gebracht werden, sondern gibt außerdem einen Hinweis darauf, wie sich die Form des Symbols entwickelt hat. Wie wir heute wissen, und der Arzt Dr. Vallbracht bestätigt, hat diese nämlich wenig mit der Form des Organs zu tun, das Blut durch unseren Körper pumpt (Chrismon 2011:12).

Im 12. und 13. Jahrhundert findet man in Darstellungen von Liebespaaren Efeublätter abgebildet. Dies ist darauf zurückzuführen, dass die Pflanze für ihre Langlebigkeit bekannt ist, eine Eigenschaft, die man sich auch für eine Liebesbeziehung wünscht(e).
Mit der Zeit wurde die Form des Blattes immer mehr vereinfacht und daraus entstand die Form des Symbols Herz, wie wir es heute kennen. Bald wurde es in der Farbe des Lebens, des Bluts und der Liebe rot eingefärbt (Hinrichs: 2011).

\section{Ein Ring für die Ewigkeit}

Jemandem sein Herz zu schenken, ist im praktischen Sinne nicht möglich, wohl aber dem Liebsten/der Liebsten einen Ring an den Finger zu stecken. So kann der Ring als vergegenständlichtes Symbol der Liebe gesehen werden.

\section{Der Kreis bedeutet Fülle, Reichtum, Gabe, auch Freude, Achtung, Wert. \\ Was uns wichtig ist, kereisen wir ein, was uns lieb ist, umringen wir. \\ Ring und Reif sind Symbole des Lebens und der Einheit.}

(Rombach o.J., zit. in Riedel 1985:89)

Dieses Gedicht weist auf die besonderen Eigenschaften des Ringes hin. Er umfängt, ist frei von Ecken und Kanten, steht für Verbundenheit und Treue. Ohne ein Ende oder einen Anfang ist er ein Zeichen für die Unendlichkeit (Riedel 1985:90). So soll, der romantischen Vorstellung nach, auch die Liebe sein. In den westlichen Kulturen gibt es seit Jahrhunderten den Brauch des Ringtausches bei der Vermählung eines Paares. So wurde ein Paar von Ringen, die ineinander verschlungen sind, zu einem weit verbreiteten Symbol für die Ehe. Der Verlobungsring gilt als Versprechen auf eine baldige 
Hochzeit, Treue und ein gemeinsames Leben. Mit der Heirat wird dieses Versprechen dann eingelöst. Durch den Austausch von Eheringen entsteht ein Bund, der halten soll, bis dass der Tod die Liebenden scheidet (Hörandner 1993:268).

Bereits in der Antike gab es den Brauch, einen Trauring zu tragen. Er wurde an den linken Ringfinger, der daher seinen Namen hat, gesteckt. Man glaubte, dass von dort eine Ader direkt zum Herzen führe (Mohr: 2012).

Im antiken Rom war der Ehering vor allem ein Zeichen dafür, dass die Mitgift übergeben worden war. Um die Ringe ganz persönlich an ihre Träger anzupassen, wurden sie auch damals schon mit Inschriften versehen. Ein Beispiel für eine antike Inschrift ist:

„Pignus amoris habes“, was so viel bedeutet wie „Du hast meiner Liebe Pfand“ (Mohr: 2012). Heutzutage werden meist der Name des Partners/der Partnerin und das Datum des Hochzeitstags in den Ring eingraviert. Der Ehering steht aber auch in der Tradition des Siegelrings, den wohlhabende Männer früher trugen, um ihren Besitz zu kennzeichnen. Bei der Hochzeit wurde der Besitz der Eheleute zusammengeführt, und der Mann schenkte seiner Anvertrauten seinen Siegelring. Symbolisch bedeutete dies: Was mein ist, ist von nun an auch dein (Maibaum: 2012).

Ein anderer wichtiger Aspekt des Eherings ist, dass durch ihn der Außenwelt gezeigt wird, dass der Ringträger/die Ringträgerin in festen Händen ist, also dem Heiratsmarkt nicht mehr zur Verfügung steht. Aber nicht nur in unserem Kulturkreis, sondern auch in vielen anderen Ländern der Welt war und ist der Ring ein Symbol für die Liebe.

In der Ausstellung sind zwei Paare von Eheringen aus dem Senegal und ein einzelner Ehering aus Ägypten zu sehen. Auf dem silbernen Ehering aus Ägypten, der 1953 in die Ethnologische Sammlung der Universität Göttingen gelangte, ist ein Symbol für Fruchtbarkeit abgebildet, nämlich die Dattelpalme. Für das Leben in Ägypten ist sie von besonderer Bedeutung: Sie spendet Schatten, Holz und Blätter dienen als Baumaterial. Ihre Früchte waren in früherer Zeit ein Grundnahrungsmittel der Menschen (Kaiser 2009:8). Ein weiterer interessanter Aspekt ist, dass die Palme, aufgrund ihrer hochaufragenden Form häufig mit dem erigierten Glied des Mannes verglichen wird (Westropp 1870:142).

Im Senegal, dem Herkunftsland der anderen Eheringe, ist das gemeinsame Essen von Datteln ein wichtiger Teil der muslimischen Hochzeitstraditionen. Der Geschmack der Früchte symbolisiert hierbei das Ideal einer senegalesischen Ehe: nicht immer süß, aber im Großen und Ganzen wohl bekömmlich. Datteln gehören daher unabdingbar zum Brautgeschenk dazu. Eheringe aus dem Süden Senegals (Casamance) sind traditionell blau/ violett, eine Farbe von der man glaubt, dass sie die Fähigkeit in sich berge, die Ehepartner vor bösen Geistern zu schützen. Diese Ringe werden von den Volksgruppen Diolas und Mandingue verwendet (Mendy, Interview vom 20.4.2012). Im Norden Senegals tragen Männer und Frauen der ethnischen Gruppe Tukuleur unterschiedlich gefärbte Ringe aus Achat. Die traditionelle Farbe der Eheringe der Frauen ist orange/braun, die der Männer grün/ weiß. Als besonderes Symbol werden auch hier die 
Initialen des Ehepartners und das Zeichen der ethnischen Gruppe in den Ring eingraviert. Da die Ringe, die in der Ausstellung zu sehen sind, keines dieser beiden Zeichen aufweisen, können wir sagen, dass sie nie tatsächlich als Eheringe getragen wurden. Im Kastensystem Senegals, das sowohl soziale Stellung wie auch berufliche Orientierung vorgibt, besitzt allein die Kaste der Teugue das Wissen über die Herstellung der Ringe. Steht eine Hochzeit bevor, muss also viel Geld gespart werden, um die Eheringe bei einem Teugue in Auftrag zu geben: ohne Ring, keine Hochzeit. Die Hochzeitsfeierlichkeiten dauern drei Tage an. Am dritten Tag findet nach westlichem Vorbild ein offizieller Ringtausch zwischen den Brautleuten statt. Nach der Hochzeit hat der Ring vor allem für ihre Trägerinnen eine wichtige Bedeutung: Er dient als Zeichen für deren verbesserte soziale Position in der Gesellschaft und bietet dadurch Sicherheit. Die Ehemänner tragen ihre Ringe nach der Hochzeit normalerweise nicht mehr, doch auch ihre soziale Anerkennung steigt mit der Eheschließung erheblich (Mendy, Interview vom 20.4.2012).

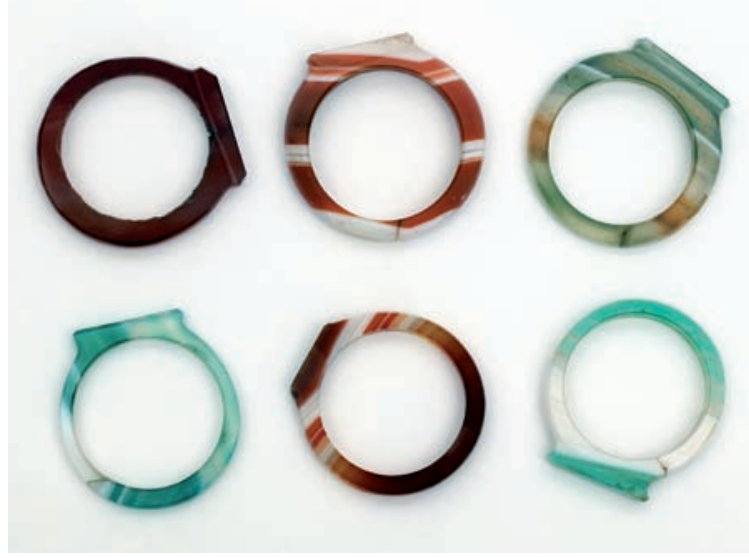

Abbildung 2: Eheringe

In anderen Kulturen gibt es weitere Zeichen für eine eheliche Verbindung, die vergleichbar mit unserem Ehering sind. Ein interessantes Beispiel hierfür ist die Heiratstatauierung (Tätowierung) der nordamerikanischen Indianer Thompson River. Bei diesem Hochzeitsbrauch tatauieren sich die Ehepartner gegenseitig die gleichen Symbole. Dieser auf ewig haltbare Körperschmuck dient ihnen bei der Heirat als Treueschwur. Weiterhin signalisiert er ihre Verbundenheit nach außen und wird als ein Talisman der Ehe, der ihre Liebe dauerhaft haltbar machen soll, betrachtet (Hell 1996:271). Besonders spannend ist dieses Beispiel, weil eine Heiratstatauierung ein Zeichen für die Ehe ist, dass bei einem Sinneswandel oder dem Verblassen der Liebe, nicht abgenommen werden kann. Sie ist also im Gegensatz zum Ehering ein wahrhaftig lebenslänglich sichtbares und haltbares Zeichen für die Liebe. 


\section{Mondscheinromantik?}

Schauen wir nach Afrika, genauer genommen nach Ghana zur ethnischen Gruppe der Ashanti, entdecken wir, dass es dort ein ausgefeiltes Symbolsystem gibt: die Adinkra.

Neben den wegen ihrer ansprechenden Formen von vielen als schön befundenen Symbole, dienen die Adinkra den Ashanti gleichfalls als Kommunikationsmittel. Die Zeichen stehen meist in Verbindung mit Sprichwörtern, Moralvorstellungen und gesellschaftlichen Werten (Turé 2004:195). So steht beispielsweise das Symbol eines hölzernen Kamms für die gesellschaftlichen Erwartungen an die Eigenschaften der Frau: Geduld, Liebe und Fürsorglichkeit (Turé 2004:329).

Durch die Adinkra können die Werte der Gesellschaft auch für die nachkommenden Generationen festgehalten werden (Turé 2004:195). Die Verwendung dieses Symbolsystems ist in der Alltagskultur der Ashanti fest verankert. Man findet sie als Verzierung auf Kleidung oder als Schmuck auf wichtigen öffentlichen Gebäuden (Turé 2004:194). Nach dem Tod einer Person werden Adinkra-Umschlagetücher, die mit Trauer-Symbolen bedruckt sind, getragen. Es ist aber auch üblich Kleidung, Schmuck und Alltagsgegenstände mit Symbolen zu versehen, die zeigen, welche Werte man persönlich als wichtig empfindet (Turé 2004:198). So dienen die Zeichen „als Warnung, Ermutigung und Rat für den Menschen" (Turé 2004:194). Unter den Adinkra finden wir auch ein Zeichen, das genauso aussieht wie unser Symbol für die Liebe, das Herz. In Ghana steht das Symbol Herz, was dort akoma heißt, für Geduld und Toleranz (Buckman 2001:10).

Die Farbe Rot, die in der westlichen Kultur für die Liebe steht, wird in Ghana in Verbindung mit Krieg und Trauer gebracht (Polakoff 1980:88). An diesem Beispiel sieht man, dass Symbolsprache eng mit der jeweiligen Kultur eines Landes verknüpft ist und sich von Kulturkreis zu Kulturkreis stark unterscheidet.

Unter den Adinkra gibt es ein anderes Symbol, das für Liebe, Treue und Hoffnung steht. Es heißt osrane ne nsoromma, was so viel bedeutet wie: Der Mond und der Stern (Buckman 2001:17). In Verbindung mit diesem Zeichen gibt es auch ein Sprichwort. Es lautet: kyekye pe aware und bedeutet, dass der Morgenstern im Himmel auf die Rückkehr ihres Mannes, den Mond, wartet (MacDonald:2009).

Zurückzuführen ist dieses Zeichen auf einen ghanaischen Mythos. Er besagt, dass Gott den Mond erschuf, um die Erde zu beleuchten. Der Mond lebte von diesem Zeitpunkt an auf der Erde. Er war jedoch einsam, so ganz allein auf dem Planeten, also schickte Gott ihm eine Gefährtin, den Morgenstern. Die beiden verliebten sich. Doch nach zwei Jahren holte Gott Morgenstern zurück in den Himmel. Der zurückgelassene Mond vermisste sie fortan ganz schrecklich, doch als er selbst in den Himmel zurückkehrte, konnte er Morgenstern nicht mehr finden (Frommlet 1999:3).

In einem anderen Land in Afrika, bei der Volksgruppe Mbadehok im Kamerun, spielt der Mond in Bezug auf Schwangerschaft, Geburt und Fruchtbarkeit eine ganz besondere Rolle.

Man sagt dort „der Mond schmiedet die Kinder“ 
(Ittmann 1953:390). Die Mbadehok bringen die Menstruation der Frau in direkte Verbindung mit dem Mond. So sagt man „sie besucht den Mond“ wenn eine Frau ihre monatliche Regel hat. Bleibt die Menstruation aus und eine Frau ist schwanger, wird gesagt, dass der Mond das Menstruationsblut der Frau zu einem Baby geschmiedet hat (Ittmann 1953:390).

An Neumond gehen die Frauen zu einer Wasserschöpfstelle um ,sich dort ein Kind zu schöpfen und es im Wasser zu trinken“" (Ittmann 1953:391).

Auch in der Kultur verschiedener Indianerstämme aus Nordamerika, wie zum Beispiel den Thompson River Indianern oder den Omaha, kommt dem Mond eine wichtige Bedeutung zu (Hell 1996:267). So ist der Mond ein wiederkehrendes Symbol bei ihren Tatauierungen (Tätowierung).

Dieser auf ewig haltbare Körperschmuck gilt unter anderem als Treueschwur bei der Hochzeit, als Liebeszauber und als Symbol für Schönheit (Hell 1996:271). Weiterhin dient das Durchführen der ersten Tatauierung als ein Initiationsritus ins erwachsene und damit heiratsfähige Alter (Hell 1996:327). Bei den Omaha tatauiert man im Rahmen eines bestimmten Rituals zur Ehrung eines tapferen Kriegers seine Tochter unteren anderem mit Mond und Sternen als den Zeichen der Nacht. Diese steht dort für die weibliche göttliche Kraft, denn sie gilt als Mutter des Tages (Hell 1996:306f.). Es ist eine große Ehre für ein Mädchen für ein solches Ritual ausgewählt zu werden, denn die Tatauierung macht sie zu einer begehrenswerten Ehefrau. Die Omaha glauben, dass eine so ausgezeichnete Frau viele gesunde Kinder zur Welt bringen wird
(Hell 1996:320).

Der Mond wird auch in anderen Kulturen mit Liebe, Romantik und Sexualität in Verbindung gebracht. In vielen Erzählungen, Liedern und Gedichten ist er es, der für romantische Stimmung sorgt. In der griechischen und römischen Mythologie wird der Mond durch eine Göttin verkörpert. Bei den Römern wurde sie Luna, bei den Alten Griechen Selene genannt. In Abbildungen der Mondgöttin trägt diese meist einen Halbmond in der Hand oder auf der Stirn (Jünger 1947:43). Sie wird mit Milde und Zärtlichkeit in Verbindung gebracht und durch ihre vollen Rundungen wird sie zum Inbegriff von Weiblichkeit (Jünger 1947:42).

Die griechische Mythologie erzählt, dass Selene sich in den schönen Jüngling Endymion verliebte. Zeus, der Göttervater, hatte diesen in einen immer andauernden Schlaf versetzt, um seine Jugend auf ewig zu bewahren. Selene besuchte ihn jede Nacht und gebar ihm 50 Kinder (Preller 1854:298). In China, steht er für das weibliche Prinzip Ying, gegenüber dem männlichen Prinzip Yang. Die Augenbrauen anmutiger Frauen werden dort mit der Schönheit des Neumonds, das Gesäß mit dem Vollmond verglichen. Es gibt in China auch eine Vorstellung die besagt, dass eine Frau schwanger wird, wenn sie eine vom Himmel gefallene „Mondperle“ verschluckt (Eberhard 1983:197). 


\section{Literatur}

\section{Buckman, Kwamena}

2000 Adinkra Symbols. London. Ewool Publivations.

\section{Eberhard, Wolfram}

1983 Lexikon chinesischer Symbole: Geheime Sinnbilder in Kunst und Literatur, Denken und Leben der Chinesen. Köln: Diederichs.

\section{Fried, Erich}

1990 Als ich mich nach dir verzehrte: 72 Gedichte von der Liebe. Berlin: Wagenbach.

\section{Frommlet, Wolfgang}

1999 Mond und Morgenstern: Eine Schöpfungsgeschichte aus Afrika. 3. Auflage. Wuppertal:

Hammer.

\section{Hell, Bernhard Peter}

1996 Die Tatauierung in Nordasien und Nordamerika. München: Kunst \& Alltag.

\section{Hinrichs, Miriam}

2011 Warum das Herz für die Liebe steht. [Elektronisches Dokument]. http://www.livenet.de/themen/wissen/194993warum_das_herz_fuer_liebe_steht.html [03.03.2012]

\section{Hörandner, Editha}

1993 Unterpfand der Treue. Von Verlobungsund Eheringen. Wien: Notring.

\section{Ittmann, Johannes}

1953 Mond und Monate im vorderen Kamerun. Anthropos 48 (3./4.): S. 389-395.

Jünger, Friedrich Georg

2001 Griechische Mythen. 5. Aufl. Frankfurt am Main. Klostermann.

\section{Kaiser, Matthias}

2009 Traditionelle Wirtschafts- und Lebensformen auf der arabischen Halbinsel. GRIN.

\section{Maibaum, Frank}

2012 Die symbolische Bedeutung der Trauringe. [Elektronisches Dokument] http://hochzeit-trauung.de/Symbolische-Bedeutung-Trauring.htm\#ZeichenderLiebe [03.03.2012]

\section{MacDonald, Jean}

2009 West African Symbols: Adinkra Symbols and Meanings. [Elektronisches Dokument] http:// www.adinkra.org [03.03.2012]

Mendy, Alain

2012 Interview am 20.04.2012

\section{Mohr, Claudia}

2012 Der Ehering - Ein Bundeszeichen.

[Elektronisches Dokument] http://www.herrlichkeiten.com/trauringe/hintergruende/ [03.03.2012] 
Preller, Ludwig

1854 Griechische Mythologie, Erster Band. Berlin: Weidmann.

\section{Polakoff, Claire}

1980 Into Indigo African Textiles and Dyeing

Techniques. New York: Anchor Press.

\section{Riedel, Ingrid}

2001 Formen. Kreis, Kreuz, Dreieck, Spirale. 8. Auflage. Stuttgart. Kreuz.

\section{Turé, Katja}

2004 Adinkra - Textilkunst und gedruckte Symbolsprache der Ashanti in Ghana (Westafrika). In: Birgitta Huse (Hrsg.). Von Kopf bis Fuß: Ein Handbuch rund um Körper, Kleidung und Schmuck für die interkulturelle Praxis. Band 4.

Münster: Waxmann

\section{Vallbracht, Christian}

2011 Interview mit Chrismon

\section{Westropp, Hodder M.}

1870 On Phallic Worship.Journal of the Anthropological Society of London 8: S. 136-146.
Asien

Kamasutra - Das Lehrbuch der Liebe

\section{Ronja Rutschmann}

Das Kamasutra (Sanskrit: kama $=$ „Liebe“ und sutra $=$ „Lehrbuch") ist ein umfassendes Regelwerk der Liebe, das vor ungefähr 1.500 Jahren von dem indischen Gelehrten Vatsyayana Mallanaga verfasst wurde. Der Ursprung des Werkes wird jedoch bis auf Nandi, den Gefährten des Gottes Shiva zurückgeführt. Er soll als erstes die Regeln der Liebe aufgeschrieben haben, die durch Generationen von Gelehrten weitergegeben und schließlich von Vatsyayana zusammengefasst wurden. Vatsyayanas Originalmanuskripte existieren heute leider nicht mehr, die älteste uns bekannte Abschrift wurde erst vor etwa 500 Jahren verfasst.

\section{Grundgedanke des Kamasutra}

Das dreifache Lebensziel eines Mannes ist dharma (Tugend, Frömmigkeit, Tradition), artha (Erwerb, Bildung, Ansehen) und kama (Liebe, Liebesgenuss, Begehren). Diese drei Ziele sollen möglichst miteinander verknüpft werden, sie dürfen sich nicht gegenseitig schädigen und keines von ihnen darf vernachlässigt werden (Oberdiek 2005:95). Das Kamasutra beschäftigt sich vor allem mit dem kama, das hier als das ,erhabenste Ziel und die Krone des Ganzen“ angesehen wird (Vatsyayana 1973:3). 


\section{Inhalt des Kamasutra}

Das Kamasutra geht weit über das Sexhandbuch hinaus, auf das es in unserer Gesellschaft seit den 1960er Jahren oft reduziert wird (Oberdiek 2005:98). Es bietet umfassende Lösungen für fast alle damals relevanten Fragestellungen zur Liebe, sei es das Umwerben eines Mädchens bis zur Heirat, das Verhalten der Ehefrauen im Harem oder Mittel, um die Potenz zu steigern. Auch der kulturhistorische Wert des Kamasutras wird häufig unterschätzt. So enthält es etwa viele Legenden und Geschichten seiner Zeit. In unserem heutigen gesellschaftlichen Kontext ist das Lehrbuch jedoch kaum noch sinnvoll anwendbar - von den beschriebenen Sexualpraktiken einmal abgesehen. Das Kamasutra ist in sieben Teile gegliedert:

\section{Allgemeine Einführung: Unter anderem} Erörterung der drei Lebensziele und Übersicht über das Buch.

2. Die Vereinigung von Mann und Frau: Beschreibung von Sexualpraktiken im weiteren Sinn, aber auch Kuss-Techniken und Regeln für das Verhalten vor und nach dem Geschlechtsverkehr.

3. Brautwahl und Heirat: Ausführung der Regeln für die Annäherung und das Umwerben von Mädchen bis zur Hochzeit.

4. Verhalten der Ehefrau: Regeln für das Verhalten einer Ehefrau, Gegenüberstellung der
Monogamie und dem Leben im Harem mit allen Vor- und Nachteilen.

5. Über die Frauen anderer Männer: Regeln des Ehebruches, Darstellung des Charakters von Mann und Frau.

6. Über die Kurtisanen: Regeln für das Verhalten von Kurtisanen - hiermit sind allerdings keine gewöhnlichen Prostituierten gemeint, sondern selbstständige, gebildete Frauen, die ein hohes Ansehen genießen, vergleichbar etwa mit einer japanischen Geisha.

Die upanisad, Geheimlehre, enthält zum Beispiel äuBerliche Hilfsmittel und Techniken, um Frauen zu gewinnen, den Penis zu vergrößern oder die Lust zu steigern (Oberdiek 2005:128).

\section{An wen richtet sich das Kamasutra?}

Das Werk richtet sich hauptsächlich an die oberste (männliche) Gesellschaftsschicht. Frauen werden generell moralisch und intellektuell niedriger eingestuft als Männer, trotzdem wird auch ihnen empfohlen, das Lehrbuch zu studieren, vor allem vor der Heirat und später mit Erlaubnis des Ehemannes. Hetären (Prostituierten), Prinzessinnen und Töchtern hoher Beamter empfiehlt Vatsyayana sogar explizit das Studium der Liebeskunst (Vatsyayana 1989:19). Auch konzentriert sich das Kamasutra auf das Vergnügen des Mannes, während die Frau hauptsächlich seinem Genuss dient. Andererseits lehrt Vatsyayana aber die Verehrung der Frau durch den Mann, u.a. da dessen geschlechtlicher Genuss 
stark von der Befriedigung der Frau abhängt.

\section{Das Kama im Kamasutra}

Mit Liebe (kama: wörtl. Sinnengenuss) ist im Kamasutra vor allem die sinnliche Liebe gemeint (Oberdiek 2005:95). Andere Formen der Liebe sind zwar anerkannt, ihnen wird aber weniger Bedeutung zugemessen. Die Leidenschaftlichkeit der Liebe wächst mit zehn Stufen, von der Liebe auf den ersten Blick, über die Schlaflosigkeit und die Verrücktheit im Geist, bis hin zum Tod. Je nachdem, welche Stufe die Liebe zu der Frau eines Anderen erreicht hat, ist in manchen Fällen auch der Ehebruch erlaubt, um die Qualen zu lindern.

Die sinnliche Liebe wird von der blinden Leidenschaft abgegrenzt, bei der keine Regeln mehr befolgt werden und folglich auch das Kamasutra als Lehrbuch nutzlos ist. Dementsprechend heißt es im Schlusssatz des Buches: „Wer den Sinn dieses Lehrbuches kennt, der zähmt seine Leidenschaft, indem er dharma, artha und kama ihre Bestimmung wahrt, die sie in der Welt einnehmen. Der Wissende also, der sich darauf versteht und auf dharma und artha achtet, erreicht sein Ziel, wenn er in Verliebtheit handelt, ohne von blinder Leidenschaft erfüllt zu sein" (Vatsyayana 1973:479).

\section{Literatur}

\section{Oberdiek, Ulrich}

2005 Kamasutra. Rezeptionen, Kontextualisierungen und Logiken. In: Alex, Gabriele und Sabine Klocke-Daffa (Hrsg.): Sex and the Body. Ethnologische Perspektiven zu Sexualität, Körper und Geschlecht. Bielefeld: transcript.

\section{Vatsyayana, Mallanaga, Mylius, von Klaus (Hrsg.)} 1989 Kamasutram. Leitfaden der Liebeskunst. Von Klaus Mylius (Hrsg.): Frankfurt am Main: Büchergilde Gutenberg.

\section{Vatsyayana Mallanaga}

1973 Das Kamasutram des Vatsyayana (nach der Übersetzung aus dem Sanskrit von Richard Schmidt neu übersetzt und herausgegeben von Ludwig Knoll). Gütersloh: Bertelsmann. 
Lotosschuhe -

Schritte wie eine Seiltänzerin

\section{Jessica Allermann}

In asiatischen Ländern gibt es viele kulturelle Praktiken, die zeigen, dass sich die Menschen Gedanken darüber machen, wie sie ihrem Partner gefallen können. Diese hängen von den jeweiligen Schönheitsidealen, die man anstrebt ab. Ein solcher Brauch ist das Füßebinden in China, das in seiner spezifischen Form nirgendwo anders auf der Welt $\mathrm{zu}$ finden ist. Hier hat das Binden der Füße von Frauen und das Tragen der dafür extra angefertigten Schuhe eine lange Tradition. Der Ursprung des Brauches ist nicht abschließend zu klären, die häufigste und wahrscheinlichste Geschichte ist die von Kaiser Li Yu und seiner Konkubine Yaoniang (Hong 1997:22): Li Yu lebte von 937-978 n.Chr. als zweiter Kaiser des südlichen Tang-Reiches. Der Überlieferung nach wollte er, dass Yaoniang als seine Dienerin und favorisierte Konkubine auf einer für sie hergestellten Lotosblüte für ihn tanzte. $\mathrm{Zu}$ diesem Zweck bandagierte sie sich ihre Füße, um sich auf besondere Art und Weise bewegen zu können. Zunächst umwickelte sie ihre Füße noch recht locker mit Seidenbändern, was mit den Spitzenschuhen der heutigen Ballerina vergleichbar ist. Daraufhin begann die Faszination für einen kleinen, weiblichen Fuß und die Weiterentwicklung dieser Praxis führte schließlich zu einer immer strafferen und engeren Art des Bindens, die den natürlichen Fuß nahezu vollständig veränderte. Die angestreb- te Idealgröße des abgebundenen Fußes lag früher bei $10 \mathrm{~cm}$. Sie wurde jedoch selten erreicht, so dass der Normalfall zwischen 12-15 cm lag (Kürschner 1901:105).

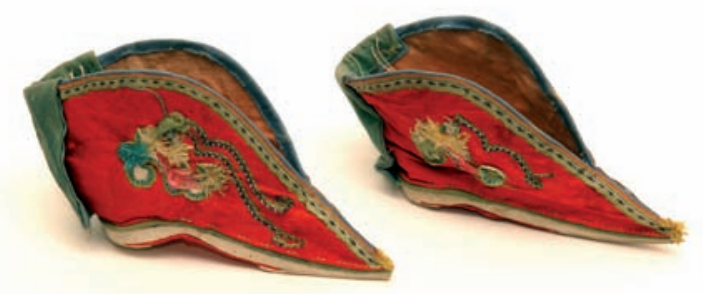

Abbildung 3: Lotosschuhe

Der Name für die so entstellten Füße ist ein Euphemismus, eine beschönigende Umschreibung: „Lotosfüße“, ,goldener Lotos“ oder „goldene Lilie“. Beide Blumen haben in China bis heute eine wichtige Bedeutung. Die Lotosblüte wurzelt im Schlamm, entsteigt aus ihm als etwas Reines, Duftendes und gilt als Attribut des Unsterblichen (Biedermann 1998:272). Die Lilie steht für Reinheit (Biedermann 1998:269). Der Name stammt zum einen aus der Geschichte von Li Yu und Yaoniang und zum anderen aus zu dieser Zeit sehr populären Gedichten und Liedern. Diese thematisieren die Füße, die Art des Tanzens und die Bewegungen des Körpers. Das Eingehen des Themas in die Lyrik unterstützte die Verbreitung des Brauches. Denn das, was als schick und modern für den Kaiser, seine Frauen und die höheren Gesellschaftsschichten galt, fand durch Nachahmung auch Eingang in die niedrigeren Schichten. So durchdrang die kulturelle 
Praxis des Füßebindens nahezu alle Bevölkerungsteile und wurde zu einem einzigartigen kulturellen Aspekt Chinas (Ko 2001:30).

Die Abschaffung des Brauches begann mit der Öffnung Chinas für den Westen. Christliche Missionare, die nach China kamen, versuchten ihre Vorstellungen von Gleichheit der Geschlechter durchzusetzen. Nach vielen gescheiterten Reformen und Revolutionen gelang es im Jahr 1902 der Kaiserwitwe Ci Xi (1835-1908), eine amtliche Anordnung $\mathrm{zu}$ erlassen, die das Füßebinden aufgrund seiner verstümmelnden Auswirkungen verbieten sollte. Dieses Verbot setzte sich nur langsam durch, da die Menschen sich nur schwer von ihren alten Traditionen und Vorstellungen lösen konnten (Andritzky et al. 1998:213).

Für die unnatürlich verformten Füße benötigten die Frauen spezielle Schuhe, um ihnen zumindest etwas Halt zu geben. Diese Schuhe nennt man in Anlehnung an die Füße „Lotosschuhe“. Ihre Herstellung fand zum einen in besonderen $\mathrm{Fa}$ briken statt, zum anderen fertigten die Frauen sie selbst in ihren Häusern an. Die typische Form, der man heute in Museen begegnet, hat eine gebogene Sohle und läuft nach vorne hin spitz zu. Es gibt Variationen der Schuhe für verschiedene Anlässe. Oft sind die Schuhe aus Seide oder Samt gemacht und mit aufwendigen Mustern oder Symbolen bestickt. Es gibt sie in nahezu allen Farben und Farbkombinationen, was sich auch in den Modellen der Ausstellung zeigt: Das etwa 10,5 cm lange Paar hat eine rot-grün-violett Kombination mit Borten und Bestickung des unteren violetten Teils. Die Stickmuster zeigen Blumenranken. Der andere, einzelne
Schuh (As1852) ist dagegen deutlich weniger bestickt, sondern schlicht in dunklem Blau mit Borten lediglich an der Spitze gehalten. Dafür zeigt er in der Mitte der 11,5 cm langen Sohle eine Art zweiten Absatz und hinten mehr Stoff mit einem Band, um ihn am Unterschenkel zuzubinden.

Da es den Frauen nicht gestattet war, ihre Füße zu zeigen, trugen sie auch beim Schlafen Schuhe. Ein solches $8 \mathrm{~cm}$ breites und $14 \mathrm{~cm}$ hohes Paar zum Schlafen findet sich auch in der Ausstellung (As1973a-b). Es ist beige und mit einer Swastika, einem Hakenkreuz, bestickt. Die Swastika symbolisiert im Alten China zum einen die vierfache Orientierung an den Himmelsrichtungen und zum anderen die Zahl Zehntausend „Unendlichkeit“. Im Buddhismus gilt das Symbol des Weiteren als Glücksbringer oder Talisman und trägt den Beinamen „Siegel auf Buddhas Herz“ (Biedermann 1998:432). Hierzu ein Zitat aus Kathryn Harrisons Roman „Die gebundenen Füßen“:

„Unter Yu-yings [Großmutter] Anleitung hatte May [Enkelin] für ihre Aussteuer sechzehn Satinschube genäht, für jede Jahreszeit vier; hatte für den Frühling die Schubspitzen mit Pfingstrosen bestickt, für den Sommer mit Lotusblüten, mit Chrysanthemen für den Herbst und mit Pflaumenblüten für den Winter. Sie hatte rote Schube für die Nacht genäht - sie schimmerten so rot an ibren weißen Beinen, dass auch der missmutigste Ehemann dabin schmelzen musste. " (Harrison 2003:55).

Bereits Monate vor dem ersten Einbinden fertigten die Mutter und die älteren Frauen des Haushalts neue Schuhe für das Kind an. Die Prozedur des 
Einbindens begann für die meisten Mädchen im Alter von vier bis sechs Jahren. Die Füße wurden entweder von der Mutter oder Großmutter das erste Mal gebunden. Dies war früher ein zeremonieller Akt, bei dem keine Männer anwesend sein durften.

Dabei wurden zuerst die Füße in einer Mixtur aus Alaun und Kräutern eingeweicht und mit einem speziellen Puder zwischen Zehen behandelt. Eine Schere wurde benötigt, um die Zehennägel kurz zu schneiden, damit sie nicht einwachsen und Infektionen auftreten konnten. Dann wurden die vier kleinen Zehen unter die Fußsohle gebogen und mit feuchten Bandagen mehrere Male fest umwickelt. Wenn sie trockneten, zogen sie sich weiter zusammen und zwar so fest, dass die Blutzirkulation gestoppt wurde und die Knochen brachen (Hong 1997:22).

„,Siehst du das weiße Band?', fragte sie [Yu-ying] und griff das Ende der Stoffrolle. ,Das ist der duftende weiße Pfad, auf dem du schreiten wirst. Dies ist die Reise vom Mädchen zur Frau: Sie machte einen Schritt zurück und ließ das Leinen betörend wie ein Banner flattern. May nickte bedächtig ". (Harrison 2003:34).

Der kleinste der ausgestellten Schuhe (As2434) ist vermutlich ein solcher Kinderschuh, da er mit einer Länge von $8,5 \mathrm{~cm}$ selbst für einen ausgewachsenen, gebundenen Fuß zu klein ist. Er ist aus rosa Stoff mit blauer Kante und mit einer Katze sowie Pflanzen bestickt. Die Katze steht für das typisch weibliche, sie ist ein Tier der Nacht und verdeutlicht somit die Verwurzelung der Frau in den dunklen, undeutlichen Seiten des Lebens (Biedermann 1998:232).
Die Prozedur des Einbindens fand innerhalb von 10 bis 15 Jahren immer wieder aufs Neue statt und währenddessen mussten sich die Mädchen täglich sorgfältig um ihre Füße kümmern, sie waschen und neu einbinden. Dazu gehörte es auch, die oft wunde und vereiterte Haut zu pflegen und neue Schuhe zu nähen, da die Füße trotz der Einschnürung wuchsen, wenngleich langsam und in geringerem Maße als bei natürlichen, unbehandelten Füßen. In den Jahren des immer wieder neuen Einbindens litten die Mädchen starke Schmerzen, die es ihnen fast unmöglich machten, zu gehen, oft war nur ein Kriechen möglich. Auch nach Vollendung der Prozedur waren sie kaum in der Lage, sich ohne einen Gehstock als Hilfe fortzubewegen. Lange und anstrengende körperliche Bewegung blieb ihnen versagt, ebenso wie das Ausüben von sportlichen Aktivitäten. Oft wurden sie in einer Sänfte herumgetragen, um die Füße nicht zu belasten.

Es ist jedoch zu beachten, dass es Variationen des Bindens gab: Funde von Schuhen als Grabbeilage von Lady Huang aus dem 13. Jahrhundert zeugen auch zu dieser Zeit von einer speziellen Fußbehandlung (Ko 2001:21). Diese unterscheidet sich jedoch von derjenigen, die Yaoniang verwendete und aus der sich der allgemein typische Schuh herausbildete: Bei den Schuhen von Lady Huang ist die Spitze nach oben gebogen und sie haben eine flache Sohle, im Gegensatz zu den bereits beschriebenen Schuhen, die eine nach unten zulaufende Spitze sowie eine gebogene Sohle haben. Es gibt somit kein einheitliches Fußbinden, sondern verschiedene Formen, die sich im Laufe der Zeit durch unterschiedliche Einflüsse verändert haben. 
Was aber ist so faszinierend an den kleinen Füßen, dass eine ganze Kultur es jahrhundertelang in Kauf nimmt, ihren Frauen ungeheure Schmerzen zuzufügen? Die Antwort auf diese Frage ist weder einfach noch einseitig: Dabei müssen grundlegende Aspekte der chinesischen Kultur beachtet werden. Besonders wichtig war in diesem Zusammenhang der Konfuzianismus, vor allem für die Zeit vor 1840. Er prägte bis in die heutige Zeit die soziale Ordnung sowie weibliche und männliche Vorstellungen nach dem ying und yang Prinzip. Das ying steht für das weibliche, dunkle, schwache und passive. Das yang für das männliche, helle, starke, aktive. Die Frau trägt die Attribute unehrenhaft, schändlich, unterlegen. Der Mann ist edel, nobel und beherrscht als Sohn des Himmels das ying. Die Unterordnung der Frau wird schon hier verdeutlicht und weiter verstärkt durch die Pflicht, absolute Loyalität und Gehorsam gegenüber dem Ehemann zu zeigen, sowie dies der Minister gegenüber dem Prinzen und der Sohn gegenüber seinem Vater tun (Hong 1997:18).

Vor der Hochzeit ist die Frau ihrem Vater, während der Ehe ihrem Mann, nach Tod des Ehemannes dem Sohn unterworfen. Ohne die Lotosfüße hatte eine Frau früher nahezu keine Chance auf eine vorteilhafte Ehe, da sie als Symbol oberster Kultiviertheit und Gepflogenheit der chinesischen Vorstellungskraft galten. Fang Ho beschreibt dies, indem sie sagt, dass die kleinen Füße ,passport to all that was good in life“ (1997:25) wären.

Die patriarchalische Hierarchie der chinesischen Kultur prägte zudem das Bild von einer, guten Frau innerhalb des Hauses, bei der Pflege und Erziehung der Kinder und Versorgung des Mannes.
Die Einschränkung durch das Füßebinden diente auch dazu, zu verhindern, dass die Frau ihren Ehemann betrügt und somit ein soziales Tabu bricht. Die weiblichen Körper kennzeichneten die untergeordnete Rolle durch ihre deutlich eingeschränkte physische Freiheit. Folglich war das Füßebinden als zweckmäßige, bändigende Maßnahme effektiv, um die weibliche Unberührbarkeit auszudrücken und durchzusetzen. Es diente als Konzept vollständiger Kontrolle und Verfügung von Männern über Frauen.

Frauen wurden damit durch die männlich-dominierte Gesellschaft als eine Art Objekt klassifiziert, wobei vor allem der sexuelle Aspekt Betonung fand. Sowohl Männer als auch Frauen sahen die höchste sexuelle Attraktivität in den kleinen, gebundenen Füßen. Dadurch, dass der Wert der kleinen Füße so hoch war, übernahmen auch Frauen dieses Schönheitsideal, strebten es bewusst an und sahen die Füße als ihren ganzen Stolz. Sie wollten den Männern gefallen und nahmen dafür große Leiden in Kauf, ungeachtet der eigenen abnehmenden Gesundheit und Fitness.

„Yu-ying besaß ein Lineal aus Elfenbein, mit dem sie Mays Füße maß. Es war nicht in Zoll eingeteilt, sondern in Grade der Lust, die Mays Füße eines Tages spenden würden. Woblgefühl. Trost. Befriedigung. Entzücken. Seligkeit. Extase. May gelangte von einer Stufe zur nächsten, während ibre Zehenknochen langsam aber unerbittlich brachen. Die Haut an ibren Füßen verweste und wuchs neu. Ihre einst so starken Wadenmuskeln wurden weich; ibre Schenkel schlaff und breit." (Harrison 2003:38). 
Europäer, die nach China kamen, verurteilten und klassifizierten den Brauch des Füßebindens als barbarisch und unmenschlich, obwohl auch in unseren westlichen Gesellschaften zu sehen war und ist, dass Frauen ihre Füße in zu enge oder zu hohe Schuhe zwängen, um Männern und sich selbst zu gefallen. Dieses Gefallen geht nicht soweit, dass Knochen im Fuß bis zum Brechen gebogen werden, aber Blasen, wunde Haut und Druckstellen an den Füßen sind auch für viele europäische Frauen, die hochhackige Schuhe tragen, nichts Unbekanntes. Des Weiteren können durch die unnatürliche Fußstellung Rückenprobleme auftreten, die Auswirkungen auf den ganzen Körper haben und zu einer dauerhaften Fehlhaltung führen.

Zusammenfassend lässt sich konstatieren, dass die fertigen, kleinen Lotosfüße ein zentrales Symbol für Ästhetik und Erotik waren, was besonders beim Tanz zur Geltung kam. Trotz des großen Reizes der Füße war es für eine chinesische Frau obligatorisch, Schuhe zu tragen und die Füße nicht offen zu zeigen. Ihre bedächtigen Schritte, die sie mit solchen Schuhen machte, wirkten wie die einer Seiltänzerin oder eine Weide, die sich sanft im Wind wiegt (Hong 1997:25).

\section{Literatur}

Andritzky, Michael, Kämpf, Günter und Vilma Link 1998 Z.B. Schuhe - Vom bloßen Fuß zum Stöckelschuh - Eine Kulturgeschichte der Fußbekleidung. Frankfurt am Main: Anabas.
Biedermann, Hans (Hrsg.)

1998 Knaurs Lexikon der Symbole. München: Droemer Knaur.

Harrison, Kathryn

2003 Die gebundenen Füße. München: List.

Hong, Fang

1997 Footbinding, Feminism and Freedom - The Liberation of Women's Bodies in Modern China.

London: Fran Cass \& Co. Ltd.

Ko, Dorothy

2001 Every Step a Lotus - Shoes for bound feet. Los Angeles: University of California Press

Kürschner, Joseph (Hrsg.)

1901 China - Schilderungen aus Leben und Geschichte - Krieg und Sieg - Ein Denkmal den Streitern und der Weltpolitik. Berlin: Deutsche Krieger-Buchhandlung. 
Die Geisha - Ein lebendes Kunstwerk

\section{Wiebke Grimmig}

Sie bemalt ibr Gesicht, um ibr Gesicht zu verstecken. Ibre Augen sind tiefes Wasser.

Einer Geisha stebt es nicht an, zu wünschen.

Einer Geisha steht es nicht an, zu empfinden.

Eine Geisha ist eine Künstlerin der fließenden Welt - sie tanzt, sie singt, sie unterbält dich. Was auch immer du willst.

Der Rest liegt im Schatten. Der Rest ist geheim.

Die Geisha, 2005

\section{Was ist eine Geisha?}

Wenn wir den Begriff „Geisha“ hören, verbinden wir damit automatisch eine fremdartig aussehende, asiatische Frau in farbenprächtiger Kleidung, die ihren Körper für viel Geld an Männer verkauft. Mit ihrem weiß geschminkten Gesicht und den roten Lippen wirkt sie wie aus dem japanischen Mittelalter entstiegen.

Tatsächlich setzt sich die Bezeichnung Geisha aus den Worten gei, was so viel wie Kunst heißt, und $s h a$, Person, zusammen und bedeutet damit so viel wie „die in den Künsten bewanderte“ oder schlicht „Künstlerin“ (Downer 2002:24). Wie diese Bezeichnung schon vermuten lässt, handelt es sich um ein Handwerk, dass es zu erlernen gilt: Nach einem Jahr der Eingewöhnung und eines ersten Trainings dauert die Ausbildung weitere fünf Jah- re (Dalby 2008:4). Bereits in dieser Zeit unterhält sie ihre Gäste bei Festbanketten in Teehäusern mit Gesang, Tanz, angeregten Unterhaltungen und schmeichelt dem Ego eines jeden Mannes, der es sich leisten kann.

Klienten, die eine Geisha aufsuchen, wünschen keine sexuellen Dienste und diese sind somit auch nicht fester Bestandteil des Abends. Vielmehr geht es um die gemeinsame Freude an den traditionellen Künsten, die die Geisha wie keine zweite in der japanischen Gesellschaft beherrscht. Die gepflegte Unterhaltung über kulturelle als auch aktuelle politische Entwicklungen, kombiniert mit gutem Essen und den Vorführungen der Geisha, machen einen solchen Abend zu einem besonderen Erlebnis für ihre (mitunter auch weiblichen) Kunden.

Die Verwechslung mit Prostituierten entsteht dennoch keineswegs zufällig: Abgesehen von den äußerlichen Ähnlichkeiten wie dem Tragen der traditionellen japanischen Kleidung kimono, den weiß geschminkten Gesichtern und verschiedenen Accessoires wie Fächer und Haarschmuck, entspringt die Geisha historisch betrachtet eben jenen Rotlichtvierteln mit denen sie noch heute in Verbindung gebracht wird. 


\section{Die Liebe als Kunstform}

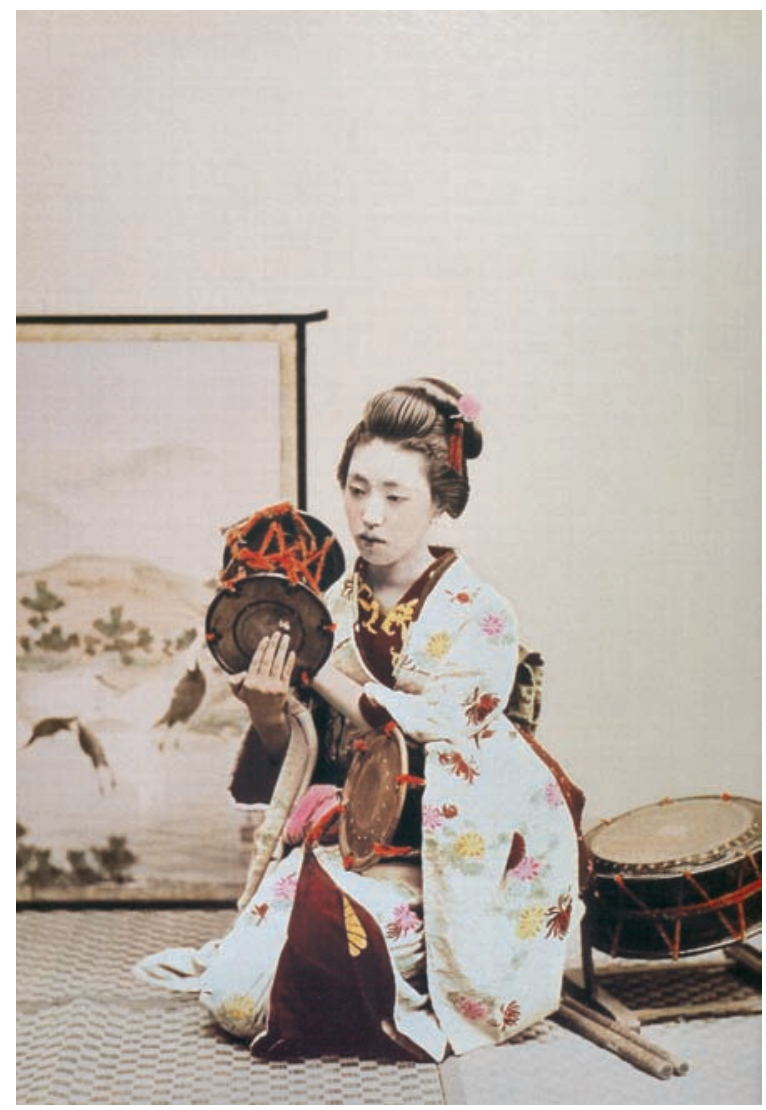

Abbildung 4: Geisha (Ausschnitt)

Hochrangige, gebildete Kurtisanen Japans entwickelten im 17. Jahrhundert erstmals die Idee, Liebe zur Währung in ihren Vergnügungsvierteln zu machen. Die Gefühle und Leidenschaften eines Mannes zu manipulieren und ihn an eine tiefe Ver- bundenheit glauben zu lassen, verdrängte sexuelle Gefälligkeiten mehr und mehr in den Hintergrund (Downer:2000). Diese ästhetische, kunstvolle und körperlose Form der Liebe ist bis heute wichtigstes Merkmal einer Geisha. Tradition, schlichte Ästhetik und Kunst haben den Sex weitestgehend abgelöst.

\section{Weder Ehefrau noch Prostituierte}

Ihre Verbindung zum ältesten Gewerbe der Welt lässt sich jedoch auch in der Gegenwart nicht unterschlagen und beeinflusst ihre Position in der japanischen Gesellschaft bis heute. Weder Ehefrau noch Prostituierte, und dennoch respektiert für ihre Disziplin beim Erlernen ihrer Künste umweht sie gleichzeitig die verlockende Aura einer verruchten, klar strukturierten Welt, in der der Alltag in Vergessenheit gerät. Doch obwohl die Geisha mit der Liebe kokettiert, kann sie niemals heiraten, ohne ihren Beruf aufgeben zu müssen. Denn eine Künstlerin ihrer Kategorie soll ihre ganze Aufmerksamkeit allein auf ihre Kunden konzentrieren können.

Dieser Widerspruch von privater und öffentlicher Person (und den meist großen Klassenunterschieden zwischen Geisha und Kunde) bot so manches Mal in der Vergangenheit den Stoff für ergreifende Liebesdramen, wenn ein unglückliches Paar gemeinsam Selbstmord beging, um auf diese Weise im Jenseits zueinander zu finden. Diese Welt aus Liebe, Schmerz und ewiger Sehnsucht machten die Geishas zu einem beliebten Thema der berühmten japanischen Holzschnitte ukiyo-e. 


\section{Ukiyo-e: Bilder des Vergnügens}

Die Ukiyo-e waren so etwas wie die Fotografien und Illustrierten Japans seit dem 8. Jahrhundert n.Chr. Das Spektrum umfasste Alltags-und Theaterszenen ebenso wie erotische und romantische Darstellungen. Ukiyo bedeutet „fließende Welt", während das Anhängsel - e „Bild“ bedeutet (Earle 1982:10). Diese „Bilder der fließenden Welt" beschreiben dabei das Lebensgefühl von Menschen, die sich der Vergänglichkeit ihres Lebens bewusst sind. Man lebte vollkommen im „Hier und Jetzt" und wollte keinen Gedanken an den nächsten Tag verschwenden. Die Geishas, darauf spezialisiert den derzeitigen Moment so angenehm wie möglich zu gestalten, stellten quasi das fleischgewordene Pendant dieses Lebensgefühls, gekoppelt mit subtiler Erotik, dar. Und so erfreuen sich die gedruckten Szenen aus den Vergnügungsvierteln, Theatern und Teehäusern immer noch großer Beliebtheit.

Heutzutage sieht man die Geisha häufig auf Postkarten und Werbeplakaten zusammen mit Kirschblüten abgebildet: Eine weitere Anspielung auf die Vergänglichkeit des Augenblicks und des Lebens; ein Bild, das nichts von seinem Reiz verloren hat. Dies könnte ein Grund dafür sein, dass die Geisha auch in einer schnelllebigen, modernen Welt ihre Position in der japanischen Gesellschaft zu behaupten vermag.

\section{Literatur}

Dalby, Liza

2008 Geisha in the 21st century - New Preface

[Elektronisches Dokument: E-mail] 15.12.2009

Downer, Lesley

2000 NBC Documentation, Studio A\&E Home Video, “The secret life of a geisha”. Farbe, 100 min.

2002 Geishas: Von der Kunst, einen Kimono zu binden. München: Wilhelm Goldmann.

Earle, Jon

1982 Japanische Holzschnitte. London: Victoria \& Albert Museum. 
Shunga - Erotische Fantasien

und große Kunst

\section{Franziska Brinkmann}

\section{Shunga verstehen}

Shunga bedeutet auf Deutsch „Frühlingsbilder“. Dies sind erotische Darstellungen in Form des traditionellen japanischen Holzschnittes. Es gibt für sie eine Vielzahl von Bezeichnungen aus unterschiedlichen Epochen: „Kopfkissenbilder“ makura-e, „Bilder zum Lachen“ warai-e oder einfach „Sex-Bilder" kosbukubon. Während der Edo-Zeit von 1603 bis 1868 erreichte die Popularität der Shungas in Japan ihren Höhepunkt. Die Edo-Zeit ist nach der berüchtigten Herrscherstadt Edo, dem heutigen Tokyo, benannt. In Edo und den anderen großen Städten jener Zeit gab es einen florierenden Handel mit solchen erotischen Holzdrucken Shungas (Grosbois 1977:7ff.).

Die Produktion des ersten erotischen

\section{Massenproduktes}

An der Herstellung eines japanischen Holzdruckes war immer eine ganze Reihe von Personen beteiligt. Der Meister zeichnete ein Motiv, welches der Schnitzer als Negativ in eine Holzplatte ritzte. Ein Drucker druckte das Bild schwarz-weiß auf feines Papier. Zunächst wurden die Holzdrucke noch von Hand koloriert, mit der Erfindung des Mehrfarbdrucks änderte sich das schnell. Beim
Drucken kamen außerdem raffinierte Techniken wie das Untermischen von Goldstaub, Glitter oder das Hervorwölben des Papiers zum Einsatz um besonders schöne Effekte zu erzielen. Schließlich verkaufte ein Händler den Holzdruck in seinem Laden. Wir haben es also mit einer frühen Form des geschäftlichen Vertriebes von Erotika zu tun.

In der Regel lag die Auflage bei 100 und 300 Exemplaren, bevor der Holzschnitt abzunutzen begann. So konnte ein breites Publikum am Genuss dieser Bilder teilhaben. Kunden waren nicht nur reiche Leute, sondern Bürger aus der aufstrebenden Mittelschicht (Koschatzky 1974:79ff.). Die meisten Holzschnitt-Meister jener Zeit fertigten neben Landschaftsbildern und Porträts auch Shungas an. Der Schöpfer des bei uns berühmten Holzschnittes „Die große Welle“ Hokusai entwarf unter einem Pseudonym viele erotische Motive für den Holzdruck, ebenso seine Kollegen Isshō, Shigenobu und Harunobu (Grosbois 1977:147f.).

Die ersten Shunga-Bände erreichten Europa 1615, doch wegen der unbekannten Sprache und der Unterschiede in der Kultur fanden sie dort kein Publikum. Die Engländer verbrannten die unsittlichen Bücher und Abbildungen mit großer Empörung (Screech 1999:13f.). Auch das in der Ausstellung gezeigte Exemplar (As1647) wurde bei seiner Aufnahme in die Ethnologische Sammlung im Katalog als „obszöne Szene“ bezeichnet, ein Standpunkt, der sich heute stark gewandelt hat. Dieser Holzdruck mit einer zweifellos erotischen Szene wurde im Jahre 1942 durch eine Schenkung von Dr. J. Voigt Teil der Göttinger Sammlung. Das genaue Alter ist unbekannt. Der Druck zeigt eine 
Frau und einen Mann, die sich beim Liebesspiel vergnügen. In der Göttinger Sammlung befinden sich noch weitere japanische Holzdrucke. Auf den bildlichen Inhalt und deren Bedeutung wird später genauer eingegangen.

Nach dem britischen Kunsthistoriker Timon Screech sind Shungas sowohl Kunst als auch altertümliche Pornografie. Die Holzdrucke zeigen Romantik und Leidenschaft mit großer Kunstfertigkeit, dienten aber im Alten Japan dazu, ihren Betrachter durch seine Erotik zu erregen (Screech 1999:13). Wir können sie in der Ausstellung insofern in ihrem kulturellen Kontext erklären und als fantasievolle Darstellung des Liebeslebens im Alten Japan begreifen (Grosbois 1977:8).

\section{Sexualität im Japan der Edo-Zeit}

Bis zum 19. Jahrhundert behandelten die Bewohner Japans Sexualität mit großer Offenheit und empfanden sie als etwas ausschließlich Gutes. Dies zeigt sich in der alten Schöpfungsgeschichte um den ersten Mann Izanagi und die erste Frau Izanami, die durch ihren Geschlechtsakt die Insel Japan erschufen. Sexualität und Liebe waren für die Menschen mit Schöpfung und Fruchtbarkeit verbunden (Grosbois 1977:14f.). In vielen Mythen taucht das Thema Sex auf: Als Ausgangspunkt für Eifersucht und Konflikte, Besänftigung für einen aufgebrachten Gott oder zur Befruchtung der Göttin der Reisfelder für eine gute Ernte. Sexualität war allgegenwärtig und ihr haftete weder Scham noch Sündhaftigkeit an. Japanische Bauern stellten bis in das 19. Jahrhundert riesige Penisse und Brüste auf
Fruchtbarkeitsfesten zur Schau. Schließlich verbot die Regierung diese kulturelle Praxis 1879 unter zunehmendem kulturellem Einfluss der westlichen Welt. Die freizügige Haltung der Bevölkerung zu ihrer Sexualität konnte damit jedoch nicht unterbunden werden (Grosbois 1977:15ff.).

\section{Sex und Liebe in der japanischen Ehe}

Die aufstrebende bürgerliche Mittelschicht der Edo-Zeit hatte klare Vorstellungen von der perfekten Ehefrau. Sie sollte genügsam sein, sich dem Mann unterordnen, Kinder bekommen und für den Haushalt sorgen. Der japanische Schriftsteller Yoshida Kenko beschrieb zu jener Zeit die Ehefrau als reizloses Geschöpf, das dem Ehemann schnell langweilig werden würde (Grosbois 1977:24). Shungas zeigen aber auch Darstellungen von Ehepaaren beim lustvollen Liebesspiel, was diese Aussage etwas relativiert (Monta 2001:35). Es gab glückliche Ehen, doch aufgrund der strengen gesellschaftlichen Regeln durften viele Verliebte einander nicht heiraten. Die Frustration in der Ehe führte dazu, dass viele Männer die Freudenviertel aufsuchten. Diese erlebten in der Edo-Zeit einen regelrechten Boom. 
Die fließende Welt - Motive aus den Freudenvierteln

Wunderschöne junge Frauen in teuren Kleidern mit vollkommener weißer Haut, schwarzem Lidstrich und roten Lippen: Das waren die Kurtisanen und Geishas des alten Japan. Geschöpfe einer Traumwelt, in welcher der Mann den Alltag hinter sich lassen und sich der Sinnlichkeit hingeben konnte (Downer 2002:83ff.). Geishas, Masseurinnen und Prostituierte, welche diese Wünsche erfüllten, waren in den Amüsiervierteln beheimatet. Besonders bekannt waren das Yoshiwara-Viertel in Tokio und das Shinmachi-Viertel in Osaka. Die Regierung sorgte dafür, dass die Amüsierviertel fortbestanden, mit dem Ziel, die männlichen Bürger in ihrer Freizeit zu beschäftigen und so politische Unruhen zu vermeiden (Zöllner 2008:75). Geishas traten meist in Teehäusern, den wichtigsten gesellschaftlichen Treffpunkten, auf und unterhielten dort das Publikum. Sie erhielten in der Geishaschule, der Ukio, eine umfangreiche Ausbildung in Musik, Gesang und Tanz und waren gebildete und höfliche Gesprächspartnerinnen (Feldman und Grodon 2006:237f.). Eine Heirat war für diese Frauen ausgeschlossen und zudem mit ihrer Arbeit nicht vereinbar. Als Künstlerin gehörte ihre Aufmerksamkeit zugleich allen Männern im Publikum und doch niemandem vollständig. Manche Geishas hatten jedoch einen Danna, einen Patron, der für exklusive Zuwendungen seitens der Geisha im Gegenzug ihre Kosten übernahm. Laut ihrem Vertrag gehörte die Geisha der Schule, welche sie ausgebildet hatte und war durch die entstandenen Schulden für Aus- bildung und Ausstattung an diese gebunden. Trotz dieser persönlichen Misere wurden Geishas zu Japans ersten Karrierefrauen. Sie besaßen die Mittel durch ihre Kontakte gesellschaftlichen Einfluss auszuüben (Feldmann und Gordon 2006:235ff.).

„Einer Geisha stebt es nicht an, zu wünschen.

Einer Geisha steht es nicht an, zu empfinden.

Eine Geisha ist eine Künstlerin der fließenden Welt.

Sie tanæt, sie singt, sie unterbält dich ..."

Dies sagt Sayuri in Steven Spielbergs Spielfilm „Die Geisha“ (2005) über ihren Beruf. Der Film griff das Thema Geisha auf und machte diese, nicht nur in Japan, sondern rund um den Globus, wieder populär. Heute wollen viele junge Mädchen in Japan wieder Geishas werden, nachdem dies in den Jahren zuvor äußerst unpopulär geworden war (Hetkämper 1990:1). Die fließende Welt, von der die Geisha Sayuri in dem Zitat spricht, war ein japanischer Lebensstil der Edo-Zeit. Das Schöne und das Vergängliche im Leben sollte demzufolge besonders genossen werden. Im Zentrum standen die Vergnügungsviertel mit ihren Bädern, Bordellen und Teehäusern, der Unterhaltungsindustrie in denen sich das schöne Leben abspielte. Sie waren nur für den Mann zugänglich, der das nötige Geld erübrigen konnte (Grosbois 1977:121f.). Geishas waren die Popstars dieser Zeit. Sie prägten Modetrends, hatten Fans und wurden von Künstlern auf Holzdrucken abgebildet (Grosbois 1977:123f.). Ein besonders populäres Beispiel ist die schöne O-sen, die um das Jahr 1767 von den Japanern besonders umschwärmt wurde. Der Meister Harunobu mach- 
te 15 Holzschnitten von ihr (Hempel 1963:43).

Auch männliche Theaterschauspieler wurden abgebildet und ebenso verehrt wie die Geishas. Ihre Fans waren in erster Linie jedoch keine Frauen, sondern Männer. Viele Samurai-Krieger, die nur an die Liebe zwischen Männern glaubten, schwärmten für die gut aussehenden Darsteller auf der Bühne (Grosbois 1977:52). Shunga zeigt auch Nanshoku, Männer-Sex, wie bei Monta (2001:29) zwischen einem jungen Schauspieler in Frauenkleidern und einem Krieger. Homosexualität zwischen Männern war in der Edo-Zeit populär (Screech: 1999:24). Lesbische Beziehungen innerhalb der Geishaschulen und Kurtisanenhäuser waren ebenso verbreitet. Von ihnen existieren jedoch weniger Abbildungen im Shunga als von der Liebe zwischen Männern (Screech 1999:215).

\section{Bild und Text - Die Geschichten hinter dem Holzschnitt}

Die meisten Shungas sind Sammlungen von zwölf Blatt, welche nicht zusammenhängen und unterschiedliche Szenen aus dem Liebesleben abbilden. Manchmal gab es auch Text, der sprechblasenartig in das Bild eingefügt war. Oft wurden bekannte Gedichte über die Schönheit der Natur zitiert. Anzunehmen ist, dass dies auch auf dem ausgestellten Exemplar der Fall ist. Manchmal kann der Betrachter aber auch die Unterhaltung zwischen den Personen mit verfolgen, wie im heutigen Comic. Diese reichen von Liebesschwüren über lustvolle Laute bis zu Streitereien zwischen den Paaren (Monta 2001:64).
Shungas finden sich auch zur Illustration in Büchern. Die japanische Literatur des 18. Jahrhunderts war ebenso offen für erotische Szenen wie die Kunst des Holzdruckes (Screech 1999:14f.). Einige Werke sind auch heute noch bekannte Klassiker, wie zum Beispiel „Die Reise um das Lieben zu erlernen“ von Suzuki Harunobu. Sie erzählt in Bildern und Text von einem Mann, der die Kunst des Liebens erlernen möchte. Er wird von einer Liebesgöttin in einen Zwerg verwandelt und soll so unbeobachtet Zugang zu Schlafzimmern in ganz Japan erhalten. Dort erfährt er alles über die Kunst des Beischlafs (Monta 2001:19ff.).

Der Voyeur ist ein beliebtes Motiv im Shunga, er kann ein Zwerg, ein Bediensteter oder ein Passant sein. Er stellt einen Bezug zum Betrachter des Shunga dar, der ebenfalls ein heimlicher Beobachter der erotischen Situation ist. Es gibt sogar aufklappbare Shungas, bei denen man hinter verschlossenen Türen oder unter Röcke schauen kann. Ein Beispiel ist das Bild „Das Brettspiel am heißen Tisch“von Utagawa Kunifusa, welches schon in seinem Namen eine Doppeldeutigkeit trägt (Screech 1999:29).

Um das Jahr 1000 unserer Zeitrechnung schrieb eine japanische Hofdame mit „Genji Monogati“ den ersten japanischen Roman. Darin geht es vor allem um die Liebesabenteuer eines japanischen Prinzen. Holzschnittmeister stellen viele der Szenen des Romans im Shunga dar. Damals galt er als Pflichtlektüre junger Leute der Oberschicht und diente diesen mit seinen anschaulichen Darstellungen als Aufklärungsbuch (Grosbois 1977:48).

Wie schon beschrieben sind Geishas und junge Theaterschauspieler häufige Motive des Shunga. Die 
meisten Darstellungen zeigen allerdings unbekannte Kurtisanen mit ihren Freiern beim Liebesspiel. Es finden sich auch Darstellungen von Ehepaaren, verliebten Jugendlichen, aber auch von sehr alten Paaren (Monta 2001:35ff.). Die Darstellung des alten Liebespaares auf dem 7. Bild des ManeemonAlbums ist besonders erwähnenswert, da Sex im Alter in unserer eigenen Kultur ein regelrechtes Tabuthema darstellt. Im Shunga sind der Fantasie keine Grenzen gesetzt; sie beziehen Paare jeden Geschlechts und Alters in allen möglichen Situationen ein. Auf manchen Abbildungen sind Paare $\mathrm{zu}$ sehen, die sich gemeinsam Shungas anschauen (Hockley 2001:420).

Allein oder zu zweit? - Der Gebrauch des Shunga

Beim Shunga gilt, dass die Fantasie des Künstlers und somit auch des Betrachters, nicht dem wirklichen Alltag im Liebesleben der Menschen entsprechen. Es handelt sich um ausgeschmückte Traumbilder aus einer Welt voller erotischer Verlockungen, die in dieser Form nur in den Köpfen der Leute existierte. Trotzdem können uns diese Bilder viel über das Liebesleben zur Zeit ihrer Entstehung erzählen (Screech 1999:14f.).

Mit dem Shunga holte sich der Betrachter die extravaganten Freuden des Vergnügungsviertels ins heimische Schlafzimmer. Sie dienten denjenigen als Behelf, die sich den Besuch eines teuren Bordells nicht leisten konnten. Timon Screech beschreibt, dass im Japan des 17. Jahrhunderts, durch die Überzahl von Männern in den Städten, eine gro-
Be Nachfrage nach Erotika bestand. Die mehrseitigen Shunga-Bände sind für Screech das, was heute Pornohefte sind (1999:31).

Es gibt unterschiedliche Thesen zum Gebrauch von Shungas. Einige Kunsthistoriker glauben, dass die Bilder zur Selbstbefriedigung benutzt wurden. Andere sind der Meinung, dass Paare in ihnen Anregung suchten. Mit großer Wahrscheinlichkeit war beides der Fall.

Es ist bekannt, dass Eltern ihren Kindern ShungaBände zur Hochzeit schenkten. Würden wir heute ein solches Geschenk von unseren Eltern erwarten? Wohl eher nicht. Dies ist ein weiterer Beleg für den offenen Umgang mit Sexualität im Alten Japan (Screech 1999:158 und Hockley 2001:420). 


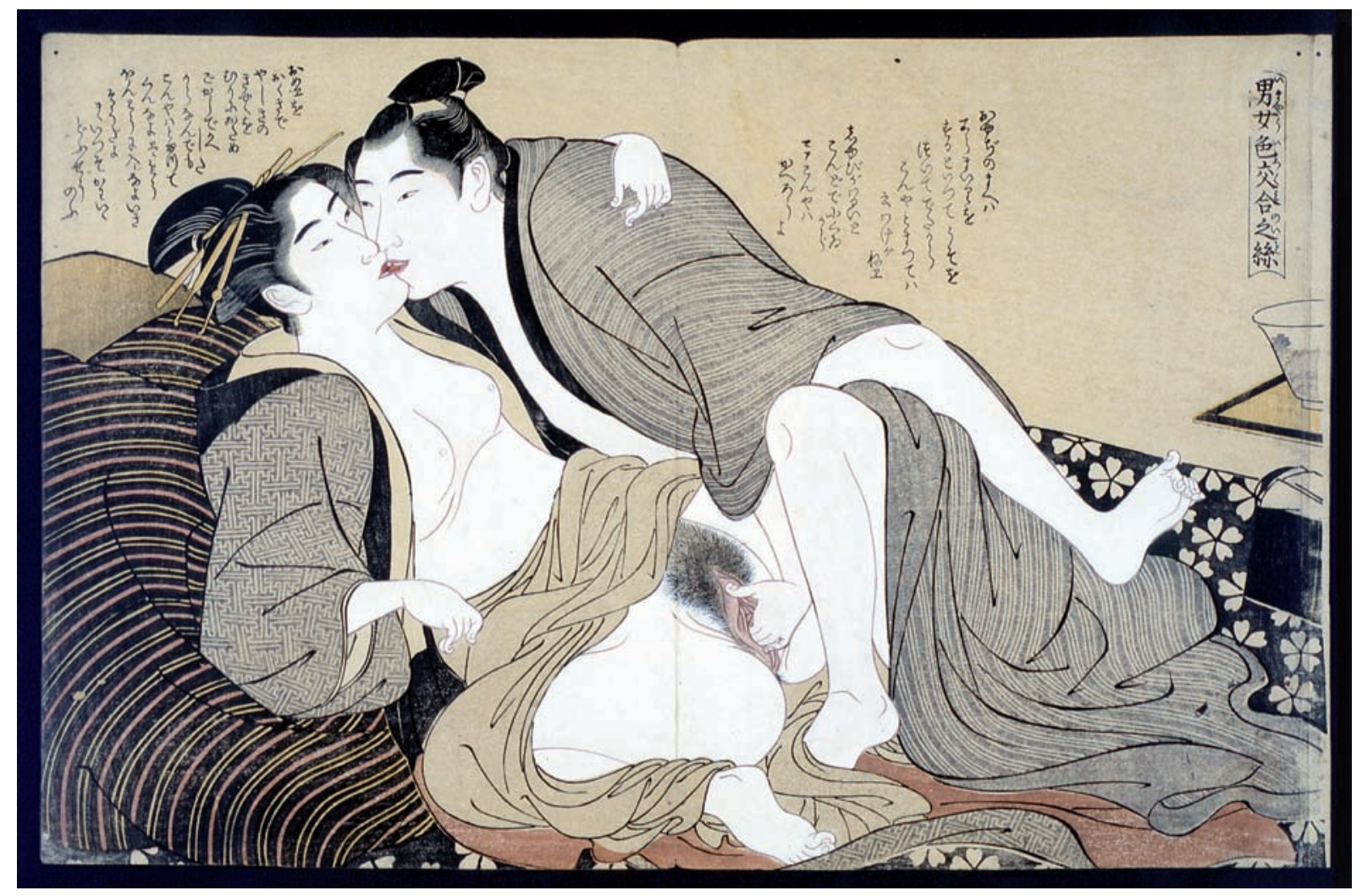

Abbildung 5: Shunga 
Der fast nackte Körper Symboliken des Shunga

Auf dem Shunga der Ethnologischen Sammlung fällt auf, dass das abgebildete Liebespaar seine Kleidung noch trägt, was keine Ausnahme darstellt. Häufig wird der Kimono nur hochgeschoben oder ein Gürtel, in Japan Obi genannt, geöffnet.

Dies liegt daran, dass Nacktheit, anders als in der europäischen Kultur, nicht als besonders erregend galt. Es war üblich, dass Männer und Frauen einander nackt in öffentlichen Badehäusern sahen. Nacktheit wurde vielmehr mit Körperpflege verknüpft als mit Erotik. Die Kleidung gibt beim Shunga außerdem Auskunft darüber, ob es sich um eine Geisha oder Bäuerin, einen Händler oder einen Samurai handelt, die sich auf dem Bild vergnügen (Grosbois 1977:121f.). Den Kimono nutzten seine Träger oftmals auch als Bettdecke (Screech 1999:119).

Die Geschlechtsteile erscheinen im Shunga um ein Vielfaches größer als in der Realität. Der Künstler hat diesen Bereich mit allen Details dargestellt. Große Geschlechtsteile stehen außerdem für große Lust und sollten den Betrachter zusätzlich erregen (Screech 1999:122).

\section{Heutige Rezeption}

Wenn wir die Bilder von Liebesakten heute betrachten, dann eher im Sinne von Kunst. Wir benutzen sie nicht zu dem Zweck, den sie einst erfüllt haben. Objekt der Begierde sind sie nur noch für europäische Kunstsammler, die auf Auktionen ein Ver- mögen für die Bilder zahlen (Screech 1999:14). Das britische Auktionshaus Christies bietet erotische Werke von Harunobu und Hokusai für viele Tausend Euro an (Katalog auf christies.com).

Während der Besetzung Japans durch die USA zum Ende des Zweiten Weltkrieges entdeckten die Amerikaner den erotischen Holzschnitt. Schockiert von dieser Schamlosigkeit erließen sie ein Gesetz, welches die Darstellung von solch eindeutigen Szenen verbot. Es ist noch heute in Kraft. Viele Europäer waren aber auch fasziniert von den Werken Hokusais, Harunobus und anderen japanischen Künstlern. Unter ihnen finden sich bekannte Maler wie van Gogh, Marc und Macke, die sich von japanischen Holzdrucken inspirieren ließen. Seit 1870 wurden im Rahmen des Japonismus, der Entdeckung und Wiederaufnahme japanischer Kunst, die Werke der alten japanischen Meister weltweit populär. Auch der Shunga fand einige Jahrzehnte später auf dem nun sexuell aufgeschlosseneren Kunstmarkt neue Sammler (Brunner 2010:19). Shunga wurde Kunst, während der Film und moderne Printmedien der japanischen Bevölkerung eine Fülle an neuen erotischen Darstellungen boten. Den Zensurgesetzen zum Trotz floriert die Pornoindustrie in Japan und wächst seit Mitte des 20. Jahrhunderts rasant. Sie ist bekannt für besonders ausgefallene Themen und drastische Darstellungsweisen. Insbesondere durch das Internet hat diese Branche eine weitflächige Verbreitung erfahren. Hierzu zählen neben Spielfilmen auch die erotischen Darstellungen in Comics und Zeichentrickserien (Brunner 2010:51). 
Erotische Mangas - moderne Shungas?

Bereits der berühmte Holzschnittmeister Hokusai benutze den Begriff Manga für seine satirischen Zeichnungen. Aus japanischem Zeichenstil und dem Einfluss amerikanischer Comics, entwickelte sich im 20. Jahrhundert eine komplett neue ComicKultur: der Manga.

Ein Phänomen, das heute auch in Deutschland und vielen anderen Teilen der Welt Fans hat.

Ihr nicht weniger populäres Gegenstück im Fernsehen ist das Anime (Brunner 2010:18f.).

Mangas sind Bestseller. Jede Altersgruppe hat eine eigene Sparte: Kinder, Jugendliche, erwachsene Männer und Frauen und sogar Senioren. Romantische Mangas, die sich an junge Leser wenden, enthalten bereits subtile erotische Szenen. Mangas für erwachsene Zielgruppen zeigen ohne Umschweife auch das Sexleben ihrer Protagonisten (Brunner 2010:57). Die Comics gelten in Japan als moralisch unbedenklich und finden reißenden $\mathrm{Ab}$ satz. Eine Erklärung für die große Nachfrage könnte im Alltag der modernen Japaner liegen, der von Arbeitsstress und starkem gesellschaftlichem Druck geprägt ist. Mangas bieten mit ihren fantastischen Geschichten von Abenteuern, Liebe und Leidenschaft eine Ausflucht aus dem Stress des Alltags (Brunner 2010:45).

Romantische Liebesgeschichten werden in Japan, im Gegensatz zum deutschen Groschenroman, sowohl von Männern als auch von Frauen gelesen. Sex steht hierbei mal mehr, mal weniger im Mittelpunkt. Doch auch, wenn er zentrales Thema ist, wird er in Japan nicht zwangsläufig als Pornografie betrachtet. Dieser Übergang wird in Europa anders ausgelegt. Schnell werden Mangas mit erotischen Inhalten mit Pornografie gleichgesetzt, wohingegen in Japan noch starke Abstufungen existieren (Brunner 2010:53).

\section{Exportschlager Anime - Pornografie}

Auf dem europäischen Markt konnte man, nach Brunner, lange Zeit den Eindruck bekommen, dass es sich bei Manga und Anime ausschließlich um Pornografie handelt (2010:51). Dies ist sowohl auf den anderen Umgang mit dem Thema Sexualität in Japan, als auch auf die Auswahl beim Import zurückzuführen. Die Fehlinterpretation, dass Comics sich vor allem an Kinder richten würden, sorgt zusätzlich für Verwirrung über Erotik-Mangas (Brunner 2010:57f.).

Anime- und Manga-Pornografie macht etwa ein Zehntel des Comic-Marktes in Japan aus. Für Erwachsene ist es gesellschaftlich akzeptiert, Hefte mit Liebesgeschichten oder erotischen Inhalten zu besitzen und zu lesen (Brenner 2007:90f.). Bei den nach Europa importierten Comics und Filmen macht Pornografie einen überdurchschnittlich großen Anteil aus. Auf dem europäischen Markt herrscht offensichtlich eine hohe Nachfrage nach japanischer Zeichentrickerotik (Brunner 2010:58). Wie kommt es, dass gezeichnete Pornografie sich so gut verkauft? Ganz einfach: Zeichentrick kennt keine Grenzen bei Kosten und Umsetzung. Es ermöglicht, heimliche Träume oder sogar illegale Praktiken zeigen zu können. Ebenso wie die Shungas lassen die Filme ihre Besitzer oft unerfüllbare, 
sexuelle Fantasien betrachten (Brunner 2010:60). In Form von Aufklärungsromanen finden Mangas auch als Ratgeber Anwendung. Die Reihe Futari et$c h i$ (dt. Titel: Manga Love Story), führt junge Leute an das Thema Sexualität heran (Brunner 2010:57).

Anfangs war Zeichentrick-Pornografie ein Mittel, die strengen Zensurgesetze zu umgehen. Bald beeinflussten die hier entstandenen Stilmittel aber auch das sexuelle Weltbild ihrer Konsumenten. Das Bild des unschuldigen Schulmädchens zum Beispiel sollte das eigentlich sexuelle Motiv der Zeichnungen verbergen. Heute ist es ein erotischer Stereotyp.

Sexuelle Symbolik ersetzt Geschlechtsteile durch Früchte oder Tentakeln, um harmlos zu erscheinen. In den letzten Jahrzehnten haben sich die Zensurgesetze in Japan deutlich gelockert, doch die unter der Zensur entstanden Spielarten bleiben bestehen (Brunner 2010:53).

In jüngster Zeit verbreitet sich Anime-Pornografie im Internet und auf Handys. Mädchen und jungen Frauen posieren mit laszivem Blick in knappen Schuluniformen oder anderen Kostümen (Brunner 2010:61). Fans und Zeichner zeigen die Bilder auf großen Plattformen im Internet. Der Zweck der Bilder ist eindeutig derselbe, den der Shunga vor über hundert Jahren erfüllte, sexuelle Stimulation, heute in digitaler Form (world-of-hentai.to). Manchmal wird ein Stoff aus der Zeit des Shunga sogar wieder aufgegriffen. Die erotischen Abenteuer des Prinzen Genji gibt es inzwischen auch als Manga und Anime (Betting 2007:1).
Fazit: Erotik in Japan damals und heute

Zwischen altjapanischen Holzschnitten und erotischen Mangas liegen viele Jahre und tiefgreifende kulturelle Transformationen. Doch beide waren in ihrer Zeit dazu bestimmt, sexuelle Fantasien anzuregen. Sie zeigen ein uns neues Verständnis von Erotik und Sexualität. Dieses hat sich in Japan unter Einfluss von außen zwar stark verändert, doch unterscheidet es sich noch immer sehr vom deutschen, welches solche eindeutig sexuelle Darstellungen mit einer gewissen Skepsis betrachtet.

\section{Literatur}

\section{Betting, Diana}

2007 Genji im Shôjo-Manga- Asakiyumemishi von Yamato Waki, Heidelberg: GRIN.

\section{Brenner, Robin E.}

2007 Understanding manga and anime. Libraries Unlimited; annotated edition. S. 37-38.

Brunner, Miriam

2010 Manga. Stuttgart: UTB Profile.

\section{Christies}

2012 Auktionskatalog. [Elektronisches

Dokument]

http://www.christies.com/lotfinder/books-manuscripts/eisen-tomioka-o-manju-5509505-details. aspx?from $=$ searchresults\&pos $=5 \&$ intObjectI $\mathrm{D}=5509505 \& \mathrm{sid}=4 \mathrm{c} 71 \mathrm{~d} 03 \mathrm{f}-9 \mathrm{cdf}-4961-9270$ cc051df79696\&page $=1$ [21.05.2012] 
Downer, Lesley

2002 Geishas: Von der Kunst, einen Kimono zu binden. München: Goldmann Wilhelm GmbH.

\section{Feldmann, Martha und Bonnie Gordon}

2006 The Courtesan's Arts: Cross-Cultural Perspectives. Oxford: Oxford University Press Inc.

\section{Grosbois, Charles}

1977 Die Liebe in der Kunst: Japan (Shunga).

Genf: Nagel.

\section{Hempel, Rose}

1963 Holzschnittkunst Japans: Landschaft, Mimen, Kurtisanen. Stuttgart: Belser.

\section{Hockley, Allen}

2003 Inside the Floating World: Japanese Prints from the Lenoir C. Wright Collection. North Carolina: Weatherspoon Art Museum.

\section{Koschatzky, Walter}

1974 Die Kunst der Graphik: Technik, Geschichte, Meisterwerke. München: DTV.

Marshall, Rob und Steven Spielberg

2005 Die Geisha. Warner Home Video. DVD.

\section{Monta, Hayakawa}

2001 The shunga of Suzuki Harunobu: mitate-e and sexuality in Edo. Kyoto: International Research Center for Japanese Studies.
Michener, James $A$.

1961 Japanische Holzschnitte von den frühen Meistern bis zur Neuzeit. München: F. Bruckmann

\section{Sreech, Timon}

1999 Sex and the Floating World: Erotic Images in Japan, 1700-1820. Reaktions Books Ltd.

\section{Zöllner, Reinhard}

2008 Geschichte Japans: Von 1800 bis zur Gegenwart. Außereuropäische Geschichte: Stuttgart: UTB.

\section{Hetkämper, Robert}

1990 Abschied von der Geisha: vier Frauen in Japan. NDR: Video. 
Das geschriebene Bild

\section{Stefan Thiele}

Ein für die Ausstellung ausgewähltes Beispiel weiblicher Figurenmalerei des Alten China ist ein Aquarell, gemalt auf Papier, welches mit Leinen verstärkt wurde (Exponat As2049): Abgebildet ist eine Dame, die durch ihre Lippenbemalung in die Zeit der Qing-Dynastie (1644 bis 1911) eingeordnet werden kann (Hua 2004:80).

Das Aquarell steht in der Tradition geschriebener Bilder. Diese erwuchsen aus kleinen Piktogrammen, die zunächst nur zu religiösen Zwecken genutzt wurden, um Kontakt zu den Göttern herzustellen (Glaser 1929:6f.). Darüber hinaus dokumentierten sie auch besondere geschichtliche Ereignisse. Im Laufe der Zeit entwickelte sich aus den Piktogrammen eine eigene Kunstform, die Kalligrafie. Charakteristisch dafür waren Utensilien wie Papier, Seide, Pinsel, Tusche und Tuschstein. Sie wurden als „Die vier Kostbarkeiten eines Literatenstudios" (Brinker 2009:10) bezeichnet und waren auch für die Figurenmalerei, die sich im 7. bis 10. Jahrhundert unserer Zeitrechnung durchsetzte, stilprägend.

Was thematisch anlässlich des ausgestellten Aquarells interessiert, ist die Darstellung einer Frau, welche in ostasiatischen Porträts aufgrund konfuzianischer Ideale ursprünglich nur eine eingeschränkte Rolle gespielt hat. Nach der Vorstellung der Philosophen jener Zeit sollten Frauen vor allem zurückhaltend und tugendhaft sein, wodurch die
Erotik in chinesischen Porträts zunächst weitestgehend unbekannt war. Frauen wurden daher vorrangig nicht um ihrer Schönheit willen porträtiert, sondern als herausragende Repräsentantinnen konfuzianischer Ideale (Seckel 1997 Bd. 2:177). Es gab aber auch Bilder von Konkubinen oder Kurtisanen. Diese wurden vor allem zu dem Zweck erstellt, dem Kaiser die Möglichkeit zu geben, eine Auswahl seiner Gespielinnen für die jeweilige Nacht zu treffen.

„Berühmt ist die Geschichte der schönen Wang Chao-chün (ca. 50-30), die es versäumte, den ₹uständigen Maler gebörig zu bestechen; er räcbte sich, indem er sie bässlicher malte als die anderen, so dass man fand, sie sei für den Barbarenfürsten gut genug (der dann um so angenehmer überrascht war, während der traurige und erzürnte Kaiser den Maler binricbten ließ). Leider hat sich das als Legende erwiesen aber dass sie erfunden werden konnte, zeigt doch, dass solche Dinge vorkamen".

(Seckel 1997 Bd. 2:41).

Im 18. Jahrhundert schließlich wurden auch Frauen gemalt, die sich in Wissenschaft oder Poesie einen Namen gemacht hatten (Seckel 1997 Bd. 2:234). Hinzu kamen in jener Zeit zunehmend auch erotische Darstellungen oder entsprechende Details, wie die sogenannten Lotosfüße, die zum Innbegriff von Sex-Appeal wurden (Gulik 1961:218).

Abgesehen von idealisierten Darstellungsinhalten, erfüllten weibliche Porträts im Alten China häufig die Funktion eines Hilfsmittels bei der Heiratsvermittlung, um ein möglichst genaues Orientierungsmuster vom gewünschten Aussehen der Zukünftigen zu haben. Zu welchem Anlass das Exponat der Ausstellung angefertigt wurde, ist nicht 
zu ermitteln. Ob es sich bei der auf dem Bild zu sehenden Frau um eine Han-Chinesin oder eine Mandschu handelt, ist ungewiss. Es ist jedoch anzunehmen, dass es sich hier eine Han-Chinesin handelt, da die Schuhspitze, die unter dem Rock zu sehen ist, die Vermutung nahe legt, dass die Frau gebundene Füße hat. Ein besonderes Merkmal der Dargestellten ist ihr Blick, mit dem sie den Betrachter direkt anzusehen scheint. Auffällig sind ihre langen Fingernägel und der sehr spitz zulaufende Schuh. Ebenso interessant sind ihre Hände, die in der traditionellen Porträtkunst eigentlich eher versteckt werden. Hier werden sie zwar ruhig gehalten, aber sie sind deutlich sichtbar, was darauf hinweisen könnte, dass es sich bei der Dame nicht um das Abbild einer real existierenden Person gehandelt hat.

\section{Literatur}

\section{Brinker, Helmut}

2009 Die chinesische Kunst. München: C. H. Beck.

\section{Hua Mei}

2004 Chinese Clothing. China Intercontinental Press.

\section{Seckel, Dietrich}

1997 Das Porträt in Ostasien (1-3). Heidelberg: Universitätsverlag C. Winter.

Glaser, Curt u.a.

1929 Die aussereuropäische Kunst. Leipzig: Alfred Kröner.

Speiser, Werner

1956 Die Kunst Ostasiens. Berlin: Safari.

Van Gulik, R.H.

1961 Sexual Life in ancient China: A preliminary survey of Chinese sex and society from ca. 1500 B.C. till 1644 A.D. Leiden: Netherlands: EJB. 
Cakrasamvara - Nur eine von Buddhas unendlichen Erscheinungsformen

\section{Taina Engineer}

Die Anfänge des Buddhismus reichen in das sechste Jahrhundert vor unserer Zeitrechnung zurück und entstammen dem hinduistischen Weltbild. Die buddhistische Lehre wurde von einem Prinz namens Siddharta Gautama gegründet, welcher der Legende nach bereits bei seiner Geburt angekündigt haben soll, dass er die Erleuchtung finden würde.

Im Buddhismus gibt es keine höher gestellten Mächte oder Instanzen. Es muss vor niemandem Rechenschaft abgelegt werden und jeder ist selbst für sein Handeln verantwortlich. Buddhisten glauben an die Wiedergeburt. Ziel eines jeden Buddhisten ist es, mit dem richtigen Handeln den Kreislauf der Wiedergeburt zu durchbrechen, um das Nirwana zu erlangen. Das Nirwana ist ein Zustand, in dem alle menschlichen Bedürfnisse, Wünsche und Sehnsüchte aufgehoben sind. Mit dem Eintreten dieses Zustandes beginnt die endgültige Erleuchtung und der Kreislauf der Wiedergeburt kann verlassen werden. (Ludwig 2011:6ff.). Die figurative Darstellung Buddhas erstreckt sich in unendlicher Vielfalt. Buddha, das ist kein Eigenname, sondern ein Ehrentitel und bedeutet zum Einen der „Erwachte“ und zum Anderen bezeichnet es die unzähligen Erscheinungsformen, welche er annehmen kann. So wird er oft in meditativen Haltungen dargestellt, aber auch zornige Grimassen oder zärtliche Posen zusammen mit einer Partnerin sind beliebte
Darstellungsformen. Diese unterschiedlichen Erscheinungen dienen allein dazu, die Gläubigen auf den rechten, buddhistischen Lebensweg zu führen. Gerade im tibetischen Buddhismus zeigen sich die Darstellungen in besonderer Vielfalt. Der Grund hierfür liegt in der langen Entwicklung, die diese Religion auf ihrem Weg von ihrem Ursprungsland Indien nach Tibet erfuhr (Luczantis 2005:43f.).

Das in der Ausstellung zu sehende Exponat (As1924) ist eine tibetische Statue Buddhas aus dem 12. Jahrhundert. Da es sich bei der Inschrift am Sockel um chinesische Schriftzeichen handelt, ist anzunehmen, dass sie von einer chinesischen Künstlerin hergestellt wurde. Der dargestellte Buddha zeigt sich in der Erscheinung des blauen Cakrasamvara. Er vereint sich zusammen mit seiner Weisheitspartnerin der roten Vajravarahi in inniger Pose (Steffan 2008:39ff.). Cakrasamvara besitzt 12 Arme und hält in den Händen, die für ihn typischen Attribute. In den beiden Händen, mit denen er seine Partnerin umschlingt, ist jeweils ein Donnerkeil zu erkennen, welcher das Absolute und Unzerstörbare symbolisiert. Zudem ist er der Gegenpol zur weiblichen Glocke, welche von ihr in einer Hand gehalten wird. Beide Partner tragen jeweils eine Schädelschale, gefüllt mit dem Nektar der Lehre Buddhas und der Unsterblichkeit. Das Hackmesser findet vor allem in tantrischen Ritualen Verwendung. Zu seinen Füßen befinden sich zwei Dämone der Unwissenheit, auf denen er tanzt, um ihnen diese auszutreiben. Passend dazu befindet sich in einer weiteren Hand eine Fangschlinge für Dämone und für Fernstehende, um diese an die Lehre zu binden (Oberdiek 1988:20ff.). Das Paar befindet sich auf 
einem doppelreihigen Lotosthron, wobei der Lotos das Symbol für Mitleid und Erkenntnis ist. Obwohl die Pose zunächst glauben lässt, dass es sich hierbei um eine rein sexuelle handelt, ist dies nicht der Fall. $\mathrm{Zu}$ sehen ist eine tantrische Vereinigung, die im Buddhismus für die Verbreitung des allumfassenden Wissens sorgen soll. Übersetzt bedeutet Tantra „Bewusstseinserweiterung“. Der Begriff setzt sich aus zwei Wörtern zusammen, welche aus dem Sanskrit, dem Alt-Indischen, stammen. Aus dem Wort Tanoti, welches mit „Erweiterung“ übersetzt werden kann und aus Trayate was so viel wie „Befreiung" bedeutet. Es wird angenommen, dass die Polaritäten des männlichen und weiblichen Prinzips in Darstellung von einer sexuellen Verbindung, die Verwirklichung der geistigen Ziele unterstützt. Insbesondere deswegen wird Tantra im westlichen Verständnis häufig fälschlicherweise allein mit Sexualpraktiken in Verbindung gebracht.

Seinen Anfang fand die tantrische Lehre im Westen zu Beginn der 1980er Jahre. Osho (19311990), ein indischer Philosoph, war hierfür der Auslöser. Er war überzeugt davon, dass ein neues Zeitalter des Bewusstseins angebrochen war und wollte dies mit der Lehre des Tantra unterstützten und verbreiten. Obwohl er viele Anhänger hatte, wurde auch negativ über ihn berichtet. In den 1970er Jahren wurde die westliche Presse auf ihn aufmerksam und bemängelte die zu offene Einstellung des Gurus gegenüber dem Geschlechtsverkehr. Zudem wurde ihm vorgeworfen, den eigentlichen Sinn der spirituellen Lehre aus den Augen verloren zu haben und nur noch profitorientiert zu handeln.

Dennoch wurde das heutige westliche Bild des
Tantras besonders durch die hinduistische Form beeinflusst, welche sich vor allem an dem sexuellen Deutungsweg orientiert. Da wenige westlich geprägte Menschen empfänglich für die östlich traditionelle bewusstseinserweiternde Lehre des Tantras sind, fasste hier in erster Linie die lustorientierte Umsetzung Fuß (Heggenstaller/Keller 2012).

Den beiden Tugenden von Weisheit und Mitgefühl kommt im tibetischen Glauben eine zentrale Bedeutung zu und soll durch die enge Körperhaltung des Paares veranschaulicht werden. Diese Vereinigung ist zugleich auch die Aufhebung der Polarität. Die Köpfe der beiden berühren sich, wobei sie sich eindringlich und liebevoll in die Augen blicken. Der männliche Part verschlingt hierbei jegliche Lebenskraft des Egoismus und des Zweifels. Der weibliche Part hingegen verkörpert die Verwandlung von Leidenschaft und Illusion in Mitgefühl und Erkenntnis. (Steffan 2008:39ff.).

In Tibet hat die Familie eine hohe Bedeutung im Sinne gemeinschaftlicher materieller Sicherung. Der Sexualität wird im öffentlichen Leben kein hoher Stellenwert beigemessen. Die Rolle der Ehefrau als maßgebender Faktor im Familienleben ist in Tibet eine andere als in den meisten asiatischen Ländern. Die Darstellung der Vereinigung von Cakrasamvara und Vajravarabi zur harmonischen Einheit ist insofern geradezu ein Sinnbild für die Gleichstellung der Geschlechter in Tibet.

Aber auch der tibetische Buddhismus ist nicht frei von patriarchalischen Strukturen. So wurden Frauen jahrtausendelang systematisch von Wissen ferngehalten, und es ist ihnen auch bis heute nicht möglich, zu einem Lehr-Buddha zu werden. 
Der Weg zur Erleuchtung steht jedoch beiden Geschlechtern gleichermaßen offen. Der Buddhismus dient der Emanzipation sowohl des Mannes als auch der Frau. Wird der rechte buddhistische Weg eingeschlagen, ist es möglich, sich von emotionalen, interkulturellen und äußeren Zwängen zu lösen. Und über das Potential dazu verfügen sowohl Männer als auch Frauen (Harrer 1953:25f.). Der Buddhismus ist eine Weltsicht ohne Hierarchien, und der Weg zur vollkommenen Erleuchtung ist das Ziel.

\section{Literatur}

\section{Ludwig, Klemens}

2011 Der tibetische Buddhismus. Brennpunkt Tibet 02: S. 6-9.

\section{Luczantis, Christian}

2005 Die Welt des tibetischen Buddhismus: Unendliche Vielfalt. Gestalt und Erscheinungsform im Buddhismus. Hamburg: Museum für Völkerkunde Hamburg.

\section{Oberdiek, Ulrich}

1988 Religionen im Himalaya. Freiburg: Stadt Freiburg. Museum für Völkerkunde.

\section{Harrer, Heinrich}

1953 Meine Tibet-Bilder. München: Heering.
Steffan, Roland

2008 Buddhas Leuchten \& Kaisers Pracht. Die Pekinger Sammlung Hermann Speck von Sternburg.

Leipzig: Museum für Völkerkunde zu Leipzig.

Keller, Jharna Birgi und Heggenstaller, Shantam Ludwig 2011 [Elektronisches Dokument] http://www. tantra-vision.de/seminare/startseite/ [März 2012] 
Herzgeist oder göttlicher Funke -

Die Wirkung von Akupunktur

\section{Ronja Kästner}

Die Akupunktur ist ein medizinisches Behandlungsverfahren, das chinesisch-japanische Ursprünge hat. Sie wurde vermutlich schon 2336 v.Chr. ausgeübt und diente damals wahrscheinlich der Austreibung von Dämonen im Körper durch Nadelstiche. In Japan wurde Akupunktur bereits 702 n.Chr. als besonderes Unterrichtsfach an Medizinschulen gelehrt.

Bei der Akupunktur werden sehr dünne $\mathrm{Na}$ deln aus Silber, Gold oder Eisen an bestimmten Stellen des Körpers eingestochen. Die Nadeln können bis zu $20 \mathrm{~cm}$ lang und bis zu $2 \mathrm{~cm}$ tief sein und fünf Minuten lang eingestochen werden (Andrae 1935:692). Die Körperstellen, welche für die Akupunktur vorgesehen sind, liegen auf den zwölf sogenannten Meridianen. Diese sind von Lebensenergie durchflossene Kanäle, die den Körper von Kopf bis Fuß überspannen. Die Traditionelle Chinesische Medizin (TCM) geht von der Existenz zweier gegensätzlicher Kräfte aus, die in fließender Wechselwirkung zueinander stehen: Ying und Yang. So wird z.B. dem Himmel Yang und der Erde Ying zugeordnet, männlich ist Yang, weiblich Ying usw. Durchfließen diese beiden Kräfte die Meridiane im Körper im Ungleichgewicht, kann es zu Unwohlsein und Krankheit kommen (Jung 1995:10). Die Reizung bestimmter (Akupunktur-) Punkte, die auf den Meridianen liegen, soll den harmonischen
Energiefluss und somit das Wohlbefinden wiederherstellen.

Akupunktur und chinesische Kräutermedizin werden seit über 2.000 Jahren u.a. in Schwangerschafts-, Geburts- und Wochenbettbegleitung eingesetzt. Wird die Technik beispielsweise in den letzten Wochen vor der Geburt angewandt, kann sich der Geburtsvorgang um bis zu zwei Stunden verkürzen.

In Japan betätigten sich ab dem 14. Jahrhundert viele Wundärzte auch als Geburtshelfer. Sie taten dies aus der Überzeugung heraus, dass der Geburtsvorgang eine Verletzung des Körpers darstelle und deshalb behandelt werden müsse (Rosner 1989:45). Im 16. Jahrhundert machte ein japanischer Arzt auf sich aufmerksam, der der chinesischen Kaiserin während seines China-Aufenthaltes mit Akupunktur zu einer schmerzfreien Geburt verholfen hatte. Takeda Masayoshi wurde daraufhin in hoher Funktion am Hof erwähnt und zum angesehenen Akupunkteur (Rosner 1989:42). Schon der chinesische Gelehrte Sun Simiao, der 581-682 n.Chr. lebte, veröffentlichte in seinen Werken Rezepturen zur „Förderung der Entwicklung des Fötus im Mutterleib“. Darin beschrieb er unter anderem Akupunkturpunkte, Nahrungsmittel und Arzneien, die den jeweiligen Reifeprozess des Fötus unterstützen bzw. auftretende Probleme behandeln sollten. Diese Schriften gelten bis heute als grundlegend für die (alternative) Behandlung innerhalb der Schwangerschaft.

Im Alten China hatten Nachkommen eine groBe Bedeutung. Sie waren einerseits Altersvorsorge und hatten andererseits die Aufgabe, gegenüber 
den Ahnen spirituelle Verpflichtungen auszuüben. Blieb der Nachwuchs bei einem Paar aus, drohte diesem Unglück, da der Schutz durch die Ahnen nicht gewährleistet war. Um die Paar-Beziehung und den Erhalt der Ehe nicht zu gefährden, kam es zu Arrangements: In einem solchen Fall wurde aufwendiger geistlicher und medizinischer Rat in Anspruch genommen, insbesondere unter dem Schutz der chinesischen Muttergöttin Guanyin.

Den klassischen Schriften der TCM folgend, basierten solche geistlichen Hilfestellungen und medizinischen Behandlungen auf der Erkenntnis, dass beim Aufeinandertreffen von Samen und Eizelle und dem Hinzutreten von Shen neues Leben entsteht. Shen kann als „Herzgeist“ oder ,göttlicher Funke“ übersetzt werden. Die Fruchtbarkeit eines Menschen ist demnach abhängig von seinem Herz und spirituellen Anteil. Samen und Eizelle werden nach der TCM aus der „Essenz“ einer Person gebildet. Durch die Behandlung der Fruchtbarkeit von Mann und Frau wird die „Essenz“ gestärkt. Insbesondere den Nieren werden nach traditioneller Vorstellung eine bedeutende Rolle zugeschrieben, da sie verantwortlich gemacht werden für die Speicherung der Lebensessenz, Wachstum und Entwicklung, Reinigung der Körpersäfte, Wasserausscheidung, sowie Sexualität und Reproduktion (Jung 1995:10).

Auch heute noch wird Akupunktur zur Behandlung von Unfruchtbarkeit bei Männern und Frauen, sowie während der Schwangerschaft eingesetzt (vgl. As603).
Literatur

Andrae, K.R.

1935 Akupunktur und Moxa. Ciba Zeitschrift 20:

S. 692-95.

\section{Rosner, Erhard}

1989 Medizingeschichte Japans. Leiden: E.J. Brill.

Jung, Iris

1995 Akupunktur als Behandlungsmethode bei männlicher Sterilität. Stuttgart: Hippokrates.

Köffges, Anita

2009 [Elektronisches Dokument] http://www. japanische-akupunktur.de/ [März 2012] 
Afrika

Der Dildo - Lustwerkzeug der Liebe

\section{Frederike Nelius}

Fragt man eine afrikanische Frau, so hat jeder Mensch das Verlangen nach zwei Arten von Liebe - jener, die dir Sicherheit gibt und jener, die deiner Sehnsucht nach wilder Leidenschaft entspricht (Van Dijk 2007:53). Liebe. Sex. Die einen reden dauernd darüber, die anderen schweigen lieber. Manche tun so, als sei es nicht so wichtig. Für manche ist es das Wichtigste auf der Welt (Van Dijk 2007:11).

Die Geschichte um Liebe und Sexualität wird in allen Kulturen unserer Erde anders erzählt und hat doch eine Gemeinsamkeit: Die Hoffnung und das Streben nach persönlichem Glück, beides Impulse, die stärker sind als alle Gesetze der Welt es je sein könnten (Van Dijk 2007:13f.). Sehnsüchte nach Nähe und Intimität sind Gefühle, die dem Menschen schon seit Jahrtausenden innewohnen und auch Sex ist mehr, als nur ein bloßer Fortpflanzungsinstinkt.

Er schafft zwischenmenschliche Beziehungen, kann glücklich machen, allerdings auch frustrieren. Nicht verwunderlich, dass in der Vergangenheit wie auch heute immer kreativere Versuche unternommen wurden, diese körperlichen Bedürfnisse zu befriedigen (Van Dijk 2007:31). So ist beispielsweise die Zuhilfenahme von phallusähnlichen Gegenständen nur ein Weg solchen Verlangen nachzugehen. Der älteste künstliche Penis, der mutmaßlich als steinerner Freudenspender gedient hat, ist 28.000 Jahre alt und wurde in der Nähe von Ulm entdeckt (Amos 2005). Auch die Pariser Bordellbesitzerin Madame Gourdan setzte im 18. Jahrhundert auf die Herstellung und den Vertrieb von Kunstpenissen aus Holz, die insbesondere bei Nonnen sehr begehrt waren (Schonewille 2004:104f.).

Ein ausgesprochenes Meisterstück unter den Dildos ist der mádigo des Hausa-Volks, der aus Westafrika stammt. Dieser in Handarbeit gefertigte, rund $20 \mathrm{~cm}$ lange stilisierte Holzpenis mit beweglichem Hodensack, diente den Frauen als Hilfsmittel bei der gegenseitigen Befriedigung (Af3272). Der mit dunkelbraunem Leder bespannte Holzphallus kam besonders in den großen Harems der Sultane zum Einsatz, da die Sultane selbst nicht immer in der Lage waren, allen ihrer Frauen gleichermaßen Freude zu bereiten.

Vor dem Gebrauch wurde das innen hohle, hölzerne Glied mit dem klebrigen Saft des Baumes dälaku, der männliches Sperma imitieren soll, (Katz 1975:482f.) befüllt und eingerieben (Tabori 1969:269). Mit zwei Lederschnüren unterhalb des Bauchnabels befestigt, drang im Schutz der Nacht eine mit einem mádigo bestückte Frau in die $\mathrm{Ha}$ remsgemächer ein, um verschiedene Frauen mit dem Holzdildo zu beschlafen (Katz 1975:482f.). Wurde im damals von den Engländern besetzten Gebiet eine Hausa-Frau mit einem Holzphallus erwischt, musste sie mit schweren Bestrafungen und sogar dem Tod rechnen (Katz 1975:482f.). Die religiösen Vorstellungen der Hausa sind hauptsächlich von islamischen Einflüssen geprägt, welche sich mit traditionellen Ansichten vermischten. 
Während in der frühislamischen Periode jabiliya Sexualität kein Tabuthema war, sondern vielmehr die religiöse Wichtigkeit des Vorspiels und das Eingehen auf die sexuellen Wünsche beider Partner als Schlüssel für das Gelingen harmonischer Beziehungen betont wurde, gestaltet sich der Umgang mit gleichberechtigter Sexualität bei den Hausa zurzeit eher schwierig (Mahdi 2006:194f.). Die auch heute noch oft praktizierte Polygynie ermöglicht HausaMännern, sofern sie über ausreichende finanzielle Mittel verfügen (Dunbar 1991:74), Liebes-Arrangements anzubahnen und die Ehe mit mehreren Partnerinnen zur gleichen Zeit zu führen, wobei des Öfteren verbale Streitigkeiten unter den eifersüchtigen Mitfrauen, genannt kishi, entstehen können (Mahdi 2006:201). Ob diese hölzernen Lustspender jetzt noch bei den Hausa-Frauen in Gebrauch sind, ist nicht bekannt.

Auch hierzulande werden erotische Hilfsmittel für Paare und Singles immer attraktiver und zunehmend salonfähiger. Nicht zuletzt trugen die sexuelle Revolution und Forderungen nach erotischer Selbstbestimmung ihren erheblichen Teil zum zwangloseren Umgang mit den Liebeswerkzeugen bei (Kotte 2003). Bei der Schöpfung lustvoller Alternativen sind der Fantasie und Abenteuerlust der Dildo-Hersteller von damals und heute keine Grenzen gesetzt: Aus Plastik, Wachs, Glas, Holz und Stein, kunterbunt oder einfarbig dürfen sie sein, solange sie die leidenschaftlichen Wünsche und Träume ihrer Besitzer wahr werden lassen. Mit abwechslungsreichen Designs, Formen und Funktionen buhlen weltweit tausende von Herstellern um die heiß begehrte Vormachtstellung im DildoGeschäft.

Während erst neue Modelle aus Kunststoff ihren Einzug in heimische Schlafzimmer antraten, so wird neuerdings wieder zunehmend auf naturbelassene Materialien gesetzt. Besonders großer Beliebtheit erfreuen sich Hausmacher-Dildos aus dem Odenwald, die ihren Kollegen aus Kunststoff in Sachen Spaßfaktor und Qualität in nichts nachstehen (ÖKO-Test 2007). An der Werkbank aus Fichtenholz gedrechselt und danach von Hand lackiert, ist jedes dieser Stücke durch seine individuelle Maserung ein Unikat (Bauer 2008).

Fest steht, ob alleine oder zu zweit, zuhause oder auf Reisen, sanft oder wild, aus Neugier oder nur als Mittel zum Zweck: Wie und wann diese Liebesspielzeuge zum Einsatz kommen, ist der persönlichen Vorstellungskraft und dem Tatendrang eines jeden einzelnen überlassen. Was Lust verschafft, kann auch Partnerschaften bereichern oder zum eigenen positiven Wohlbefinden beitragen. Hilft es der Liebe, sei es zu sich selbst oder zu anderen, ist alles was glücklich macht erlaubt. Doch wenn es darum geht, das eigene Liebesleben aufzupeppen, gilt das Motto: Alles kann, nichts muss.

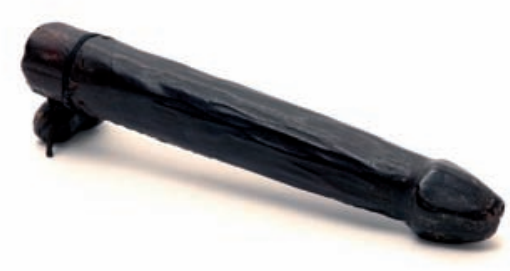

Abbildung 6: Dildo 


\section{Literatur}

\section{Amos, Jonathan}

2005 Ancient Phallus unearthes in cave. BBC

News [Elektronisches Dokument] http://news. bbc.co.uk/2/hi/science/nature/4713323.stm

[26.02.2012]

\section{Bauer, Ralph}

2008 Familienunternehmen expandiert mit Holzdildos. [Elektronisches Dokument] Der Tagesspiegel http://www.tagesspiegel.de/weltspiegel/ sexspielzeug-familienunternehmen-expandiert-mitholzdildos/1181674.html [27.02.2012].

\section{Dunbar, Roberta Ann}

1991 Islamic Values, the State, and 'the Development of Women' - The Case of Niger. In: Cole, Catherine and Mack, Berverly (Hrsg.). Hausa Women in the Twentieth Century. Madison: University of Wisconsin Press.

\section{Kotte, Hans-Hermann}

2003 [Elektronisches Dokument] Stern- Magazin Beziehungswelten. http://www.stern.de/wissen/ gesund_leben/2-beziehungswelten-ally-mcbeal-injedem-schlafzimmer-508095.html [27.02.2012]

\section{Mabdi, Hauwa}

2006 Gender and Citizenship - Hausa Women's Political Identity from the Caliphate to the Protectorate. Göteburg: Göteburg University Press.
Katz, Jonathan Ned. (Hrsg.)

1975 Homosexuality: Lesbians and Gay Men in Society, History and Literature. New York: Arno Press Inc.

ÖKO-Test: Vibratoren

2007 [Elektronisches Dokument]

http://www.oekotest.de/cgi/index.cgi?artnr= 64005 ; bernr $=06$; seite $=01 ; \mathrm{co}=$; suche $=$ vibrator [27.02.2012].

\section{Schonewille, Peter}

2004 Dildos im Dutzend. In: Van Vilstreren, Vincent und Rainer-Maria Weiss (Hrsg.). 100.000 Jahre Sex - Über Liebe, Fruchtbarkeit und Wollust. Assen: Waanders/Helms-Museum.

Tabori, Paul

1969 The Humor and Technology of Sex. New York: Julian Press.

Van Dijk, Lutr.

2007 Die Geschichte von Liebe und Sex. Frankfurt am Main: Campus. 
Der Buschmannrevolver als Instrument für den Liebeszauber

\section{Viet Hoang}

Die Ethnologische Sammlung beherbergt unter anderem ein Zauberartefakt der San (Buschmänner), den sogenannten Buschmannrevolver (Af4681a-f). $\mathrm{Da}$ dieser in der Literatur unter dem Aspekt des Liebeszaubers nicht ausreichend behandelt wird, stützt sich dieser Text auf ein Interview vom 8.2.2012 mit dem Göttinger Afrika-Experten Professor Dr. Ulrich Braukämper, welcher den hier beschriebenen Buschmannrevolver in Botswana erwarb und sich sei- nerseits auf die Informationen einer Sanfrau bezieht.

Der Buschmannrevolver ist ein Miniaturbogen von etwa $10 \mathrm{~cm}$ Größe. Er ist voll funktionsfähig und verschießt Pfeile von Zahnstochergröße, die in einem Miniaturköcher transportiert werden. Der Bogen ist aus Holz und Sehnen gefertigt, die Pfeile sind ebenfalls aus Holz. Sie besitzen weder Federn noch andere Flugstabilisatoren. Die Spitze ist angedeutet. Der Köcher wurde früher wahrscheinlich aus Antilopenleder gefertigt. In heutiger Zeit wird das Leder von Haustieren, insbesondere von Ziegen, verwendet.

Der ausgestellte Buschmannrevolver wurde von Professor Dr. Ulrich Braukämper auf einer Forschungsreise am 28.9.2001 von einer Souve-

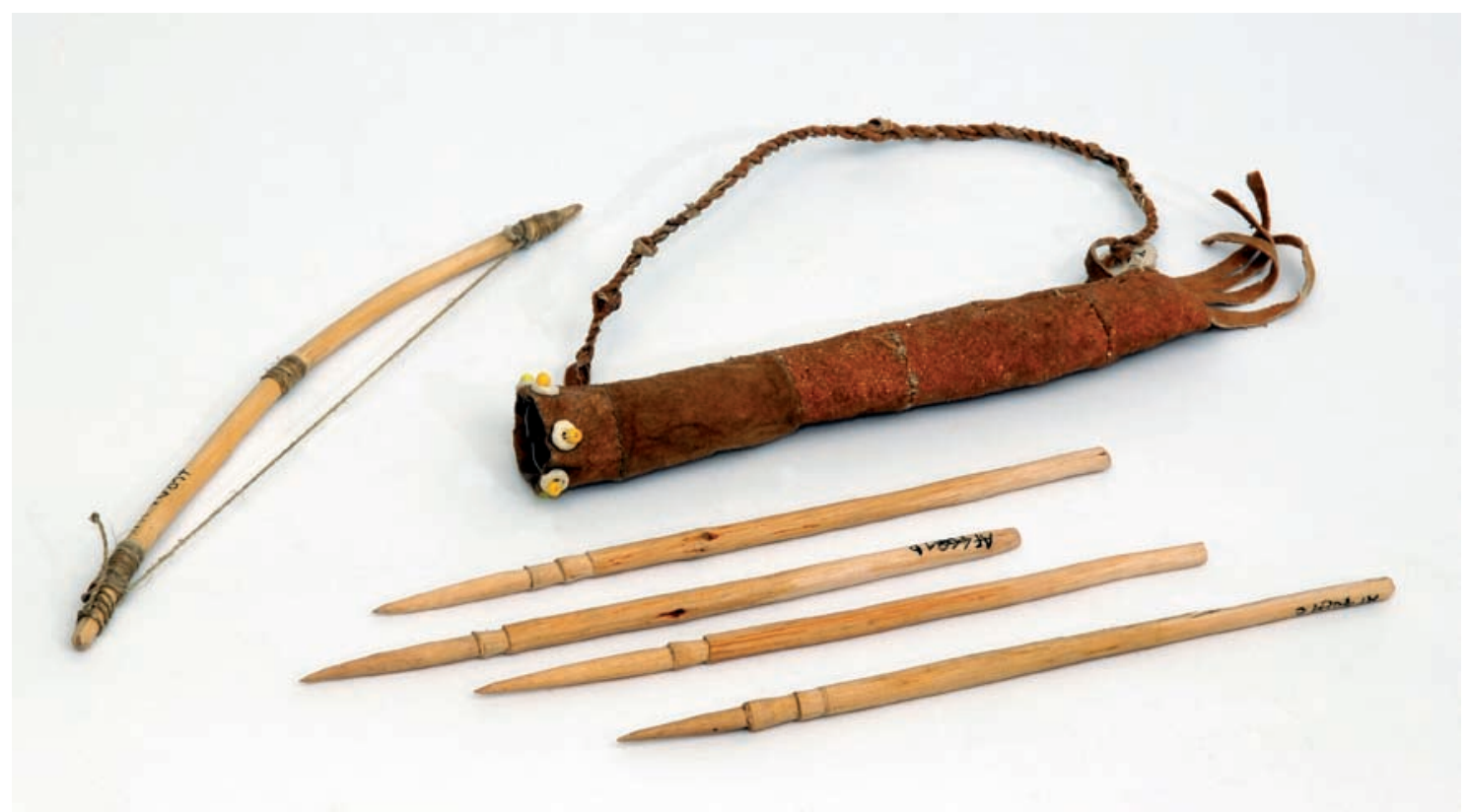

Abbildung 7: Buschmannrevolver 
nirhändlerin in Botswana erworben. Der Name „Buschmannrevolver" könnte sich auf das GröBenverhältnis beziehen. Im Vergleich zu einem normalen Jagdbogen, hat der Buschmannrevolver ein ähnliches Verhältnis wie ein Gewehr zu einem Revolver.

Es kursiert der Mythos, die Buschmänner würden den Buschmannrevolver als Attentatswaffe verwenden (Nippold 1957:175ff.; Hirschberg 1975:394ff.). Dazu würden die Pfeile vergiftet und der Bogen unter der Kleidung versteckt. Dies entspricht wohl nicht ganz der Wahrheit, denn der Bogen ist nicht stark genug, um die winzigen Pfeile zu einer physischen Bedrohung zu machen. Erstens hat der Bogen nur eine sehr geringe Reichweite von einigen Metern und zweitens können die Pfeile die Haut nicht durchdringen, womit das Gift unbrauchbar wäre. Vielmehr geht es dabei um die Vorstellung, dass sowohl rituelle Spezialisten als auch übernatürliche Wesen auf einen Menschen die Fähigkeit, andere zu heilen, aber auch Krankheiten übertragen können, indem sie auf diesen spirituelle Pfeile abschießen (Forkl 1997:54).

Der eigentliche Zweck des Bogens ist aber ein Liebeszauber. Es ist nicht klar, ob nur Männer Frauen verzaubern oder auch umgekehrt. Der oder die Angebetete wird bei dem Zauber mit einem Pfeil beschossen, während eine Zauberformel aufgesagt wird. Wenn der Pfeil von dem oder der Auserwählten aufgenommen wird, ist der Zauber geglückt und eine Liebebeziehung arrangiert. Wird der Pfeil von dem Beschossenen zerbrochen, ist der Zauber missglückt.

Es ist anzunehmen, dass früher Medizinmänner für die Herstellung verantwortlich waren, um dem Artefakt die nötige Magie und Macht einzuhauchen. Heutzutage wird der Buschmannrevolver als Touristensouvenir verkauft und die Produktion ist nicht mehr in Händen von Spezialisten.

\section{Literatur}

\section{Forkl, Hermann}

1997 Heil- und Körperkunst in Afrika. Katalog der gleichnamigen Ausstellung. Stuttgart: LindenMuseum.

\section{Nippold, Walter}

1957 Der Buschmann-Revolver als Zaubergerät und die Buschmann-Revolver der Göttinger Ethnographischen Sammlung. In: Göttinger völkerkundliche Studien Bd. II. S. 169-183.

\section{Hirschberg, Walter}

1975 Khoisan: Sprechende Völker Südafrikas. In: Hermann, Baumann Die Völker Afrikas und Ihre Traditionellen Kulturellen Teil 1. Allgemeiner Teil und südliches Afrika. Wiesbaden: Franz Steiner. S. 383-408. 
Gesichtsmasken der Makonde -

Abbilder eines Schönheitsideals

\section{Tina Krüger}

\section{Geschichte}

Die Makonde leben im Nordosten von Mosambik und im Südosten von Tansania. Verwandtschaftsbeziehungen werden bei den Makonde über die Mutter weitergegeben. Ehepaare beziehen nach der Heirat ihren Wohnsitz im Herkunftsort der Frau.

Angehörige der Makonde werden zu den bekanntesten Künstlern Ostafrikas gezählt (Gabriel 2002). Ihre wichtigsten Werke sind die handgeschnitzten Holzmasken. Ursprünglich wurde nur helles, frisches Holz (njala oder mtene) benutzt. Erst mit dem Aufkommen der Auftragskunst für Europäer zu Anfang des 21. Jahrhunderts begannen die Künstler schwereres und dunkleres Holz zu verwenden (Jahn 1994:433). Im Gegensatz zu anderen Ethnien Ostafrikas wird den Makonde ein für diese Region untypisch scheinendes Feingefühl für Kunst und Ästhetik nachgesagt. Thre Masken sind oft mit Schmucknarbenaufsätzen oder Echthaarschmuck verziert. Die Oberflächen werden geschliffen und bearbeitet, teilweise mit Farben bemalt (Gabriel 2002:25ff.). Nur wenige autorisierte Personen durften die Masken herstellen. Das Wissen um diese Kunst wurde dabei innerhalb der Familie weitergegeben. Maskenschnitzen war ein prestigebesetztes Amt, das die Künstler freiwillig neben ihrer Subsistenzwirtschaft auf den Feldern betrieben. Obwohl sich unterschiedliche Stile unterscheiden lassen, die auf eine Vielzahl an Künstlern hinweisen, sind fast alle von ihnen anonym geblieben. Heute gibt es neben den lang tradierten Kunstformen eine große Bandbreite an Airport-Art, die den Makonde-Stil imitiert und die lokalen Kunstmärkte fast inflationär mit dieser Art Masken übersät.

\section{Was die Masken ausmacht}

Einer Legende nach, schnitzte sich der erste Mann eine weibliche Holzfigur, die über Nacht zum Leben erwachte. Zusammen bekamen sie viele Kinder. Diese Frau wird als Urahnin der Makonde gesehen (David 2007:57).

Man unterscheidet generell zwischen zwei Maskentypen: Aufsatzmasken und Gesichtsmasken. Den in Mosambik lebenden Makonde wird dabei eher die Herstellung der plastischen Aufsatzmasken, auch mapiko zugeschrieben. Diese Art von Maske ist dreidimensional, der menschlichen Kopfform nachempfunden und wird dem jeweiligen Träger über den Kopf gestülpt, wobei sie diesen komplett umschließt. Die Mapiko-Masken stellen diverse Charaktere, Tiere und Teufelsimpressionen dar. Die in Tansania lebenden Makonde werden eher mit den Gesichtsmasken assoziiert. Auch hier finden sich unterschiedliche Portraits und Tierfiguren. Die Gesichtsmasken haben im Unterschied zu den Mapiko-Masken eine halbrunde Form und werden von vorne auf das Gesicht des Trägers gesetzt und mit Bändern oder ähnlichem fixiert. Neben den Masken stellen die Makonde auch geschnitzte Brustplatten her (David 2007:57). Bei dem Groß- 
teil aller Masken und Brustplatten handelt es sich um die Darstellung weiblicher Figuren. Sie zeigen viele Charakteristika der Makonde-Körperkunst. Beide Maskentypen wurden oft mit Echthaar und Körpertatuierungen verziert (Gabriel 2002:31). Besonders Schmucknarben und Lippenpflöcke sind in diesem Zusammenhang von Bedeutung, da sie charakteristische Schönheitsmerkmale in der Makonde-Tradition sind. Die Schmucknarben werden oft aus Wachs aufgetragen und modelliert, so dass sie sehr plastisch auf den Masken zu sehen sind (Jahn 1994:437).

\section{Schmucknarben}

Die Herkunft, der auf den Masken zu sehenden Schmucknarben, liegt wahrscheinlich in der Zeit des Sklavenhandels. Durch Aufritzen des Körpers unter Zugabe von Asche entstanden gewölbte Narben auf der Haut. Damit sollten die Makonde-Frauen verunstaltet werden, um sie vor dem Raub durch Sklavenhändler zu bewahren (Younge 2008:10). Mittlerweile haben sich eben diese Narben in der Makonde-Kultur etabliert und gelten als ein wichtiges Schönheitssymbol (Af2050 und Af2051). Die Narben werden sehr künstlerisch gestaltet und tragen je nach Muster verschiedene Bedeutungen. Eine Frau ohne Schmucknarben auf ihrem Körper wird oft nicht als schön empfunden.

Die Unterschiede im Schönheitsverständnis der verschiedenen Ethnien Mosambiks ist ein aktuelles Thema. Es wurde zum Beispiel in einem Roman von der Schriftstellerin Paulina Chiziane behandelt. Der Roman „Niketche“ erzählt die Geschichte ei- ner polygamen Lebensgemeinschaft, in der jede der fünf Frauen aus einer anderen Region Mosambiks stammt und somit im Roman Stellvertreterin für die Bräuche der jeweiligen Region ist.

Der folgende Auszug beschreibt eine Situation, in der die Protagonistin Rami eine traditionelle Liebesratgeberin aus dem Norden aufsucht:

„Wir haben uns einen Moment mit der Analyse gegensätzlicher Ansichten beschäftigt. In der Kultur des Südens heißt es, dass eine glatte Haut unter den Händen weggleitet wie ein Fisch. Die Männer mögen das nicht. Nicht obne Grund haben die Frauen der alten Generation dicke Tätowierungen auf den Hüften, auf dem Bauch, auf der Brust und im Gesicht um die Haut uneben und begehrenswert zu machen. Wir kamen auf einen Konsens: auch die Sinnlichkeit ist kulturell unterschiedlich".

(Chiziane 2010:44f, Übersetzung: Tina Krüger).

\section{Verwendung der Masken}

Den Masken wird eine magisch-religiöse Funktion zugeschrieben. Sie stellen die Möglichkeit dar, eine Verbindung zwischen dem Diesseits und den Ahnen herzustellen. Dazu werden sie während der Initiationsriten von Jungen und Mädchen benutzt. Während dieser Zeremonien fungieren sie als Tanzmasken. Die Masken werden den Tänzern mit Stoffen vorgebunden, so dass ihr Gesicht nicht zu erkennen ist (Jahn 1994:440).

Auch das Thema der Initiationsriten findet sich in dem Roman Niketche wieder. Dieser Auszug spielt in derselben Situation wie der vorige und macht deutlich, welche große Bedeutung die Initiations- 
riten für das Stiften von Liebe, Sex und Ehe haben: „Rami: Was lernt ihr also bei diesen Riten, dass ibr euch mehr wie Frauen fühlt als wir?

Ratgeberin: Viele Dinge: von der Liebe, der Verführung, der Mutterschaft, der Gesellschaft. Wir lehren die wichtigsten Regeln für ein gutes Zusammenleben. Wie willst du in deiner Ehe glücklich sein, wenn du die grundlegendsten Lektionen über Liebe und Sex nie bekommen hast? Bei der Initiation lernst du deine innersten Geheimnisse und Schätze kennen. (...) Die Initiationsriten bilden dich für das Leben aus und lehren dich zu lächeln. Du lernst die Anatomie und alle Gestirne kennen, die in dir kreisen. Du lernst den Rhythmus der Herzen kennen, die in dir schlagen.

Rami: Das Herz ist nur eins.

Ratgeberin: Die Frau hat zwei. Ein überlegenes und ein unterlegenes. Manchmal sogar drei, wenn sie ein Kind in sich trägt.

Rami: So wichtig sind diese Riten?

Ratgeberin: Obne sie bist du so leicht und unbeständig wie der Wind".

(Chiziane 2010:38f, Übersetzung: Tina Krüger).

Ausschließlich Männer dürfen bei den Zeremonien mit den Masken tanzen. Die Tänze sind kraftvoll und teilweise erschreckend. Es wird auch der Geschlechtsakt zwischen Mann und Frau tänzerisch dargestellt.

In Anbetracht der matrilinearen Gesellschaftsordnung mit Wohnsitz im Herkunftsort der Frau und des mythischen Symbolcharakters der Frau an sich, basierend auf dem Entstehungsmythos der Ethnie, kann die Exklusion der Frau als Maskentänzerin eventuell als Versuch gedeutet werden, den Män- nern der Makonde einen höheren Stellenwert und eine furchterregende Aura durch die energiegeladenen Tänze zu verleihen (ebd.).

\section{Briefmarken}

Neben Kunstmärkten und Auktionen finden sich die Makonde-Masken sogar in Deutschland in einem ganz alltäglichen Bereich des Lebens wieder. So wurde im Jahr 1994 zum 125jährigen Bestehen des Museums für Völkerkunde zu Leipzig eine Briefmarke der Deutschen Post mit dem Abbild einer im Museum vorhandenen Makonde-Maske versehen.

Auch in Mosambik gab es bereits im Jahr 1981 eine Briefmarken-Edition, die die einheimische Wertschätzung des Kunsthandwerk der Makonde in ihren Facetten widerspiegeln sollte und eine der typischen Mapiko-Aufsatzmasken zeigt, die im Zusammenhang mit den Initiationsriten und den dabei kommunizierten Schönheitsidealen wie auch auf die Ehe vorbereitenden Regelwerken steht. 


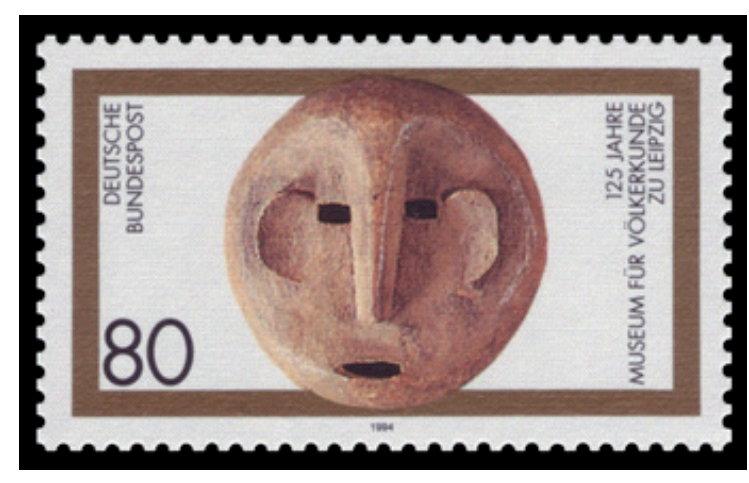

Abbildung 8: Briefmarke Deutsche Bundespost, herausgegeben 1994.

Siehe auch Maske in der Ausstellung Af2052.

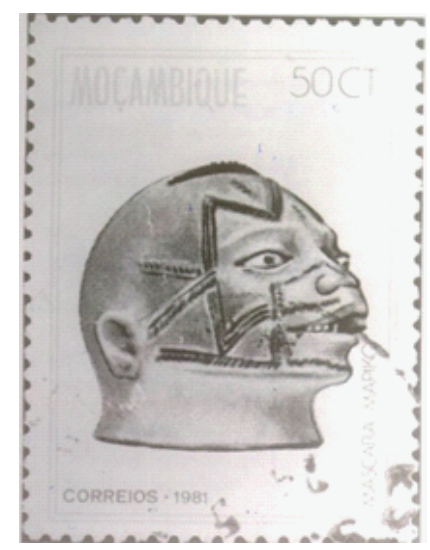

Abbildung 9: Briefmarke aus Mosambik 1981

\section{Literatur}

\section{Chiziane, Paulina}

2008 Niketche: Uma historia de poligamia. Lisboa: Caminho.

\section{David, Jean}

2007 Tribal Art. Auktionskatalog. [Elektronisches Dokument] www.kollerauktionen.ch/shared/pdf/.../Kataloge/ Afrika7_low.pdf

[19.01.2012] Zürich: Galerie Walu.

\section{Gabriel, Alexandra}

2002 Zeitgenössische Malerei in Kenia unter besonderer Berücksichtigung der Künstler Joel Oswaggo, Meek Gichugu und Chain Muhandi. [Elektronisches Dokument] http://www.freidok.uni-freiburg.de/volltexte/339/ [19.01.2012] Freiburg: Albert-Ludwigs-Universität Freiburg.

2002 Bildkatalog I (I-V). Bildkatalog zum Kontext (Abb. 1-65). [Elektronisches Dokument] http://www.freidok.uni-freiburg.de/volltexte/339/ Freiburg: Albert-Ludwigs-Universität Freiburg. [19.01.2012]

Jahn, Jens (Hrsg.)

1994 Tanzania. Meisterwerke afrikanischer Skulptur. Sanaa za mabingwa wa Kiafrika. Berlin: Haus der Kulturen der Welt. 
Mobl, Max

1997 Meisterwerke der Makonde - Ebenholzskulpturen aus Ostafrika, eine Bilddokumentation. Heidelberg: Mohl.

1995 Meisterwerke der Makonde - Ebenholzskulpturen aus Ostafrika, eine Bilddokumentation (Ergänzung zu Band I). Heidelberg: Mohl.

1977 Meisterwerke der Makonde - eine ostafrikanische Dokumentation. Heidelberg: Mohl.

\section{Miranda, Maria Geralda de}

2010 Niketche: Uma História de rupturas, ou o feminine em constant desafio. In: e-scrita. Revista do curso de Letras da Uniabeu. [Elektronisches Dokument] http://www.uniabeu.edu.br/publica/ index.php/RE/article/view/49/pdf_32 Angra dos Reis: Uniabeu.

\section{Müller, Wolfgang}

2005 Körperveränderung. Hirschberg, Walter (Hrsg.): Wörterbuch der Völkerkunde. Berlin: Reimer. S. 210.

2005 Schmuck. In: Hirschberg, Walter (Hrsg.): Wörterbuch der Völkerkunde. Berlin: Reimer. S. 332 .

Müller, Wolfgang und Dietrich Scbleip 2005 Tatauieren, Tätowieren. Hirschberg, Walter (Hrsg.): Wörterbuch der Völkerkunde. Berlin: Reimer. S. 368.

\section{Younge, Gavin}

2008 Making ugly/preserving self: Makonde and the Cape slave trade. Paper presented at the 24th Annual Conference of the South African Association of Visual Arts Historians, Universiteit van Stellenbosch. [Elektronisches Dokument] http://uct.academia.edu/GavinYounge/Papers/1000125/Making_ugly_preserving_self_ Makonde_and_the_Cape_slave_trade [Stand 19.01.2012] Cape Town: University of Cape Town. 
Vom Zauber afrikanischer

Fruchtbarkeitspuppen

\section{Wieblee Schaper}

Puppen - hierzulande sind sie als Kinderspielzeug oder als kostbare Sammlerstücke bekannt. Doch auch in anderen Kulturen gibt es sie, und dort geht ihre Funktion weit über die eines Spielzeugs hinaus.

Ihr Aussehen unterscheidet sich deutlich von den bei uns verbreiteten Puppen. Statt der relativ lebensnahen Darstellung als Babys oder Kleinkinder, sind die für die Ausstellung ausgewählten afrikanischen Puppen (Af2064, Af3245, Af3495, Af3501, Af3831, Af4239, Af4682) in der Regel deutlich abstrakter. Oft lässt sich nicht auf den ersten Blick erkennen, dass sie menschliche Wesen verkörpern sollen. Meistens sind sie aus Holz gefertigt und teilweise reichhaltig mit Glasperlen, Straußeneiplättchen, Leder und anderen Naturmaterialien verziert. Die Puppen werden fast immer von Spezialisten mit großer Kunstfertigkeit in langer Arbeitszeit hergestellt (Hoffmann 1995:81; Paul 1970:139). Dadurch ist jede der Puppen ein außergewöhnliches Einzelstück. Zudem sind sie häufig nicht als Spielzeug für Kinder gedacht. Sie haben die Bedeutung und Funktion als Kultgegenstände und sollen bei Frauen für Fruchtbarkeit und gesunde Kinder sorgen. Obwohl die Puppen in vielen Regionen und Völkern Afrikas die Gebärfähigkeit anregen sollen, unterscheiden sie sich doch sehr in ihrer Gestaltung und tatsächlichen Anwendung (Stelzig 2001:2).
Jungen Frauen dienen sie oft als Wegbereiter für Heirat, Empfängnis und Geburt (Eisenhofer und Wolf 2010:90).

\section{Das „hölzerne Kind“ der Saramo}

Bei den Saramo, die im tansanischen Hinterland leben, gibt es eine Fruchtbarkeitspuppe mit dem Namen mwana ya kiti, was ,,hölzernes Kind“ bedeutet (Hoffmann 1995:81). Die Mädchen der Saramo nutzen die Puppe auch als Mittel zur Steigerung ihrer Schönheit (Stelzig 2001:2). Die mwana ya kiti ist zylinderförmig und wird aus einem einzelnen Stück Holz herausgearbeitet. Sie hat nur angedeutete Arme, keine Beine und ein menschliches Gesicht lässt sich nur erahnen. Auf dem Kopf befinden sich zwei Bögen, die v-förmig auseinandergehen. Diese dienen zur Befestigung von Haaren, die in mühevoller Kleinarbeit in die Löcher in den Bögen eingearbeitet werden. Letztendlich entsteht daraus eine aus Haarwülsten zusammengesetzte Bubikopf-Frisur (Hoffmann 1995:81), bei der die einzelnen Haarstränge jeweils mit Lehm oder Glasperlen abgeschlossen werden (Paul 1970:30). Auf dem Rumpf der Puppe befinden sich außerdem zwei deutliche Hervorhebungen im Brustbereich und eine Hervorhebung knapp oberhalb des Sockels. Es wird davon ausgegangen, dass die Erhebungen im Brustbereich einen Busen andeuten sollen, wohingegen bei der unteren Erhebung Unklarheit herrscht. Entweder handelt es sich hierbei um einen Penis, wodurch in Kombination mit den anderen Erhebungen beide Geschlechter auf einmal gezeigt werden, oder es handelt sich um den 
hervorstehenden Bauchnabel eines Neugeborenen (Paul 1970:30). Die Herstellung einer mwana ya kiti geschieht ausschließlich durch handwerklich geschickte Männer, obwohl sie nur von Frauen gebraucht wird. Eine mwana ya kiti wird einem Mädchen nach der ersten Regelblutung von einer Lehrmeisterin übergeben. Das Mädchen muss daraufhin das Dorf verlassen und lebt für längere Zeit alleine an einem abgeschiedenen Ort (Hoffmann 1995:82). In dieser Zeit muss sie sich intensiv um ihre Puppe kümmern und sie hegen und pflegen als wäre es ihr eigenes Kind. Wenn dieser Zeitraum vorüber ist, wird ein großes Fest für das Mädchen arrangiert. Dort darf sie das erste und einzige $\mathrm{Mal}$ die Puppe der Öffentlichkeit zeigen. An das Fest schließt sich häufig noch die Vermählung des Mädchens an (Paul 1970:31ff.).

\section{Von der Puppe zum Baby:}

Die Akua'ba der Akan und Ashanti

Anders als bei den Saramo ist die Fruchtbarkeitspuppe bei den Akan und Ashanti in Ghana eher für ältere, bereits verheiratete Frauen gedacht, die noch immer kinderlos sind. Denn dies stellt für die Frauen der Akan und Ashanti einen großen Mangel dar. Sie gelten als unvollkommen und vom Unglück verfolgt, weshalb sie eine niedere Stellung in der Gesellschaft einnehmen. Bleibt also die Schwangerschaft trotz mehrerer Versuche aus, so geht eine Frau mit einer Puppe zu einem Heiler oder Wahrsager. Dieser belegt die Puppe mit einem Fruchtbarkeitszauber, der sich auf die Frau überträgt und ihr zur Schwangerschaft verhelfen soll (Stelzig 2001:2ff.). Damit der Zauber seine Wirkung entfalten kann, soll sie die Puppe in einem Tuch auf dem Rücken wie ein richtiges Kind bei sich tragen (Benzing 1970:74). Außerdem muss die Puppe auch wie ein eigener Sprössling umsorgt, gefüttert und gebadet werden und bekommt einen Namen. Dieses Verhalten endet jedoch nicht mit einer geglückten Schwangerschaft, sondern erst dann, wenn ihr Kind auf die Welt gekommen ist (Stelzig 2001:2ff.). Auf diese Weise soll garantiert werden, dass der Nachwuchs gesund und schön wird. Genannt werden diese Puppen Akua'ba, was „Akuas Kind" heißt. Dies deutet auf die Entstehungsgeschichte dieser Art von Fruchtbarkeitspuppe hin (Ross 1996:43ff.): Eine Frau namens Akua wünschte sich vergeblich seit längerer Zeit ein Kind. In ihrer Not wandte sie sich an einen Heiler, der ihr sagte, dass sie sich eine hölzerne Puppe anfertigen lassen und diese immer bei sich tragen solle. Dies tat Akua auch und kümmerte sich um die Puppe wie um ein echtes Neugeborenes. Die anderen Frauen des Dorfes jedoch verspotteten sie deshalb - so lange, bis sie tatsächlich ein gesundes, schönes Kind bekam. Dann taten es ihr plötzlich viele kinderlose Frauen nach, um auch schwanger zu werden und gesunde schöne Kinder zu bekommen (Forkl 1997:93). Die Akua'ba der Akan und Ashanti verfügt über einen zylindrisch-ovalen Holzkörper, auf dem ein Nabel und weibliche Brüste zu sehen sind. Der Hals der Puppe besteht aus nach oben hin schmaler werdenden ringartigen Einkerbungen. Der Kopf ist scheibenartig (flach und rund), einzig im unteren Bereich der Scheibe sind eckige Ausbuchtungen, zusätzlich ist die Scheibe am Rand 
mit Ornamenten verziert. Das Gesicht der Puppe wird durch ausladende, geschwungene Augenbrauen, aus denen zugleich die Nase hervorgeht, betont. Da es sich im unteren Drittel des Kopfes befindet, entsteht der Eindruck einer hohen Stirn. Das so geformte Gesicht und auch der ringartige Hals weisen auf die Schönheitsideale der Akan und Ashanti hin (Benzing: 1970:75).

\section{Die Puppe der Herero: \\ Erst Kinderspielzeug, dann Kultgegenstand}

Anders als bei den zuvor genannten Gegenständen ist die Puppe der namibischen Herero nicht nur für die Herbeiführung einer Schwangerschaft gedacht. Sie können sowohl Spielzeug als auch Kultobjekt sein. Ferner wird sie nicht von Experten hergestellt, sondern von den Puppenbesitzerinnen selbst oder deren Vätern. Das für die Ausstellung ausgewählte Objekt (Af3245) ist hantelförmig gestaltet: Sie besteht aus einem Stab, an dessen Enden sich jeweils eine Kugel befindet. Die obere Kugel stellt hierbei den Kopf dar, der Stab und die untere Kugel bilden den Rumpf. Arme und Beine werden durch Perlenschnüre angedeutet. Zudem ist ihr Körper reichhaltig mit Perlenschnüren, Leder, Pelz, Knochen und Straußeneiplättchen verziert. Durch die Vielzahl der Materialien und Farben unterscheidet sich die Herero-Puppe auch in ihrer Gestaltung von den zuvor genannten Holzpuppen. Die Puppe nimmt eine Begleiter-Rolle im Leben eines HereroMädchens ein: Da das Mädchen die Puppe häufig selbst herstellt und die somit stattgefundene, Geburt $^{`}$ des ,Puppenkindes ${ }^{`}$ zum Teil sogar mit einem eigenen Fest gefeiert wird, findet bereits im frühen Alter auf spielerische Art eine Identifikation mit der Mutterrolle statt (Stelzig 2001:2). Später, in der Pubertät des Mädchens, symbolisiert die Puppe die Bereitschaft, nun die Ehe einzugehen und Mutter zu werden; sogar junge Männer fangen in dieser Zeit an, solch eine Puppe als Zeichen der Ehebereitschaft mit sich zu tragen. Nach der EheschlieBung übernimmt die Puppe dann die Funktion eines Fruchtbarkeitsbringers und soll darüber hinaus dafür sorgen, dass das Kind gesund und schön auf die Welt kommt oder sie sogar Zwillinge gebärt. Aber auch nach der Geburt des Kindes hat die Puppe keineswegs ausgedient. Sie wird wie ein Zwilling des Neugeborenen betrachtet und bildet eine Art Zweites Ich des Kindes, weshalb sie wie das eigene Kind behandelt und immer mitgetragen wird. Wird die Puppe beispielsweise beschädigt, so droht auch dem Kind Unheil. Die Puppe ist aber nicht nur ein bedeutender Teil des Lebens der Besitzerin, sondern sie dient darüber hinaus als Herberge für die Seelen bereits verstorbener Vorfahren. Wenn die Besitzerin nachlässig mit der Puppe umgeht, zeigt sie damit geringschätziges Verhalten gegenüber ihren Ahnen und zieht so deren unheilbringenden Zorn auf sich, der zu Unglück und Krankheiten führt (Stelzig 2001:3). 


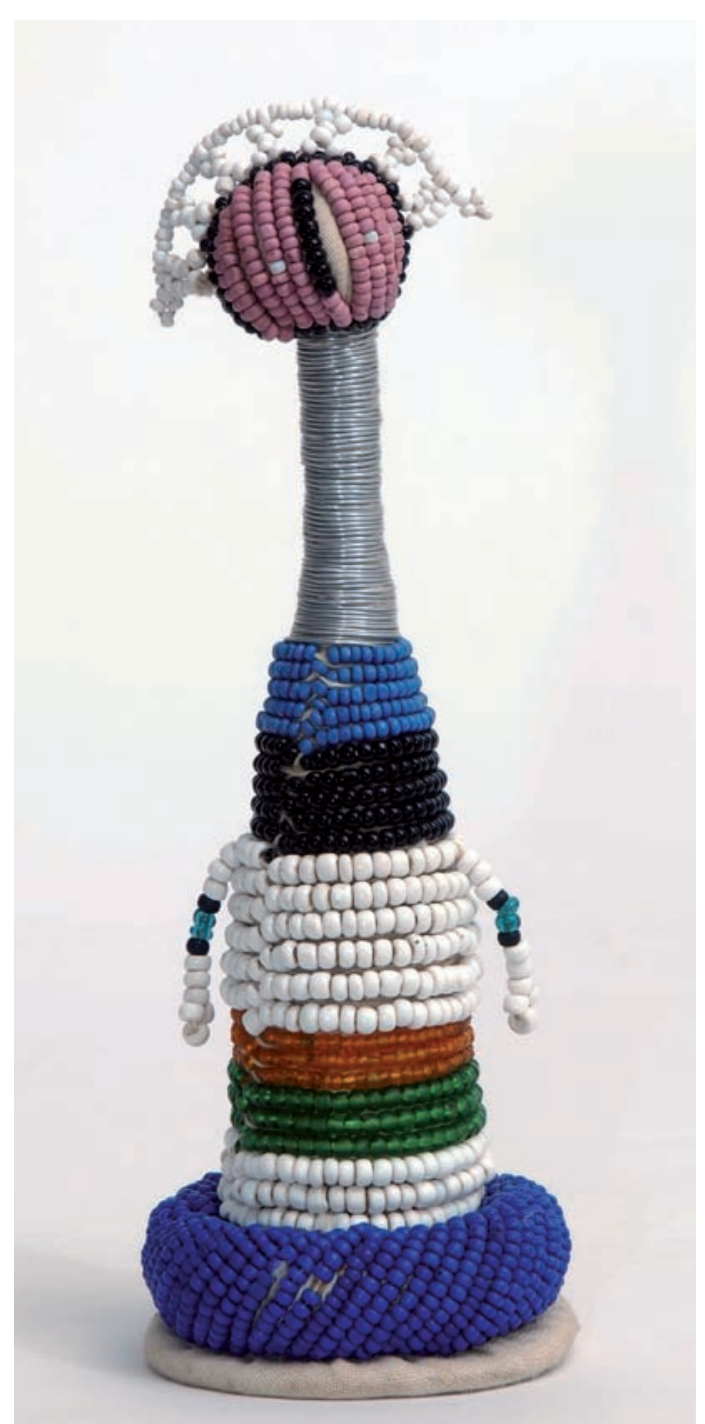

Abbildung 10: Fruchtbarkeitspuppe

\section{Zusammenfassung: Die Aufgaben der Puppen}

Die in der Ausstellung vorgestellten Puppen spielen mithin eine bedeutende Rolle in der Vermittlung von Weiblichkeit und Mütterlichkeit, da Mädchen und Frauen an ihnen und mit ihnen die Aufgaben der Säuglings- und Kinderpflege üben. Darüber hinaus können die gezeigten Puppen aber auch die Aufgabe eines Fruchtbarkeitsbringers einnehmen und zusätzlich auch ein Hilfsmittel für eine sichere Geburt gesunder und schöner Kinder sein. Zudem können sie als, Wohnstätte' für die Seelen verstorbener Vorfahren dienen. Die Puppen werden demnach nicht als (reine) Kinderspielzeuge gesehen, sondern nehmen einen wichtigen Platz in der Gesellschaft ein. Auch wenn in hiesigen Kulturen einige Puppenarten, beispielsweise solche aus Porzellan, nicht als Kinderspielzeuge gedacht sind, sondern kostbare Statussymbole sind, so lässt sich ihre Funktion nicht mit den hier beschriebenen Puppen vergleichen. Schließlich kann das gesamte Wohlergehen der Puppenbesitzerin direkt von ihrer Puppe abhängen. 


\section{Literatur}

\section{Benzing, Brigitta}

1970 Die Fruchtbarkeitspuppe der Ashanti im National Museum in Accra, Ghana. In: Tribus: Jahrbuch des Linden-Museums: Stuttgart: LindenMuseum, Gesellschaft für Erd- und Völkerkunde Stuttgart e.V., Band 19. S. 71-78.

\section{Eisenhofer, Stefan und Norbert Wolf (Hrsg.)}

2010 Afrikanische Kunst. Köln: Taschen. S. 90.

\section{Forkl, Hermann}

1997 Heil- und Körperkunst in Afrika. Katalog der gleichnamigen Ausstellung. Stuttgart: LindenMuseum Stuttgart.

\section{Germann, Paul}

1929 Die Afrikanische Kunst. In: Glaser, Curt et. al. Die außereuropäische Kunst. Leipzig: Kröner.

\section{Hoffmann, Doris}

1995 Afrikanische Holzpuppen: Zwei Beispiele aus Namibia und Tansania aus: Eschwege: Dollami. Faszinierende Puppenwelt. 2. Jg. Nr.1/1995.

\section{Paul, Sigrid}

1970 Afrikanische Puppen. Baessler-Archiv Beiträge zur Völkerkunde. Herausgegeben im Auftrage des Museums für Völkerkunde Berlin. Reimer.
Ross, Doran H.

1996 Akua's Child and other Relatives: New Mythologies for old Dolls. In: Isn't s/he a Doll? Play and Ritual in African Sculpture. Cameron, Elisabeth Lynn (Hrsg.). Los Angeles: UCLA Fowler Museum of Cultural History.

\section{Stelzig, Christine}

2001 Nicht zum Spielen allein... Afrikanische Puppen aus der Sammlung W. und U. Horstmann. Lübeck: Herausgegeben von der Völkerkundesammlung. 
Bitetelelo-Lieder und Bongo-Flava -

Von Liebe in der Musik

\section{Eva Wenzel}

Bei dem für die Ausstellung ausgesuchten Objekt handelt es sich um einen Schurz aus schwarzen, etwa $15 \mathrm{~cm}$ langen Grasfasern (Af1381). Grasschurze dieser Art wurden um 1913, als das Objekt erworben wurde, von Mädchen der Haya im heutigen Tansania um die Hüfte getragen, bevor sie heirateten. Solche Gürtel waren als Äußerung der Sittlichkeit und als Zeichen für unverheiratete Mädchen zu verstehen.

Die Bevölkerungsgruppe der Haya besiedelt die Provinz Kagera im nordwestlichen Tansania. Das Territorium liegt am Westufer des Viktoriasees. Im Norden ist es von Uganda und im Westen von Rwanda begrenzt. Die Bevölkerung ist in Klans eingeteilt. Einige dieser Klans sind aristokratisch und stellen damit die Häuptlinge für die verschiedenen kleinen Häuptlingstümer bzw. Königreiche. Die Administration war mit der Kolonisation durch die Deutschen etwa ab 1890 und die Briten ab 1916 immer zentralisierter geworden (Weiss 1996:16; Taylor 1962:138). Eine weitere starke Einflussnahme durch die Kolonialmächte erfolgte mit der Einführung von sogenannten Cash Crops (va. Kaffee und Bananen), die bis heute nicht für den eigenen Verbrauch auf familiärer Ebene, sondern für den Verkauf angebaut werden (Taylor 1962:133f.; Weiss 1996:17). Diese ökonomischen Veränderungen führten zu einer zunehmenden Mobilität der Men- schen und zu einer stärker vermischten Zusammensetzung der Dörfer. Darüber hinaus brachte die Politik Tansanias besonders in den Jahren nach der Unabhängigkeit 1961 eine vermehrte Auflösung der tribalen Strukturen mit sich.

Unabhängig von früher geltenden Regeln des Umgangs der Geschlechter miteinander, wie sie sich von den o.g. Grasschurzen als Zeichen für unverheiratete Mädchen ablesen lassen, gibt es für Liebe und Ehe auch im heutigen Tansania eine reichhaltige Symbolik. Das wird jedem spätestens dann klar, wenn er sich die Musikvideos lokaler Künstler ansieht, die ihre Geliebte anschmachten oder an Liebeskummer leiden. Doch der öffentliche Umgang mit Liebe unterliegt bestimmten Regeln und Grenzen. Diese werden von tansanischen Jugendlichen in Form der Bongo-Flava-Musik umgangen. Insofern bewegt sich die Thematik der arrangierten Liebe im Spannungsfeld zwischen gelebten Traditionen und deren Bruch.

\section{Die Eheschließung der Haya}

Ehen werden exogam geschlossen, das heißt, es wird außerhalb der eigenen Gruppe, hier des Klans des eigenen Vaters und der eigenen Mutter, geheiratet. Das Alter bei der ersten Heirat ist bei Mädchen zwischen 15 und 18 Jahren, während die Männer in den 20ern sind. Dies kann natürlich auch stark variieren. Es werden zumeist eine Grundform der traditionellen Eheschließung busbwere und 6 weitere Formen, die sich davon regional und in Einzelfällen leicht unterscheiden können, ausgemacht. Der Mann oder sein Stellvertreter bittet die Brauteltern 
um deren Einverständnis. Ist dieses erteilt worden, wird durch ein rituelles Geschenk, zumeist eine Ziege, die Verlobung offiziell eingeleitet. Damit wird auch der Prozess des Austausches verschiedener Güter in Gang gesetzt, bei dem besonders der Bräutigam bestimmte Gaben an die Familie der Braut zu leisten hat (vermehrt auch in Form von Geld). Nach einiger Verlobungszeit finden die verschiedenen Zeremonien der Eheschließung statt, an dessen Ende die Braut sich beim Wohnort des Mannes einrichtet.

Neben dieser Form der Eheschließung gab es in der Vergangenheit auch verschiedene andere Praktiken, bei denen diese Autorität der Eltern umgangen wurde. Das Paar kann beispielsweise die Unterstützung des Bruders und der Dorfältesten erbitten, damit diese die Eltern überzeugen. Es kann auch durchbrennen, indem der Mann einem Verwandten der Braut erklärt, dass er sie abholt. Das Mädchen hinterlässt ihrem Vater nur ein Zeichen, dass sie wegläuft, um zu heiraten. Ist sie am Wohnsitz des Mannes angelangt, wird sie von dessen Verwandten rituell gewaschen und der Bräutigam setzt sich so schnell wie möglich mit den Eltern des Mädchens in Verbindung, um einen Brautpreis auszuhandeln. Nach ersten Abweisungen werden sie das irgendwann akzeptieren. Es finden aber keine Hochzeitszeremonien statt (Taylor 1962:134f.).

Für ein Paar gab es also verschiedene Möglichkeiten, sich gegen die Eltern durchzusetzen. Wie stark dabei die Initiative des Mädchens war, ist nicht eindeutig zu ermitteln. Doch scheint sie gröBer zu sein als üblich. Heute hat sich hier selbstverständlich einiges verändert. Zum einen gibt es durch die Mission christliche Eheschließungen, zum anderen führen verschiedene Einflüsse dazu, dass das Brautpaar immer mehr Entscheidungsgewalt hat. Demnach können die Eheschließung, die Motivationen und die Wahl des Ehepartners heute sehr unterschiedlich sein.

\section{„Mann“ und „Frau“ bei den Haya}

Unter den Haya gibt es wie in jeder Gesellschaft Tabus, eine Reihe von Untersagungen und Regeln der Sittlichkeit, die mit Sexualität und der Beziehung zwischen Geschlechtern und unter Familienmitgliedern zusammenhängen. So gilt Sexualität grundsätzlich als eine Sache der Erwachsenen. Dieser Status wird mit der Ehe in Verbindung gebracht. Denn aus der Sicht der Haya sind Mann und Frau nur durch diese vollständig. Die Geschlechter bilden einen Gegensatz, der sich besonders durch die gesellschaftlich definierten Aufgaben und Rollen äußert, formen in der Ehe aber eine notwendige Einheit. Diese Verbindung in der Ehe ist nicht durch eine Hierarchie geprägt. Die Position der Frau im Haushalt ist ebenso bedeutend und einflussreich wie die des Mannes außerhalb des Hauses. Die Geschlechter füllen also zwei gleich bedeutende Bereiche der Gesellschaft und des Familienlebens aus (Mutembei 2001:47f.). Damit wird deutlich, warum sich der Status des Mannes in der Gesellschaft durch seine Heirat verändert. Sein Ansehen wird erhöht, er bekommt eine andere Anrede, kann an Diskussionen unter Erwachsenen teilnehmen und Aufgaben in Gesellschaft und Politik übernehmen. Bei der Frau sieht es ein bisschen anders aus. Auch für sie ist die 
Ehe die Bedingung für ihr Leben als Erwachsene, sie erreicht ihren vollen Status aber erst mit der Geburt ihres ersten Kindes (Mutembei 2001:175).

\section{Sexualität, Ehe und die sexuelle Erziehung}

Themen, die mit Sex und Geschlechterbeziehungen zusammenhängen, unterliegen bestimmten Verboten und Regeln, sodass man nicht offen darüber spricht. In Liedern, Gedichten, Rätseln und Geschichten wird Sexualität bildlich und durch Anspielungen behandelt (Mutembei 2001:51f.). Auf die Art wird Wissen über das entsprechende Verhalten in der Gesellschaft, der Familie und der Ehe auch den jüngeren Mitgliedern der Gesellschaft durch orale Tradition vermittelt. Auch diese Form der Wissensweitergabe ist stark institutionell eingebunden. Es gibt Richtlinien und Regeln, die sich z.B. an dem Alter, dem Geschlecht, der Situation, wer anwesend ist und in welchem Lebensabschnitt sich die jeweiligen Personen befinden, orientieren (Mutembei 2001:80).

\section{omugole kuhanwa-}

\section{Die Ermahnungen der Braut}

Diese Art der Wissensvermittlung wird unmittelbar vor der Hochzeit und während der Hochzeitszeremonien durchgeführt. Einen wesentlichen Beitrag zur sexuellen Aufklärung der Braut leisten Lieder und Gedichte in den verschiedenen Phasen der Heiratszeremonien, durch die sie auf ihre Rolle als Ehefrau und Mutter vorbereitet werden soll. Diese Ermahnungen der Braut omugole kuhanwa begin- nen während der Feier zu ihrer Verabschiedung am Abend vor der Hochzeit. Die Braut wird von ihren älteren weiblichen Familienmitgliedern in die Bananenfelder geführt, die in einem traditionellen HayaDorf jedes Haus umringen. Dort sind sie ungestört und vermitteln der jungen Frau Wissen, das sich besonders mit den neuen Aufgaben und der neuen Position beschäftigt.

Am frühen Morgen ihres Hochzeitstages wird die Braut ein letztes Mal im Haus ihres Vaters gewaschen und die Gruppe des Bräutigams kommt, um sie abzuholen. Ein wichtiger Teil der Zeremonie ist der Brauch des okumwiha ababibelo („Heben der Braut vom Schoß“). Dabei nehmen Vater und Mutter die Braut jeweils auf ihren Schoß und geben ihr noch einmal Ratschläge. Schließlich legt der Vater die Hand seiner Tochter in die des Bräutigams oder seines Stellvertreters und übergibt sie damit ihrer neuen Familie (Mutembei 2001:80f.; Cory and Hartnoll 1945:142f.).

„obushwele bulimwa, tibukomwa nka nkwi“: „Ehe muss gepflegt werden, sie kann nicht gesammelt werden wie Feuerholz.“

Auch auf der folgenden Prozession zum Haus ihres zukünftigen Mannes wird die Braut von sogenannten Bitetelelo-Liedern begleitet. Diese Hochzeitslieder, die oft wie ein Dialog zwischen zwei Parteien aufgebaut sind, werden von den Frauen und Mädchen, die die Prozession bilden, gesungen und drehen sich um Ehe und die Aufgaben einer Ehefrau (Mutembei 2001:79). 
Ein Beispiel für ein solches Lied ist der Text „Obushwele bulimwa“:

Ija mawe bakutole

Ija nyoko yakwiha ababibelo

Ija wakula wachuka

Ija nkuchwel" ekizina.

Mara okunde obulile nyakusinga

Obulile otaliba mbifamuki:

Omukazi nkahiga obushwele

bwayanga

Ebyaro byona nkabigenda

byabulanshai

[...]

Kanagobile Kimwani omwa

Nkorwankorwa, Omushaija Bagachwa

yayemayo: Ati $[\ldots]$

mbwenu mawe ogye

obige ekitula

Kolakibona oteke amajwi

obenentule

Noija kugwamu entongo kyalemil"

abasholomi.

Oshale ojwale notongeza oti:

„obushwele bulimwa, tibukomwa nka

nkwi"

[...] (Mutembei 2001:230f.)

Los, komm Frau, sodass sie dich halten. Komm, deine Mutter hat dich von ibrem Schoß gehoben. Komm, du bist genug gewachsen, um eine Erwachsene zu sein. Komm, ich erzäble dir eine Geschichte.

Und denke darüber nach und akzeptiere, bitte hör zu, sei kein Mensch vom Typ „Mich kümmern nicht die Konsequenzen". Frau, ich suchte nach Ehe, aber es war schwierig, zu heiraten. Ich ging zu allen Dörfern, aber obne Erfolg.

[...]

Als ich Kimwani in Nkorwankorwa erreichte, rief ein Mann, Bagachwa, nach mir und sagte: , [...]

Jetzt, Frau, geh und suche nach einem Auberginenbaum, wenn du einen siebst, knie nieder und suche. Du wirst eine Aubergine finden, die dem Schnitter (Bauern bei der Erntel Tod) trotzte. Heb sie auf und trage sie, indem du sagst: „Ehe muss kultiviert (gepflegt) werden, sie kann nicht gebündelt/gesammelt werden wie Feuerhol: "

$[\ldots]$

In dem Lied richtet sich eine ältere Frau an die Braut und erzählt ihr eine Geschichte über die Ehe wie auch auf die Bedeutung der Bräuche. Dieser Beginn dient vor allem dazu, die Autorität der älteren Generation und der Gesellschaft zu bestätigen, sowie dazu, die große Bedeutung der Traditionen und das Einhalten der Hochzeitsbräuche hervorzuheben. Damit wird bereits auf die wesentliche Aussage des Liedes verwiesen:

In der Geschichte wandert eine Frau durch die Welt, um eine Ehe zu schließen. Doch da sie nicht den Vorstellungen der Gesellschaft und Sitten gefolgt ist, konnte sie kein angemessenes Wissen über die Ehe erwerben. Sie ist daran gescheitert, eine Ehefrau zu werden, bis ein Mann sie auffordert, den Traditionen zu folgen und durch die Bräuche zu erkennen, was Ehe ist.

Auffällig ist das Zitieren eines bekannten Sprichworts: „obushwele bulimwa, tibukomwa nka nkwi"(„Ehe muss kultiviert (gepflegt) werden, sie kann nicht ge- 
bündelt/gesammelt werden wie Feuerholz.") Hier heißt es, dass Ehe etwas Schwieriges sei, das Arbeit bedarf und gepflegt werden muss. Landwirtschaftliche Arbeit ist Aufgabe der Frau und das Suchen von Feuerholz Männerarbeit. Indirekt werden hier also männliche und weibliche Eigenschaften und Vorgehensweisen gegenübergestellt. Die Frau ist in der Lage, die Ehe zu pflegen, weil sie weiß, was sie bedeutet, während der Mann diese Fähigkeiten nicht hat.

Die Ratschläge des Liedes richten sich nicht nur an die Braut, sondern an alle Zuhörer, also auch an die anderen Frauen der Gruppe. Damit werden alle im Hinblick auf die Ehe und die Traditionen erzogen und Wissen reproduziert.

Das Tragen eines Grasschurzes weist also darauf hin, in welchem Lebensabschnitt sich das junge Mädchen befindet. Legt sie den Schurz ab, signalisiert das den Übergang in eine andere gesellschaftliche Position. Darüber hinaus bedeckt das Kleidungsstück einen intimen Bereich, der in der Gesellschaft nicht öffentlich diskutiert wird.

\section{Das Brechen von Tabus durch Bongo-Flava}

In Tansania begegnet einem immer und überall, in Bussen, auf der Straße, in Radio und TV eine bestimmte Musikrichtung, die Bongo-Flava genannt wird. Sie hat sich Anfang der 1990er Jahre aus dem amerikanischen Hip-Hop entwickelt und ist innerhalb kürzester Zeit sehr populär geworden. Inzwischen haben immer mehr eigene Interpretationen, lokale Einflüsse und ein breites Publikum zur Emanzipation vom amerikanischen Hip-Hop beigetragen und damit bildet Bongo-Flava eine eigenständige Musikrichtung. (Stroeken 2005:488f.). Die Bezeichnung Bongo-Flava wird von den meisten tansanischen Jugendlichen folgendermaßen erklärt: Bongo stammt von dem Begriff ubongo $\mathrm{ab}$, der so viel wie Verstand bedeutet. Bongo bezeichnete in der Vergangenheit die größte Stadt des Landes Dar Es Salaam, denn man ging davon aus, dass jemand, der in der Stadt überleben will, wo die Lebenssituation so extrem schwierig ist, ubongo, Verstand, benutzen müsste. Diese Bezeichnung wurde mittlerweile auf ganz Tansania erweitert, auf das Bongo-Land (siehe hierzu auch Stroeken 2005:488). Bongo-Flava ist also der Sound aus dem Bongo-Land und zeichnet sich besonders durch die Texte in Kiswahili aus, der offiziellen Landessprache Tansanias. Thematisiert wird alles, was für die Künstler wichtig ist. Im Vordergrund stehen die Schwierigkeiten, das Leben im Land zu meistern, die korrupte Elite und die Probleme der Gesellschaft. Die Musik ist also durchaus gesellschaftskritisch. Das oberste Credo ist, die Realität, das wahre Leben darzustellen (Stroeken 2005:502). Auch wenn es sich bei den Künstlern zumeist um junge Menschen handelt und die Musik wie die Szene in Stil, Sprache und Lebenssituation der Jugend eingebettet sind, richtet sich die Musik an die gesamte Bevölkerung und erreicht Menschen in allen Teilen des Landes (Stroeken 2005:493).

Liebe, Beziehungen und Sexualität werden ausführlich behandelt. Sie nehmen unter Jugendlichen einen hohen Stellenwert ein und bestimmen ihren Alltag, ihr Verhalten und ihre Gespräche. Die Musik bricht also die Tabus, die noch immer auf diesen 
Themen liegen. Es ist unerwünscht, in der Öffentlichkeit Liebesbekundungen zu zeigen, in der Schule findet kaum Aufklärung statt und mit den Eltern kann man nicht darüber sprechen. So finden die jungen Leute andere Wege, sich darüber auszutauschen, wie etwa die Musik und die dazugehörigen Musikvideos. Man kann Parallelen ziehen zu der informellen Erziehung der jungen Haya. Auch hier wird die Musik als ein Medium genutzt, das schon länger für die Vermittlung von Wissen bekannt war und erprobt worden ist. Für Jugendliche bedeutet dieses Medium eine wichtige Informationsquelle und sie werden so zu bestimmten Auffassungen und Vorstellungen erzogen und übernehmen auch Sprache und Symbole in den Alltag. Sie kommunizieren ihre Einstellung zu Liebe über die Musik. Man kann erkennen, was junge Tansanier unter Liebe verstehen und welche Fragen und Auseinandersetzungen ihnen wichtig sind. Dabei unterscheidet sich das, was als Wissen über Liebe produziert wird, von den Hochzeitsliedern der Haya, wo besonders die Aufgaben der Geschlechter, der gesellschaftliche Status als Erwachsener und die Herstellung gesellschaftlicher und familiärer Beziehungen durch die Ehe im Vordergrund stehen. Die Bongo-Flava-Lieder setzen sich deutlich mehr mit Gefühlen, Treue bzw. Untreue, Liebeskummer und den verschiedenen Problemen, die in einer Beziehung auftreten können, auseinander. Sie orientieren sich an den Wünschen und Ängsten der Jugend und nicht an dem, was die Gesellschaft bzw. die ältere Generation als bedeutsam erachtet.

\section{Literatur}

\section{Cory, Hans und M. M. Hartnoll}

1970 [1945] Customary Law of the Haya Tribe Tanganyika Territory. Westport, Connecticut: Negro Universities Press.

Ishengoma, Johnson M.

2005 African Oral Traditions: Riddles among the Haya of Northwestern Tanzania. International Review of Education 51(1): S. 139-153.

\section{Mutembei, Aldin Kaiz ilege}

2001 Poetry and aids in Tanzania: changing metaphors and metonymies in Haya oral traditions. Leiden: Univ., Research School of Asian, African and Amerindian Studies.

\section{Stroeken, Koen}

2005 Immunizing strategies: hip-hop and critique in Tanzania. Africa 75(4): S. 488-509.

\section{Taylor, Brian K.}

1963 The western Lacustrine Bantu: (Nyoro, Toro, Nyankore, Kiga, Haya and Zinza, with sections on the Amba and Konjo). London [u.a.]: Internat. African Inst.

\section{Weiss, Brad}

1996 The Making and unmaking of the Haya lived world: consumption, commoditization, and everyday practice. Durham [u.a]: Duke Univ. Press. 


\section{Ozeanien}

Die Brauthaube ambusap der Iatmul aus Papua-Neuguinea

\section{Lisa Gutt}

Die ambusap ist eine Art Kopfschmuck der Iatmul aus dem mittleren Sepik-Gebiet in Papua- Neuguinea (Oz3405). Sie wird als Brauthaube bezeichnet, da sie bei der Hochzeitszeremonie von der Braut getragen wird und als ihr wichtigstes Schmuckstück gilt (Greub 1985:182).

\section{Ambusap - Das Charakteristikum der Braut}

Die ambusap ist eine aus Pflanzenfasern geflochtene Haube. Sie ist mit Nassaschneckenscheiben und Kaurischnecken besetzt, reicht bis auf den Rücken hinab und endet in der Form eines kleinen, aufklappbaren Krokodilkopfes (Badanowitz und Möller 2009:15). Dieser ist ein Verweis auf den Schöpfungsmythos der Iatmul, nach deren Vorstellung das Urkrokodil einst die Welt erschaffen hat. In der Heirat verbinden sich nun männliches und weibliches Prinzip, sodass eine Einheit entsteht (Raabe 2008:65).

In erster Linie dient die Brauthaube als Schmuck der Braut während der Hochzeitszeremonie. In der Gesellschaft der Iatmul stellt sie eine Ausnahme dar, da das Tragen von Schmuck in der Regel den Männern vorbestimmt ist (Badanowitz und Möller 2009:14f.). So kann auch die Brauthaube bei beson- deren Ritualen vom anderen Geschlecht getragen werden, um als Braut verkleidet eine Ahnenfrau darzustellen (Greub 1985:182).

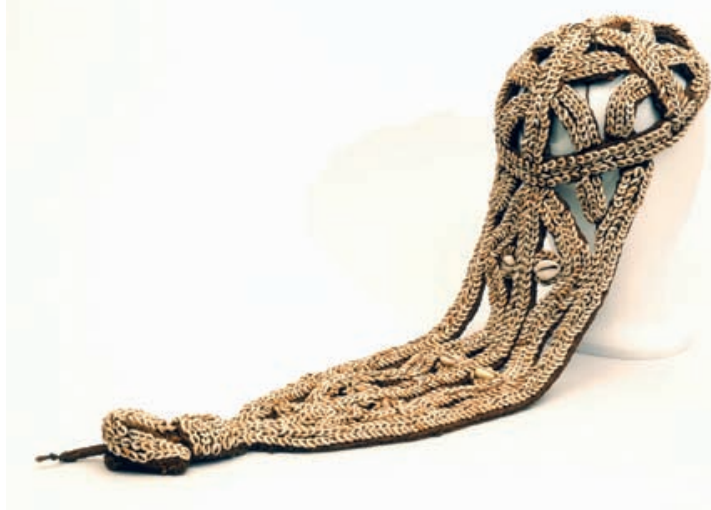

Abbildung 11: Brauthaube

Der Mann als Objekt - Liebe bei den Iatmul

Das Thema „Liebe“ ist bei den Iatmul Angelegenheit der Frauen (Hauser-Schäublin 1985:521). Nur den Frauen steht es zu, einem Mann ihr Interesse zu zeigen. Somit geht die Initiative zu ehelichen $\mathrm{Zu}-$ sammenschlüssen immer von ihnen aus. Den Männern bleibt oft nichts anderes übrig, als die Frauen, die um sie werben, zu heiraten. Dieser Umstand führt dazu, dass einige Männer vorübergehend das Dorf verlassen und vor den um sie werbenden Frauen flüchten. So berichtet z.B. Yaknabis, ein Mann aus der Ethnie der Iatmul, er sei im Erwachsenenalter von seiner Arbeit auf einer Missionsstation in sein Dorf Kararau zurückgekehrt. Dort 
verliebte sich eine bereits verheiratete Frau in ihn, kam in sein Haus und wollte auch ihn zum Mann nehmen. Er schickte sie zurück zu ihrem Ehemann, aber die Frau gab nicht auf, sodass Yaknabis in ein anderes Dorf floh. Doch die Frau folgte ihm penetrant. Nachdem er sie zu ihrem Ehemann zurück gebracht hatte, beschloss er schließlich wieder zur Lohnarbeit auf eine Station zu gehen, um ihr zu entrinnen. Nicht nur diese eine Frau folgte ihm damals, er wies jedoch auch alle anderen ab, da er nicht vor seinem älteren Bruder eine Ehe eingehen wollte. Als er später nach Kararau zurückkehrte, war dieser vermählt und auch Yaknibis heiratete eine Dorfbewohnerin und wurde Vater von drei Kindern (Hauser-Schäublin 1985:523ff.). Da es für die Männer der Iatmul keine Möglichkeit gibt, ihre Gefühle offen zu zeigen, haben sie die Möglichkeit des heimliche Praktizierens von Liebeszauber, um die Angebetete von sich zu überzeugen - Frauen hingegen ist diese kulturelle Praxis verwehrt (Hauser-Schäublin 1985:525).

\section{Die Einleitung der Ehe -}

\section{Partnersuche bei den Iatmul}

Um eine Ehe bei den Iatmul einzuleiten, gibt es verschiedene Strategien. Eine Form besteht darin, dass eine Frau der Schwester des auserwählten Mannes Betelnüsse (Mat219) übergibt, diese werden dann von ihr an den Bruder weitergereicht. Nimmt jener die Betelnüsse an, ist er mit der zukünftigen Ehefrau einverstanden und lässt ihr, wieder über seine Schwester, auch Betelnüsse zukommen. Es wird ein Treffen arrangiert, um die Hochzeit zu besprechen, die Frau packt ihre Sachen und wartet, dass der Bräutigam sie nachts vom Haus ihrer Eltern in sein Haus führt (Hauser-Schäublin 1977:73).

Oft begeben sich die Frauen, vor allem bereits einmal verheiratete, jedoch einfach direkt in das Haus des ausgewählten Mannes, um ihm ihr Vorhaben mitzuteilen (Hauser-Schäublin 1977:74). So z.B. Kwapmei, eine Frau aus Kararau. Sie berichtet, dass sie als sie sich in einen Mann verliebte, plante in das Haus seiner Eltern zu ziehen. Für dieses Vorhaben suchte sie sich einen bestimmten Tag aus, nahm während der Dämmerung ein Bad, legte ihren Schmuck an und packte ihre Habseligkeiten. Ihren Eltern erzählte sie nichts von ihrem Plan. Nachts ging Kwapmei heimlich zum Haus ihres zukünftigen Mannes und setzte sich zu ihm und seinen Eltern. Niemand hatte etwas gegen ihren Einzug. Somit waren die beiden so gut wie verheiratet, durften sich jedoch vor Übergabe des Brautpreises, welche die Hochzeitszeremonie bildet, weder körperlich nahe kommen, noch miteinander durchs Dorf gehen (Hauser-Schäublin 1985:521ff.). Eine weitere Form der Einleitung der Ehe bietet sich bei einer Versammlung der Männer im Dorf. Dort werden die Frauen aufgefordert, den Namen des gewünschten Ehemannes zu nennen, und wenn dieser dagegen nichts einzuwenden hat, gilt die Hochzeit als beschlossen (Hauser-Schäublin 1977:74). 
In den Händen der Männer Hochzeit bei den Iatmul

Hochzeit und Ehe legalisieren auch bei den Iatmul die Beziehung zwischen Mann und Frau. In der Regel heiraten die Iatmul-Frauen im Alter zwischen 14 und 18 Jahren. Die Hochzeitszeremonie besteht im Wesentlichen aus der Übergabe eines Brautpreises von der Familie des Bräutigams an die Familie der Braut. Dieser legitimiert die Beziehung zwischen den Ehepartnern (Hauser-Schäublin 1977:73; Hauser-Schäublin 1985:525). Früher zog die Frau erst nach der Hochzeit in das Haus ihres Ehemannes, der oftmals mit den Familien seiner Brüder zusammenlebt (Hauser-Schäublin 1985:520), doch etwa seit dem Zweiten Weltkrieg geschieht dieses oft schon davor. Mittlerweile bedeutet der Einzug beim Bräutigam, im Gegensatz zur Geschichte von Kwapmei, auch die Aufnahme geschlechtlicher Beziehungen, so dass oft schon mehr als ein Kind gezeugt wird, bevor die Beziehung durch die Übergabe des Brautpreises offiziell als Ehe zählt (Hauser-Schäublin 1977:73). Jedoch lebt die Frau bis zur Hochzeitszeremonie in einem unsicheren Status. So kann es passieren, dass der Bräutigam den Brautpreis verweigert und die Frau nach einiger Zeit wieder abweist. Ein solches Verhalten wird bei den Iatmul allerdings nicht gerne gesehen (Hauser-Schäublin 1977:77f.).

Die Hochzeitszeremonie der Iatmul ist also eine Transaktion zwischen der Familie der Braut und der des Bräutigams und somit nicht primär eine Angelegenheit zwischen zwei Personen. Die Übergabe des Brautpreises wird ausschließlich von Männern durchgeführt, der Zeitpunkt der Übergabe wird vom Bräutigam, Bruder und Vater der Braut festgesetzt (Hauser-Schäublin 1977:83). Traditionell besteht der Brautpreis der Iatmul aus Muschelgeld. Dieses wurde hierfür an eine mehrere Meter lange Schnur aus Pflanzenfasern gereiht. Mit einer ähnlichen Schnur wurde auch die Braut ausgestattet. Zusätzlich wurde sie mit Baumharz eingerieben, mit roter Farbe bemalt und bekam als besonderes Charakteristikum die Brauthaube. Der Wert des Brautschmucks stand immer in einem bestimmten Verhältnis zur Höhe des Brautpreises.

Bei der Übergabe des Brautpreises gab es lange Diskussionen über die Qualität des Muschelgeldes, diese fallen jedoch mittlerweile weg, da der Brautpreis seit etwa 1950 in Form von Geldscheinen überreicht wird. Die Höhe des Brautpreises wird von dem Vater und den Brüdern der Braut festgelegt. Er ist besonders hoch, wenn die Braut das älteste Kind der Familie ist und bereits für ihre Mutter eine hohe Summe bezahlt wurde. Heute bringt die Braut Geld und eine Aussteuer (z.B. Kochtöpfe und Paddel) im Wert von etwa zwei Dritteln des Brautpreises mit in die Ehe (Hauser-Schäublin 1977:83; Hauser-Schäublin 1985:525f.).

Der Brautpreis bedeutet die Ablösung der Frau von ihrer Familie und die Angliederung an die Familie des Bräutigams. Dies beinhaltet auch alle Dienstleistungen, die die Frau nun für ihre neue Verwandtschaft leistet, so z.B. die Versorgung der Familie mit Grundnahrungsmitteln. Oft zahlt der Vater der Braut deshalb auch eine kleinere Geldgabe an den Vater des Bräutigams, damit seine Tochter auch nach der Hochzeit noch regelmäßi- 
gen Kontakt zu ihrer Familie halten darf (HauserSchäublin 1985:527).

\section{Und nach der Hochzeit?}

Nach der Hochzeit treffen die unterschiedlichen Wünsche von Frauen und Männern in Hinblick auf das Zusammenleben aufeinander. Die Frauen versuchen, in einer harmonischen Gemeinschaft mit ihrem jeweiligen Ehemann zu leben, während die Männer möglichst abgenabelt von der Frau umso fester in die Männergemeinschaft integriert sein möchten. Die hieraus resultierenden ehelichen Spannungen sind vor allem bei jüngeren Ehepaaren $\mathrm{zu}$ finden und nehmen mit der Dauer einer Ehe ab (Hauser-Schäublin 1985:527).

\section{Literatur}

Badanowitz, Nadja und Möller, Viviane 2009 Geschlechterrollen, Arbeitsteilung und Schmuck. In: Hauser-Schäublin, Brigitta und Krüger, Gundolf (Hrsg.). Die Macht der Ahnen kulturelle Zeugnisse aus Neuguinea: Leitfaden zur Sonderausstellung in der Ethnologischen Sammlung der Universität Göttingen. S. 12-15.

Greub, Suzanne

1985 Kunst am Sepik: Ausdruck und Ornament; Bildwerke einer alten Tropenkultur in PapuaNeuguinea. Basel: Tribal Art Center.

\section{Hauser-Schäublin, Brigitta}

1977 Frauen in Kararau: zur Rolle der Frau bei den Iatmul am Mittelsepik, Papua-Neuguinea. Basel: Ethnologisches Seminar der Universität. (Basler Beiträge zur Ethnologie, 18).

\section{Hauser-Schäublin, Brigitta}

1985 Der geliebte Mann, die vergewaltigte Frau: Das Beispiel der Iatmul am mittleren Sepik, Papua-Neuguinea. In: Gisela Völger (Hrsg.). Die Braut: geliebt, verkauft, getauscht, geraubt: Zur Rolle der Frau im Kulturvergleich, Bd. 2, Köln: Rautenstrauch-Joest Museum. S. 520-527.

Raabe, Eva Ch. (Hrsg.)

2008 Reisen und Entdecken - vom Sepik an den Main: Hintergründe einer Ausstellung. Frankfurt am Main: Museum der Weltkulturen. 
Brautpreis - Die Frau als Ware?

\section{Ronja Rutschmann}

Der Ausdruck „Brautpreis“ hat im Deutschen einen faden Beigeschmack. Damit verbunden sind Assoziationen wie „Unterdrückung der Frau“, „Zwangsheirat“ oder sogar „Frauenhandel“. Ein Brautpreis bedeutet jedoch auf keinen Fall, dass die Braut „verkauft“ wird - auch wenn der Begriff dies vermuten lässt (Haller 2005:163). Um Missverständnissen vorzubeugen, bevorzugen viele Ethnologen daher mittlerweile den Ausdruck „Brautgabe“.

\section{Brautpreis}

Der Brautpreis wird definiert als „die Gesamtheit der Waren, Wertgegenstände oder Geldzahlungen, die vom Bräutigam oder seiner Verwandtschaft überreicht werden" (Panoff und Perrin 2000:48). Dabei bestimmen Brauch und sozialer Status von Braut und Bräutigam die Höhe und Zusammensetzung. Auch wenn hier keineswegs von einem „Handel“" oder „Kauf“ die Rede ist, passt der Brautpreis nicht in unsere romantischen Vorstellungen von Liebe. Nach dem westlichen Ideal, wie es auch in Filmen und Büchern vermittelt wird, sollen sich zwei Personen möglichst ungeachtet der ökonomischen Umstände ineinander verlieben und heiraten. Die „Bezahlung“ einer Braut will da nicht so recht ins Bild passen (Panoff und Perrin 2000:48).

In vielen außereuropäischen Gesellschaften verbindet eine Hochzeit jedoch nicht nur zwei
Menschen miteinander, sondern auch zwei Familien oder Klans - wobei die Liebe häufig eine eher untergeordnete Rolle spielt (Haller 2005:221). Der Brautpreis dient hier meist der feierlichen Besiegelung der Heirat und der Verbindung zweier Familien. Er ist Teil der Rituale, die für eine Eheschließung notwendig sind. Ein Brautpreis ist auBerdem häufig in Gesellschaften üblich, in denen eine Frau außerhalb der eigenen Gruppe heiratet - beispielsweise in Papua-Neuguinea. Dadurch wird die Gruppe der Braut für den Verlust eines Mitgliedes entschädigt (Panoff und Perrin 2000:48). Auch soll der Brautpreis die gute Behandlung der Tochter in ihrer neuen Familie sicherstellen (Haller 2005:161f.). Die Zahlung eines Brautpreises verhindert außerdem, dass Ehen leichtfertig geschlossen werden - er garantiert also die Ernsthaftigkeit und die Stabilität der Ehe (Panoff und Perrin 2000:48).

\section{Der Brautpreis bei den Gargar}

Die Gargar sind eine Ethnie im Nordwesten PapuaNeuguineas. Ihr Siedlungsgebiet befindet sich im Flussbereich des Green River und erstreckt sich bis über die Grenze Indonesiens (Sauerland 1996:1). Heute leben die Gargar in zwölf Dörfern, die alle durch verwandtschaftliche Beziehungen miteinander verbunden sind (Bermanseder 1996:18).

Ehen werden traditionell zwar innerhalb der eigenen Ethnie, jedoch außerhalb des eigenen Klans oder Dorfes arrangiert. Die Übergabe des Brautpreises nimmt dabei einen großen Stellenwert ein, unter anderem, da er wichtige Allianzen zwischen den einzelnen Familien und Dörfern schafft (Se- 
bastian 1996:20f.). Die Höhe des Preises hängt vom „Wert" der Braut ab (Cox und Aitsi 1988:24) und wird zwischen dem Bräutigam, seinem Vater und dem Brautvater ausgehandelt (Sebastian 1996:20). Dabei spielen Faktoren wie Schulbildung (Cox und Aitsi 1988:24), Brautpreis der Mutter oder Jungfräulichkeit eine Rolle (Rossi 2008:136). Dies erklärt, warum die Verhandlungen über die Höhe des Brautpreises unter Umständen sehr langwierig sein können (Peter 1975:169) - ein zu geringer Brautpreis würde für die Familie der Frau oftmals einen Gesichtsverlust bedeuten. Aber nicht immer versucht die Familie des Bräutigams, die Zahlung möglichst niedrig zu halten, denn auch für die soziale Stellung des Mannes ist die Höhe des Brautpreises mitunter von Bedeutung. Schließlich ist dies eine gute Gelegenheit, seinen Wohlstand zu beweisen (Rossi 2008:136).

Es kann jedoch auch vorkommen, dass die Familie eines jungen Mannes nicht in der Lage ist, den Brautpreis zu zahlen - etwa wenn mehrere Söhne kurz hintereinander heiraten wollen. In dem Fall ist es möglich, ein Mädchen aus der eigenen Gruppe gegen die Braut einzutauschen. Teilweise wird die Zahlung aber auch aufgeschoben, bis das Ehepaar eine Tochter im heiratsfähigen Alter hat. Mit deren Brautpreis werden dann die Schulden des Vaters beglichen (Peter 1975:169).

Die Übergabe des Brautpreises besiegelt die Heirat. Einen Teil des Brautpreises erhält die Braut selbst. Der andere Teil geht an die Familie der Braut, um sie für die nun fehlende Arbeitskraft zu entschädigen. Der Brautpreis setzte sich früher vor allem aus Wertgegenständen wie Arbeitsgeräten,
Schmuckbändern, Schweinen, Hundezahnketten und Muscheln zusammen. Mit dem zunehmenden westlichen Einfluss spielten auch Geldzahlungen eine immer größere Rolle. Teilweise ist es hierbei zu einer regelrechten Inflation gekommen. So müssen sich heute viele Familien verschulden, um den geforderten Brautpreis zu zahlen (Sebastian 1996:20f.).

Seit den 1980er Jahren verliert der Brautpreis in Papua-Neuguinea jedoch langsam an Bedeutung. Vor allem die gebildete jüngere Generation wächst zunehmend unter westlichem Einfluss auf und lehnt die traditionellen Wertvorstellungen teilweise ab. Auch finden Hochzeiten heute häufig außerhalb der eigenen Ethnie oder sogar außerhalb PapuaNeuguineas statt, wo die Heiratsregeln nicht mehr gelten. Aufgrund der Verteuerung des Brautpreises bevorzugen junge Menschen zum Teil uneheliche Partnerschaften, um die Zahlung zu umgehen (Cox und Aitsi 1988:24f.). 


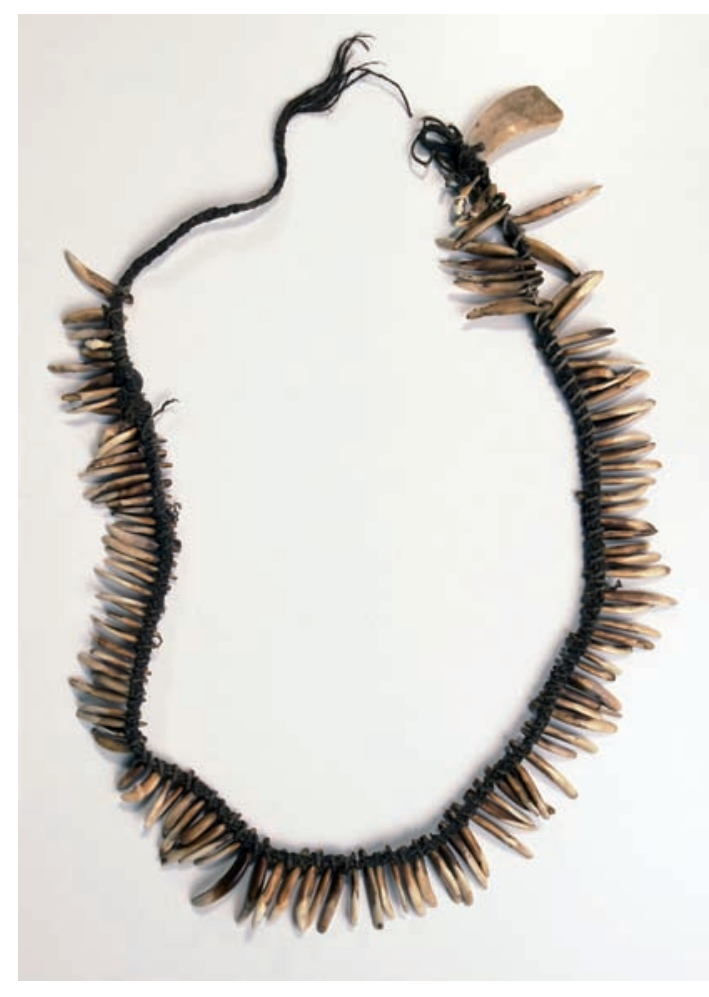

Abbildung 12: Brautgeld

Bei dem ausgestellten Objekt (Oz3761) handelt es sich um einen Schmuckgegenstand der Gargar, der auch als Brautgeld verwendet wurde. Solche Ketten bestehen aus durchbohrten Hundezähnen, die an einer Schnur verflochten sind. Sie wurden von Männern als Hals- und Stirnschmuck und von Frauen ausschließlich als Halsschmuck getragen. Die Stirnbänder bestehen aus drei schmalen Bändern, an denen Nassaschnecken befestigt sind.
Sie dienten als Tanz- und Alltagsschmuck der Männer (Oz3745).

\section{Literatur}

\section{Bermanseder, Bettina}

1996 Soziale Organisation. In: Krüger, Gundolf (Hrsg.) Sagohammer und Konservendose - Einblicke in die Kultur der Gargar in Neuguinea;.

Göttingen: Kinzel, S. 20-21.

Cox, Elizabeth und Louis Aitsi

1988 Papua New Guinea. In: Taiamoni Tongamoa (Hrsg.), Pacific Women - Roles and Status of Women in Pacific Societies; Suva: Univ. of the South Pacific, S. 23-37.

\section{Haller, Dieter}

2005 dtv-Altlas Ethnologie. München: dtv.

Panoff, Michel und Michel Perrin

2000 Taschenwörterbuch der Ethnologie. Berlin:

Reimer.

\section{Peter, Brigitte}

1975 Im Dschungel der Gargar - Ein Neuguinea-Buch. Wien: Wiener Verlag.

\section{Rossi, Wilhelm}

2008 Todeszauber im Klassenzimmer - Von den Problemen einer Schule in Neuguinea.

Münster: LIT. 


\section{Sauerland, Stephan}

1996 Topographie und Klima. In: Krüger, Gundolf (Hrsg.) Sagohammer und Konservendose - Einblicke in die Kultur der Gargar in Neuguinea; Göttingen: Kinzel, S. 20-21.

\section{Sebastian, Maren}

1996 Brautpreis. In: Krüger, Gundolf (Hrsg.) Sagohammer und Konservendose - Einblicke in die Kultur der Gargar in Neuguinea; Göttingen: Kinzel, S. 20-21.
Love-making und die gesellschaftliche Rolle der Zeremonialjungfrau taupou in der traditionellen Kultur Samoas

\section{Gundolf Krüger}

Das Meer prägt bis heute das Leben auf den meisten Inseln von Ozeanien. Innerhalb dieser riesigen Region im Pazifischen Ozean finden sich aufgrund besiedlungsgeschichtlicher Verbindungen und einer maritimen Wirtschaftsweise ganz ähnliche Erscheinungsformen in der materiellen Kultur und im sozialen Leben. Dies wird unter anderem bei der Verwendung bestimmter Materialien von Meerestieren für die Herstellung von Schmuck deutlich.

Die festen Bestandteile von den am Riff beheimateten Meerestieren wie Muschelschalen, Schneckengehäuse, Knochen und Zähne sowie die Stacheln von Seeigeln bilden bei der Schmuckherstellung nach wie vor ein weit verbreitetes und sehr beliebtes Rohmaterial.

In der weitläufigen Inselwelt von Samoa im westlichen Polynesien sind insbesondere die Stacheln von Seeigeln, die auf Schnüren aus Pflanzenfasern zu Halsketten aufgezogen werden, ein kultureller Marker. Früher dienten sie dort zum einen als Talismane zum Schutz vor Bootsunglücken und Kriegsgefahr. Zum anderen waren sie ein beliebtes Mittel zum Love-making (Oz1985). Junge Männer versuchten mit ihnen das andere Geschlecht zu verzaubern und für sich zu gewinnen, indem sie mit den aufeinander geschlagenen Stacheln nächtens vor dem Schlafhaus der Angebeteten einen gläser- 
nen und betörenden Klang erzeugten. Durch die Geräusche blieb vielen Bewohnern in einem Weiler oder Dorf dieses Liebeswerben im Sinne eines Annäherungsversuches und sich daraus eventuell ergebendem Sex nicht verborgen. Das war auch so gewollt, denn wo und zwischen wem sich gegebenenfalls eine Liebesbeziehung mit nachfolgender Verehelichung anbahnte, sollte auf diskrete Weise signalisiert werden.

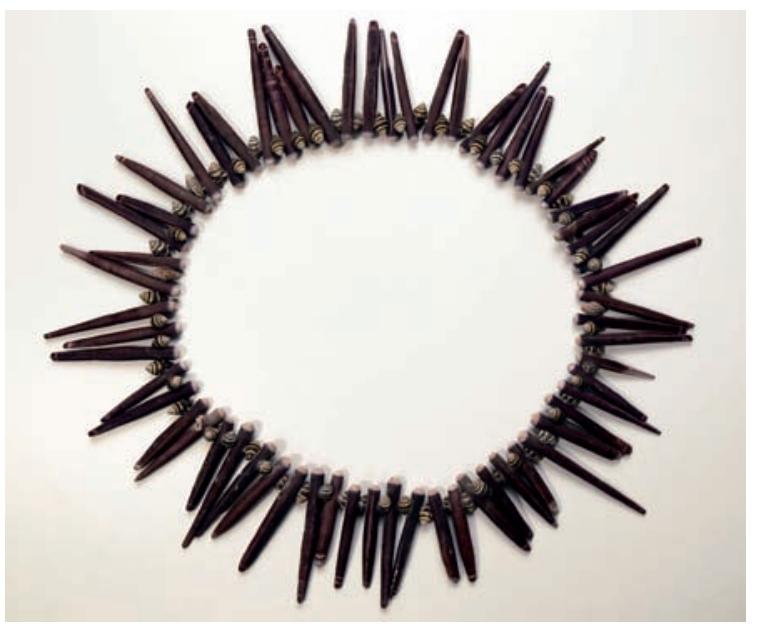

Abbildung 13: Kette aus Seeigelstacheln

Während heute solche überwiegend aus Seeigelstacheln und Kaurischnecken zusammengesetzten Halsketten vornehmlich an die Touristen verkauft werden, sind sie im Bewusstsein der Samoaner indes neben anderen Schmuckornamenten immer noch ein materialisierter Ausdruck für traditionell verankerte und teilweise noch heute wirksame Mechanismen der sozialen Ordnung. Waren die Hals- ketten aus Seeigelstacheln innerhalb der stratifizierten Gesellschaft von Samoa allgemein in Gebrauch und Zeichen für eine eher freie Partnerschaftswahl, so indizierte neben einem opulentem Halsschmuck das Tragen eines bestimmten Kopfschmuckes $t u$ inga die Bedeutung junger Frauen für das zeremonielle Amt einer sogenannten Zeremonialjungfrau taupou. Bei solchen Frauen vollzog sich das Lovemaking im institutionellen Rahmen und wurde öffentlich arrangiert. Eine taupou hatte trotz ihrer privilegierten sozialen Stellung weniger Einfluss auf die Wahl ihres Partners und zukünftigen Ehemannes als andere Mädchen.

Aus der Schicht des Adels ali'i stammend, wurde für jedes Dorf nu'u eine Zeremonialjungfrau durch die Ratsversammlung fono gewählt. Solche Versammlungen gibt es auch heute noch. Sie setzten sich aus dem Kreis der Familienoberhäupter matai zusammen. Da die für Samoa charakteristischen hierarchisch gegliederten Familiengruppen 'ainga jeweils über ein matai verfügen, waren und sind es diese, die das soziale Leben und die alltägliche Politik maßgeblich bestimmen. Sie diskutieren Empfehlungen des Häuptlings ali'i nui, die durch dessen Sprecher, den tulafale, in der Ratsversammlung verkündet werden, und sie können mit ihrer Macht Vorschläge von oben einschränken bzw. modifizieren. Für die Wahl der taupou waren früher die Stimmen der matai von entscheidender Bedeutung, denn eine Zeremonialjungfrau hatte ein ganzes Dorf bei besonderen festlichen Anlässen zu repräsentieren und das Ansehen der Gemeinde und deren politischer Führer, die Familienoberhäupter matai, zu mehren (vgl. Emde 1988:2ff.). 


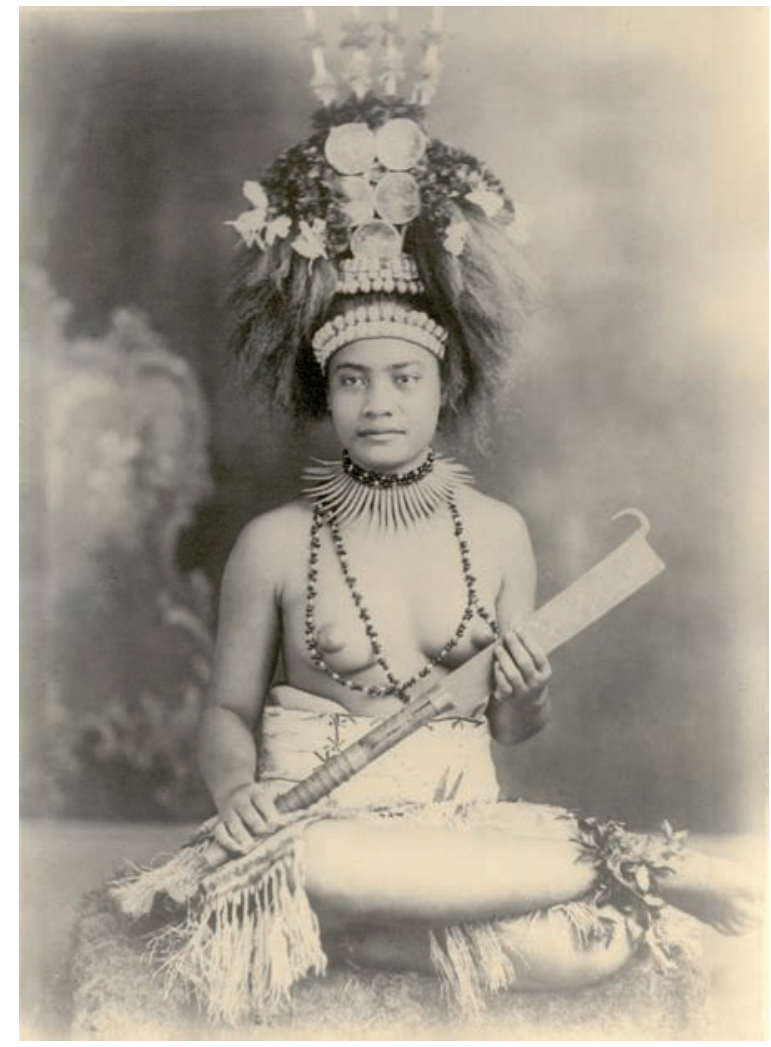

Abbildung 14: Samoanische Zeremonialjungfrau

Schon als kleines Mädchen wurde die angehende taupon sorgfältig auf ihr Amt als Gastgeberin des Dorfes bei Ratsversammlungen, bei der Bewirtung von Besuchern eines Dorfes, bei Tanzveranstaltungen oder Kawa-Trinkzeremonien sowie als Begleiterin des Dorfhäuptlings auf dessen Reisen in andere Dörfer, vorbereitet. Von allen schweren Arbeiten befreit, wurde sie gründlich in den traditionellen
Künsten der Frauen ausgebildet. Dazu gehörte das Mattenflechten, die Herstellung von Rindenbaststoff siapo (Tapa) und dessen textile Verarbeitung zu Stoffbahnen, der Sitztanz und die Zubereitung des Zeremonialgetränks 'ava (Kawa), das auch heute noch in Samoa zur Bewirtung von Gästen dient. Die Aufgabe der tampou bei der Kawa-Zeremonie war es früher, das aus Bestandteilen der Wurzel des sogenannten Rauschpfeffer-Strauches (Piper methysticum) mit Wasser hergestellte Getränk den Anwesenden gemäß der Reihenfolge und Sitzordnung ihres Titels und sozialen Ranges zu servieren. Neben ihrer Ausbildung erhielt die taupou eine ausgedehnte Schönheitspflege, ihre Hände waren besonders gepflegt, ihre Haut wurde mit Kokosöl geschmeidig gehalten und durfte nicht zu stark der Sonne ausgesetzt werden, so dass sie sich von anderen Mädchen durch eine gewisse Hellhäutigkeit sina unterschied. Ältere Frauen umsorgten die taupou ständig und wachten über ihre Jungfräulichkeit. Bei Eintritt in die Pubertät wurden ihre Haare kürzer geschnitten und die Körperhaare rasiert. Sobald ihre Vorgängerin verheiratet worden war, übernahm sie die offizielle Rolle als taupou und Anführerin des Bundes der unverheirateten Mädchen, Frauen titelloser Männer und verwitweter bzw. geschiedener Frauen aualuma (vgl. Krämer 1902:32f. und Koch 1976:162f.).

Erkennbar in ihrer zeremoniellen Funktion als Gastgeberin war die taupou durch einen mehrteiligen Kopfschmuck tuinga, bestehend aus einer Perücke aus gebleichtem bzw. blondiertem Menschenhaar, einem drei- und mehrstäbigen Stirnornament, das mit geschliffenen Perlmuttscheiben verziert war 
(vgl. Engelhard/Mesenhöller 1995), sowie einem Ornament aus den roten Bauch- und Kehlfedern des als heilig erachteten Sega-Papageis (Coriphilus fringillaceus). Dazu trug die Zeremonialjungfrau ein Diadem mit Scheiben aus der Schale der Nautilus-Meeresschnecke, eine Halskette aus geschliffenen Pottwal-Zähnen, einen Ziergürtel, Blumenkränze und als wertvollsten Teil ihrer Ausstattung eine sehr fein geflochtene Matte aus Pandanus 'ie tonga, die sie wie einen Rock um die Hüften trug. Derartige Matten dienen bis heute neben der samoanischen Geldwährung als Mitgift oder Zahlungsmittel beim Haus- und Bootsbau. Der Preis solcher feinen Matten betrug bereits während der deutschen Kolonialzeit von Samoa (1900 bis 1914) bis zu 200 Goldmark - was mit etwa 1000 Euro vergleichbar ist und für damalige Verhältnisse einen sehr hohen Wert darstellte.

Entstammte eine taupou einer angesehenen $\mathrm{Fa}$ milie 'ainga mit viel Macht und besaß mehrere feine Matten 'ie tonga, wurde sie für junge Häuptlingssöhne besonders begehrenswert. Aufgrund der ambilinearen Verwandtschaftsordnung in Samoa gab es keine Heiratsvorschriften, entweder ausschließlich der patrilinearen oder der matrilinearen Deszendenz zu folgen, sondern eine Familie war stets bemüht, in jene Familie hinein zu heiraten, von der sie sich mehr Macht und Einfluss versprach. Insofern war die taupou unabhängig ihrer Zuordnung zur mütterlichen oder väterlichen Abstammungslinie allein aufgrund der genannten sozialen Attribute und persönlichen Qualitäten in ihrer institutionalisierten Rolle als Zeremonialjungfrau zentraler Dreh- und Angelpunkt für die samoanische Ehe- politik. Gelang es einem Häuptlingssohn unter Voraussetzung des Einverständnisses beider Familiengruppen die Zuneigung oder gar Liebe einer taupou für sich zu gewinnen, war die Basis für eine Eheschließung gegeben. Unter Beteiligung der Dörfer von Braut und Bräutigam wurde dann die Heirat am Ort des letzteren vollzogen. Die Feier dauerte in der Regel drei Tage. Nach anfänglicher Vorführung des Brautschatzes, vornehmlich der feinen Matten 'ie tonga, erfolgte die öffentliche Defloration der Braut. Die Entjungferung wurde mit dem Zeigefinger vollzogen, ursprünglich in vorkolonialer Zeit durch den Bräutigam, später im Zuge der Kolonialisierung durch ältere Frauen aus dem nahen Umfeld der Braut. Zum Beweis wurde als Unterlage für die Defloration eine aus den langen weißen Fasern eines Urticaceen-Strauches (Cypholophus macrocephalus) geflochtene Matte 'ie sina verwendet, die als sogenannte Matte der Nacht 'ie o le po für den späteren ersten Geschlechtsakt der Vermählten diente. Auf dieser weißen Matte sollte für alle Beteiligten das beim Durchstechen der Jungfernhaut entstandene Blut zu sehen sein (Thode-Arora 2001:223). Die weiße Farbe sina repräsentierte symbolisch das Totenreich und wurde zugleich mit einer Kulturheroin gleichen Namens assoziiert, die früher als Rollenvorbild für die taupou diente (vgl. Hofmann 2012:51f, 62, 114). Wie aus alten Quellen widersprüchlich hervorgeht, musste eine taupou einerseits mit drakonischer Bestrafung z.B. in Form einer Steinigung rechnen, wenn sie nachweislich keine Jungfrau mehr war; andererseits aber ist auch die Rede davon, dass eine vermeintliche Defloration von älteren Frauen übernommen wurde, wenn 
diese wussten, dass die Braut bereits Sex gehabt hatte: Entweder verwendeten sie dann Hühnerblut oder verletzten die Braut mit einem heimlich mitgeführten kleinen Haifischzahn im Vaginalbereich so sehr, dass es blutete (Stuebel o.J.:113ff.; Emde 1988:9).

Der Jungfräulichkeit wurde in vorkolonialer Zeit übrigens ein völlig anderer Wert als innerhalb der christlichen Religion beigemessen. Während mit dem Jungfräulichkeitsideal im Christentum eine asexuelle Lebensführung im Zeichen einer Identifizierung mit dem wiederauferstandenen Christus assoziiert wird, war die taupon „eine einnehmende junge Dame aus gutem Hause und in ihrer Jungfräulichkeit betörend erotisch. Das verlieh ihr in den Augen der Samoaner einen einzigartigen Wert, denn auch in Samoa war man sich der unbestreitbaren Tatsache bewusst, dass ein junges Mädchen seine Jungfräulichkeit nur einmal verlieren kann. Aus diesem Grund waren junge Häuptlinge so sehr auf die Ehre erpicht, eine taupou zu deflorieren“ (Freeman 1983:252).

Folgt man dem zeitgenössischen samoanischen Schriftsteller Albert Wendt, so steht außer Frage, dass Zeremonialjungfrauen taupou den Versuchen vorehelicher Verführung immer wieder ausgesetzt waren und bei Sympathie oder Liebe auch nachgaben (Wendt 1982:91ff.). Symbolisch war öffentlich sichtbares Blut indes jener Marker, durch den dann die Vermählung als Abschluss des ersten Hochzeitstages erfolgen durfte. Der zweite Tag diente dem Geschenke-Tausch beider Hochzeitsparteien, am abschließenden dritten Tag war die Gruppe des Bräutigams Gastgeber eines großen Essensgelages.
Mit dem Heiratsarrangement, das durchaus auf einer bereits zuvor erwachten Liebesbeziehung basieren konnte, endete die offizielle Rolle der taupou, und eine ausgewählte Nachfolgerin trat das Amt der Zeremonialjungfrau an (vgl. Krämer 1902:35ff. und Koch 1976:163).

\section{Literatur}

Emde, Sina

1988 Die Dorfjungfrau von Samoa. Unveröffentlichte Hausarbeit, Institut für Ethnologie der FU Berlin: S. 12.

Engelhard, Jutta, Beate und Peter Mesenhöller (Hrsg.) 1995 Bilder aus dem Paradies. Koloniale Fotografie aus Samoa. Köln: S. 176.

\section{Hofmann, Matthias Claudius}

2012 'O 'ie toga: eine samoanische fait-social total. Zur Transformation kultureller Bedeutungen von „Zeremonialmatten“ in Samoa. Magisterarbeit zur Erlangung des akademischen Grades eines Magister Artium an der Sozialwissenschaftlichen Fakultät der Georg-August-Universität Göttingen: S. 122 (unveröffentlicht).

Koch, Gerd

1976 Südsee. Führer durch die Ausstellung. Museum für Völkerkunde Berlin. Staatliche Museen Preussischer Kulturbesitz, Bd. 1. Berlin: S. 214. 
Krämer, Augustin

1902 Die Samoa-Inseln. Bd. 1. Stuttgart: S. 507.

\section{Stuebel, $O$.}

o.J. Samoanische Texte. Hrsg. v. F.W.K. Müller. Veröffentlichungen aus dem Königlichen Museum für Völkerkunde Berlin, Bd. IV, Heft 2-4.

Thode-Arora, Hilke

2001 Tapa und Tiki. Die Polynesien-Sammlung des Rautenstrauch-Joest Museums. Köln: S. 391.

Wendt, Albert

1982 Der Clan von Samoa (Roman aus WestSamoa). Wuppertal: S. 383.
Zeichen der Schönheit -

Die Kunst des Tatauierens

in Polynesien

\section{Luise Weinhold}

Die Kunst des Tatauierens wird in Polynesien, wie auch in anderen Teilen der Welt, seit vielen Jahrhunderten betrieben. Die Bedeutung des polynesischen Wortes tatau ist unklar (Cattani 1922:5). Es wird als ,Markierung“ (Thomas 2005:33), ,Wunde schlagen' (Deimel 2005:13), ,blaue Zeichen' (Thomas 2005:35) oder ,ordnungsgemäß‘ (wegen der festgelegten, oft symmetrischen Muster; Springer 1929:667) übersetzt. Die Tatauierung wurde aus verschiedenen Motivationen vorgenommen, so konnte sie dazu dienen, als Schmuck die Attraktivität beider Geschlechter für das jeweils andere Geschlecht zu erhöhen, das Erreichen des heiratsfähigen Alters bei Mädchen anzuzeigen, Prestige von Menschen mit hohem gesellschaftlichen Rang auszudrücken, den Unterschied zwischen Sklaven und freien Menschen markieren und auch eine magische Bedeutung besitzen (Deimel 2005:13). Das Tatauieren wurde bei fast allen Männern und bei einem Großteil der Frauen vorgenommen, untatauierte Mitglieder einer Gemeinschaft konnten sozial geächtet und von der Teilnahme an bestimmten Ritualen ausgeschlossen werden. Männer wurden oft erst mit einer vollständigen Tatauierung zu einem vollwertigen Mitglied der Gesellschaft (Deimel 2005:15). 
Es gibt verschiedene Arten des Tatauierens: Die Narbentatauierung, die Stichtatauierung und die Nahttatauierung. Bei der Narbentatauierung wird Schmutz mit einem scharfen Gegenstand geritzt in Wunden gerieben, damit es zur Narbenbildung kommt; bei der Stichtatauierung wird mit einem spitzen Gerät Farbe in die Haut geschlagen und bei der Nahttatauierung wird ein verrußter Faden unter der Haut durchgezogen, so dass ein schwarzes Muster zurückbleibt. (Deimel 2005:13). Tatauiert werden meistens das Gesicht, die Lippen, die Beine und das Gesäß bis hin zum ganzen Körper inklusive der Genitalien. Bei Frauen sind die Tatauierungen oft kleiner als bei den Männern. Das Tatauieren selbst wird bis heute von einem gesellschaftlich hoch angesehenen Tatauierspezialisten oder einer -spezialistin durchgeführt (Trowell 1967:251).

Das Instrument für die Stichtatauierung bestand früher meist aus einem hölzernen oder knöchernen Griff und einer scharfen Spitze aus Stein, heute eher aus Metall (Oz2040, Oz2041, Oz2042). Als Farben konnte Ruß oder pflanzlich gewonnene Farbe dienen, welche oft einen blauen Ton hatte (Deimel 2005:14).

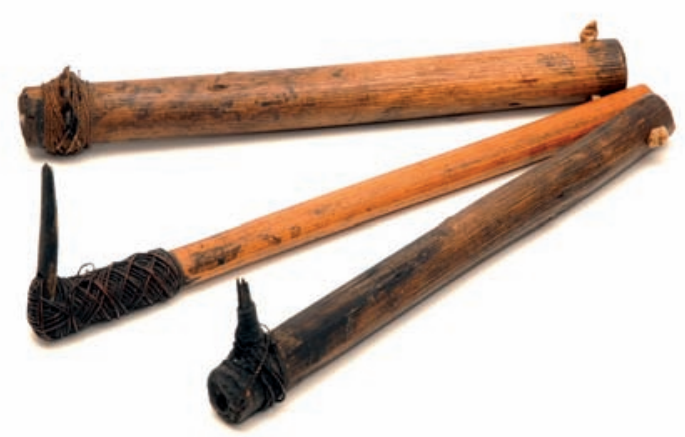

Abbildung 15: Traditionelle Tatauiergeräte

Der Prozess des Tatauierens stand in der Vergangenheit mit bestimmten Tabus, wie dem Verzicht auf bestimmte Speisen und sexuelle Aktivität, in Zusammenhang (Deimel 2005:14). Die Durchführung ging mit großen Schmerzen einher, die bis zur Ohnmacht führen konnten. Durch unhygienische Bedingungen und das Einreiben von Speichel des Tatauiermeisters in die Wunden, konnte das Durchführen des Tatauierens zu Entzündungen und der Verbreitung ansteckender Krankheiten, manchmal sogar zum Tod führen (Cattani 1922:47f.). Während der Kolonialzeit im 18. bis 19. Jahrhundert versuchten christliche Missionare das Tatauieren zu verbieten, was in einigen Gegenden Polynesiens Erfolg hatte. Erst während der letztne Jahrzehnte hat man in Polynesien wieder angefangen, die alte Tradition des Tatauierens wiederzubeleben (Deimel 2005:15). Unter polynesischen Jugendlichen werden mittlerweile auch englische Wörter oder westliche Symbole für Modetatauierungen benutzt (Brison 2007:128). 
Symbolik der Tatauierungen

Die Muster variierten von kleinen, zarten Linien, über Ranken und manchmal auch zoomorphen Verzierungen bis hin zum Einfärben ganzer Körperteile, wie die des Gesichtes oder der Lippen. Gesichtstatauierungen werden moko genannt, auBerdem kann zwischen zwei Tatauierstilen unterschieden werden, dem klassischem moko und dem puhoro. Der moko-Stil umfasst Spiralen, die Ranken von Bäumen und Gewächsen wie Farnen imitieren. Er war früher vor allem Chiefs vorbehalten, während puhoro durch das Freilassen von Hautpartien auf dunkel eingefärbtem Hintergrund ein allgemein verbreitetes Muster bildete (Thomas 2005:36).

\section{Heirat, Liebe und Partnerwahl}

Tatauierungen dienten in früherer Zeit zur Zierde und zur Steigerung der sexuellen Attraktivität. $\mathrm{Zu}$ den Pubertäts-Tatauierungen zählte das Anbringen von ersten Mustern bei Mädchen und Jungen im heiratsfähigen Alter. Dies geschah als Initiationsritus, der die jungen Leute in die Gemeinschaft der Erwachsenen einführte. Mit dem Ritus wurde durch die Tatauierung ein äußerlich sichtbares Zeichen für die Freigabe des zuvor meist untersagten Geschlechtsverkehrs gesetzt.

Für Mädchen gab es zudem spezielle Kennzeichnungen durch Tatauierungen der Knöchel. Diese signalisierten den Beginn ihrer Geschlechtsreife. Darüber hinaus gab es bei Frauen ferner Hochzeits-Tatauierungen, zumeist auf Kinn und Lippen angebracht, und schließlich Witwen-Tatau- ierungen auf der Zunge (Cattani 1922:15f.).

\section{Literatur}

Brison, Karen J.

2007 Our wealth is loving each other: self and society in Fiji. Lanham: Lexington Books.

\section{Cattani, Paul}

1922 Das Tatauieren: eine monographische Darstellung vom psychologischen, ethnologischen, medizinischen, gerichtlich-medizinischen, biologischen, histologischen und therapeutischen Standpunkt aus. Basel: Schwabe.

\section{Deimel, Claus}

2005 Haut und Hülle. Vom Schmücken und Kleiden. Dresden: Museum für Völkerkunde.

\section{Springer, Anton}

1929 Die außereuropäische Kunst: ostasiatische Kunst, indische Kunst, islamische Kunst, afrikanische Kunst, indianische Kunst Amerikas, malaiisch-pazifische Kunst.

\section{Thomas, Nicholas}

2005 Tattoo. Bodies, Art, and Exchange in the Pacific and the West. Durham: Duke University Press.

\section{Trowell, Margaret}

1967 Afrika und Ozeanien. Baden-Baden: Holle. 


\section{Abbildungsnachweis}

Titelabbildung

\section{BiKat73}

Auf der Rückseite von Blumenbachs Hand folgende Beschriftung:

Cosim Ali Chan, der 1763 von den Engländern vertriebene Nabab von Bengalen, nachher Faquir in Dehli, in Hindustan gemalt. Geschenk des englischen Residenten Braun in Bern (Schwiegersohn Hallers), der vorher Oberst eines Regiments der Sepoys in Bengalen gewesen war, 1794.

Abbildung 1: Grafik Hormonmodell

Viet Hoang und Tina Krüger

Abbildung 2: Herz, Ring und Mondperle - Liebessymbole im interkulturellen Vergleich 6 Fingerringe

Af2812

Aus gefärbtem Achat mit angeschliffenen Facetten. Senegal. Hirsch \& Co., 1951.

Abbildung 3: Lotosschuhe - Schritte wie eine Seiltänzerin

As1417 a-b

1 Paar Frauenschuhe, spitze Form, roter Stoff mit bunter Stickerei. China. Geschenk Düker, 1940.

Abbildung 4: Die Geisha - Ein lebendes

Kunstwerk

Burns, Stanley B., MD und Elizabeth A. Burns.

2006. Geisha - A photographic history 1872-1912.
Powerhouse Books. Brooklyn, NY. S.93.

Abbildung 5: Shunga-Erotische Fantasien und große Kunst

As1647

Japanischer Farbholzschnitt, erotische Darstellung (38,5 x 25 cm). Geschenk Voigt, 1942.

Abbildung 6: Dildo - Lustwerkzeug der Liebe Af3272

Nachbildung männlicher Genitalien, bestehend aus einem 19,5 cm langen und ca. $3 \mathrm{~cm}$ starken penisförmigen Holzstück, das mit dunkelbraunem Leder überzogen ist und einem kleinen Lederbeutel mit zwei Kugeln. Das Gerät wurde von Hausafrauen zur geschlechtlichen Befriedigung benutzt. West-Afrika. Geschenk Germann, 1957.

Abbildung 7: Der Buschmannrevolver als Instrument für den Liebeszauber

Af4681 a-f

Mit diesem Instrument kann auch weiße Magie, wie z.B. Liebeszauber ausgeübt werden. Dabei werden die Pfeile mit entsprechenden Wunschformeln in Richtung der imaginären Person abgeschossen, deren Liebe man erwidert haben möchte. Der Köcher besteht aus Leder, 4 Fransen am unteren Ende. 4 Pfeile aus hellem Holz, ca. 16 cm lang. Botswana. Geschenk Braukämper, 2012.

Abbildung 8: Briefmarke Deutsche Bundespost, herausgegeben 1994.

Abbildung 9: Briefmarke Mosambik 1981. In: Gabriel, Alexandra, Abb. 22. 
Abbildung 10: Vom Zauber afrikanischer Fruchtbarkeitspuppen

Af4682

Solche Puppen werden in vielen Teilen Afrikas als Fruchtbarkeitssymbole und Ausdruck des Kinderwunsches getragen. Diese hier ist typisch für die Ndebele Südafrikas - zu erkennen an den aufeinander gelegten Ringen am Hals, der optisch verlängert werden soll. Südafrika.

Geschenk Braukämper, 2012.

Abbildung 11: Die Brauthaube ambusap der Iatmul aus Papua-Neuguinea

Oz3405

Braut- oder Schmuckhaube aus pflanzlichem Material, mit Kaurischnecken besetzt. Am Rückenteil der Haube ist ein Schlangenkopf zu sehen. Die Haube ist $27 \mathrm{~cm}$ lang. Papua-Neuguinea. Raw Material Processing Company, 1963.

Vergleichsobjekt: Museum der Weltkulturen Frankfurt am Main. In: Raabe, Eva (Hrsg.), 2008 Reisen und Entdecken. Vom Sepik an den Main. S. 64-65. Dieses Objekt zeigt einen Krokodilskopf.

Abbildung 12: Brautpreis - Die Frau als Ware? Oz3761

An ihrem oberen Ende durchbohrte Hundezähne sind auf einer Schnur miteinander verflochten. Gesamtlänge ca. $70 \mathrm{~cm}$. Von Männern als Hals- und Stirnschmuck getragen, hauptsächlich als Brautgeld verwendet. Papua-Neuguinea. Kauf Peter, 1974.
Abbildung 13: Love-making und die gesellschaftliche Rolle der Zeremonialjungfrau taupou in der traditionellen Kultur Samoas

Oz1985

Kette mit Seeigelstacheln und Schneckengehäusen. Geschenk Museum für Völkerkunde Berlin, 1939.

Abbildung 14: Samoanische Zeremonialjungfrau (Historische Fotografie, Sammlung Leber, ca. 1902).

Wissenschaftliches Kulturarchiv Institut für Ethnologie.

Abbildung 15: Zeichen der Schönheit - Die Kunst des Tatauierens in Polynesien Oz2040; Oz2041; Oz2042 Tatauiergeräte für Mädchen Aus Bambus und pflanzlichem Material. Am vorderen Ende des Geräts ist mit Schnur ein Schildpatt-Plättchen angebracht, das durchbohrt ist, ca. 16-17 cm. Fiji. Kauf Speyer, 1941. 
Überall auf der Welt träumen Menschen von der großen Liebe. Wie sie ihre Gefühle ausleben, ist von Kultur zu Kultur verschieden. Vorstellungen von Liebe und romantische Ideen werden vor allem durch Kunst, Literatur und Musik überliefert. Schönheitsideale und Liebessymbole prägen unsere Wahrnehmung, und auch Gegenständliches beeinflusst unser Verhalten im Alltag. Anhand von ausgewählten Exponaten aus Asien, Afrika und Ozeanien, die aus der Ethnologischen Sammlung der Universität Göttingen stammen, wird versucht, folgenden Fragen nachzugehen: Wie verhält es sich mit romantischer Liebe in Gesellschaften, in denen die Anbahnung von Beziehungen und schließlich Ehen arrangiert werden? Wie drückt sich diese Liebe aus? Und welchem Wandel unterliegt sie? 